\title{
Don't Fear the Meter: How Longer Time Limits Bias Managers to Prefer Hiring with Flat Fee Compensation
}

\author{
Indranil Goswami, University at Buffalo \\ (goswami4@buffalo.edu) \\ Oleg Urminsky, University of Chicago \\ (oleg.urminsky@chicagobooth.edu)
}

First Version: December 2016

Current Version: Sept 2019

Please contact authors for updated copy before citing or circulating 


\begin{abstract}
Time limits and deadlines are pervasive in organizational settings. Managers work under time limits themselves and also manage time limits for others. While the motivational effect of time limits on individual and group performance has been studied extensively, little is known about how time limits shape people's reasoning about others' behavior and decisions. We investigate the effect of time limits on managers' choice of compensation schemes for hiring temporary workers in games with financial consequences. We find a biased preference among managers for flat fees over time-metered fees, particularly under longer time limits, resulting in lost earnings for managers. The sub-optimal choices occur because managers over-estimate task completion time, due to the effect of time limits on beliefs about workers' behavior and about the scope of the task. The bias is observed regardless of whether task quality is fixed or variable, and persists among actual managers.

Keywords: Deadlines; Temporal Judgments; Employment Compensation; Flat Fee Bias
\end{abstract}




\section{Introduction}

Time limits and deadlines are not only pervasive in our personal lives, but also play a key role in work settings. While researchers have extensively studied the motivational effect of time limits (or deadlines) on the performance of individuals and groups (Bryan \& Locke, 1967; Amabile, DeJong, \& Lepper, 1976; Ariely \& Wertenbroch, 2002; Waller, Zellmer-Bruhn, \& Giambatista, 2002), little is known about the indirect effects that deadlines might have on how people make consequential economic choices. In this paper, we investigate how deadlines affect choices between two different pervasive types of hiring schemes, via beliefs about how long other people will take to complete tasks.

In organizational settings, managers often need to acquire and allocate the resources necessary to complete projects on time. Estimates of completion time are a key input for such allocation decisions. Underestimating the necessary resources could delay or even preclude project completion. At the same time, overestimation can also be problematic, because providing for ultimately unnecessary resources is often costly. Consider a manager who is deciding between paying temporary workers a flat fee (e.g., piece-rate) or a metered (e.g., per-hour) fee to complete a project. If the manager underestimates the amount of time workers will take, the total cost under a per-hour compensation scheme (or a metered fee) may turn out to be more than expected. On the other hand, overestimating the amount of time workers will take may lead the manager to 
prefer an expensive lumpsum compensation scheme (or a flat fee ${ }^{1}$ ), potentially “overpaying" compared to the metered fee option.

We propose that managers tend to excessively rely on flat-fee compensations, due to a systematic overestimation of workers' completion time, particularly when deadlines are longer. Across fourteen experiments, (six described in detail in the paper, and another eight in the Online Appendix), we demonstrate this effect of deadlines on choices of compensation schemes. We generalize our findings to different types of tasks (e.g., both fixed vs. variable work quality) and among different populations (e.g., both general population and experienced managers). Using workers' actual task completion times, we document economic losses for managers stemming from their over-reliance on flat fees when hiring workers under longer (versus shorter) external deadlines.

The bias in time estimation arising from different time limits is potentially multiply determined. The bias is consistent with managers' lay motivational theories about per-minute workers" "slacking" by strategically taking more time under longer time limits to earn more. While little empirical work has studied such managerial beliefs about slacking, similar strategic worker behavior has been discussed in the literature as “holding-back", “soldiering”, or "goldbricking” (e.g., Pendleton, Lupton, Rowe, \& Whittle, 2019; Roy, 1952; Taylor, 1896). The bias is also consistent with a cognitive heuristic, such that managers perceive the scope of the work as being more extensive under longer time limits. We find evidence suggesting that both factors contribute to the findings. In particular, the bias persists even when workers' motivation is not relevant to

\footnotetext{
${ }^{1}$ The flat fee payment scheme used in this paper is similar to piece-rate payment schemes used in industrial production systems. However, we limit our investigation to workers completing just one task rather than the multiple tasks typically observed in industrial production systems.
} 
decision making (suggesting a cognitive scope inference) and when additional information about project scope is provided (suggesting a motivational process route).

Overall, we find an extremely robust bias in the choice of simulated employment compensation schemes - a domain in which little evidence for non-normative decisions has previously been demonstrated.

\section{Theoretical Development}

Prescriptive, forward-looking models of cost-benefit analysis assume that managers can either accurately estimate relevant inputs, such as workers' time, or can at least estimate an unbiased probability distribution of the time needed (Dumond \& Mabert, 1988; Sugden \& Williams, 1978). Foundational work in industrial and organizational psychology invested a great deal of effort into defining and timing the steps in industrial processes (e.g., Lowry, Maynard, \& Stegemerten, 1940), precisely because of the importance of having accurate inputs into such decisions. While this approach is well suited for the manufacturing assembly line, it is a much more difficult task for managers in the modern economy, where tasks are often highly variable in type and scope and rely more on worker flexibility and initiative.

\subsection{Biases in Time Estimation}

Estimates of task completion time are duration judgments of a prospective (usually non-experienced) event, and such judgments are often biased (over or underestimated) and highly malleable (see Halkjelsvik \& Jørgensen, 2012 and Roy, Christenfeld, \& Jones, 2013 for comprehensive reviews). The susceptibility to bias in prospective duration judgments has even been documented among professionals making estimates about a familiar task (Jørgensen, Teigen, \& Moløkken, 2004) and successful 
time managers (Francis-Smythe \& Robertson, 1999). This can happen because it is difficult for decision makers to learn from experience (Meyvis, Ratner, \& Levav, 2010). Indeed, while retrospective time judgments of experienced events may seem easier to estimate, even such estimates are systematically affected by factors such as how long ago the event occurred (Neter, 1970), availability of attentional resources (Block, 1992) and retrieval of cues from memory (Zauberman, Levav, Diehl, \& Bhargave, 2010). Therefore, even experienced decision-makers with access to accurate feedback may fail to effectively utilize past information (Buehler, Griffin, \& Ross, 1994; Gruschke \& Jørgensen, 2008) in making prospective completion time estimates.

Perhaps as a result of these inherent difficulties in making time judgments, time estimates are sensitive to contextual cues, such as self-generated time goals in lab studies (König, 2005; Thomas \& Handley, 2008), naturally occurring and experimentally manipulated deadlines (Buehler et al., 1994), as well as customers' expected times among experienced professionals (Aranda \& Easterbrook, 2005; Grimstad \& Jørgensen, 2007; Jørgensen \& Sjøberg, 2001). One particularly pervasive contextual cue is the time available, such as an external deadline. Managers may incorporate such cues into their estimates of workers' task completion times, and then base their subsequent decisions on those estimates. When this occurs, the economic efficiency of their decisions, such as choices between compensation schemes to hire workers will depend on the degree to which incorporating the deadline affects the accuracy of their estimates.

\subsection{Effect of Deadlines on Choices of Compensation Schemes}

In many labor-intensive industries like retail, hospitality, machine shops, and auto services (MacPherson, 2014) managers face a choice between hiring workers with a per- 
unit-time compensation scheme (e.g., payment is based on amount of time spent working) or a flat-fee compensation scheme (where the fixed or salaried payment is based on completing a given task, regardless of time spent). Employer preferences for such types of hiring schemes have been found to depend on a host of rational factors, including the extent to which effort or output can be monitored (Hölmstrom, 1979), transactional costs of performing such monitoring and controlling activities (Williamson, 1981), uncertainty in the environment (Prendergast, 2000), stage in the organizational life cycle (Madhani, 2010), and the potential for sorting and self-selection of the best-fit employees into an organization (Lo, Ghosh, \& Lafontaine, 2011).

Research in non-employment contract settings has, however, documented systematic biases favoring flat rate or non-metered payment. For example, non-optimal preferences for flat-rate (generally with unlimited use) over metered payment plans have been documented in the domains of cell-phone services, internet tariff plans, and gymmemberships (DellaVigna \& Malmendier, 2006; Lambrecht \& Skiera, 2006; Train, McFadden, \& Ben-Akiva, 1987). Multiple explanations for such biased behavior have been proposed, including risk aversion (Lambrecht \& Skiera, 2006), pain of paying (Prelec \& Loewenstein, 1998), and pre-commitment for self-control (DellaVigna \& Malmendier, 2006).

In this paper, we study when, in the context of employment compensation, employers' choices between flat fee and metered compensation options may be nonoptimal. In particular, we identify deadlines as a key influence on managers' choices and find that longer deadlines lead to non-optimal choices. 
Deadlines can affect manager's judgments about others' (e.g., workers') taskcompletion times for several reasons. Our studies rule out some of the ways time limits might influence managers. As the upper bound of how long a task could take, time limits could be normatively informative. Even when time limits are not informative, managers may simply anchor their estimate on the time limit as the sole available starting point when prompted to make an estimate (Halkjelsvik \& Jørgensen, 2012). However, we demonstrate that the effects of the controlling time limit on contract choice occur even when the time limit is not informative, when managers are not prompted to make time limit estimates prior to choosing contracts, and when multiple anchoring cues are available.

Instead, we focus on two mental processes that we believe may underlie the preference for flat-fee contracts under long time limits. Manager's estimates may be based on a belief that workers will work faster when the deadline is closer, either because having less time available may increase efficiency (Parkinson, 1955) or because being subjectively closer to the completion goal motivates more effort investment (Gjesme, 1975; Hull, 1932; Kivetz, Urminsky, \& Zheng, 2006) and reduces procrastination (Ariely \& Wertenbroch, 2002). Relatedly, managers may believe that workers are likely to engage in "slacking", intentionally delaying completion when wages are a function of time spent doing the job, which would have more of an effect on completion time under longer time limits. Finally, deadlines could also affect completion time estimates on account of a perceptual mechanism that associates scope of work with length of time limits. In the next two sections, we elaborate on the antecedents and the consequences of 
these cognitive and motivational processes that might bias managers to overestimate others' completion times.

\subsection{Biased Beliefs about Slacking}

When time-based compensation schemes are used, workers may have a perverse incentive to delay task completion so that they earn more total wages. Industrial sociologists have identified piece-rate workers engaging in the strategic behavior of "goldbricking" (also referred to as "holding-back" or "soldiering"; Taylor 1896; Roy 1952), by tacitly limiting production to ensure that the quota set by the management was not exceeded. Such behavior was driven by a concern that managers might subsequently reduce the piece-rate price if the quota were exceeded (p. 430, Roy, 1952).

While this concern is not relevant to the experiments in this paper, managers might be concerned about a related strategic "holding-back" behavior that workers could engage in to earn more money. In particular, managers might be concerned that when metered fees are used, workers might intentionally delay completion up to the deadline to earn higher total wages. We refer to this potential worker behavior as "slacking," and we investigate managers' beliefs about slacking as a potential explanation for their time estimates and compensation choices.

Extant literature does not provide empirical evidence on the incidence of the kind of slacking behavior that we study in this paper. However, based on normative principalagent theories that expect workers to be effort-averse and shirk whenever they can (Alchian \& Demsetz, 1972; Fehr \& Goette, 2007), workers would be predicted to slack as much as they can. At the same time, research in psychology suggest that the extent to which such self-interest is an important predictor of behavior is often overestimated 
(Ferraro, Pfeffer, \& Sutton, 2005) and intrinsic motivation is often underestimated

(Heath, 1999). Therefore, it is possible that managers underestimate the extent to which workers might internally highlight the importance of finishing the task, even if it means not claiming the maximal compensation.

In repeated interactions, the motivation to accrue reputational capital and the possibility of retaliation may limit the extent of workers' strategic slacking. In one-shot interactions, as tested in this paper, the incentives against slacking are reduced. At the same time, however, one-shot interactions make it difficult for people to decide how much to trust others, as there is limited scope for feedback and learning. Therefore, to the extent people have an aversion to risk betrayal (Bohnet \& Zeckhauser, 2004), managers might systematically err on the side of caution and overestimate others' task completion time, particularly when the external deadlines are longer. Thus, whenever managers overestimate the degree of slacking, time-based compensation schemes will be less attractive, particularly so when there are longer external time limits which provide greater opportunities for workers to engage in such strategic behavior.

\subsection{Biased Beliefs about Task Scope}

In people's everyday experience, tasks involving more work often have longer time limits. The prevalence of this 'directional rule' in everyday life can give rise to an over-generalized belief about a 'bi-directional association' between time limits and scope of work. Such a generalized association could lead to over-learned judgments about task scope based on time limits. Over-learned responses have been found in everyday judgments, in a variety of domains, even when cues are not informative (e.g., distance based on visual clarity, Brunswik 1943; frequency based on subjective value, Dai, 
Wertenbroch, \& Brendl, 2008; the value of services based on their duration, Yeung \& Soman, 2007).

Furthermore, research on attribute substitution (Kahneman \& Frederick, 2002) suggests that decision-makers sometimes automatically substitute highly salient information for other factors in a decision, reframing the question posed to them, and remaining unaware of having done any such substitution. When deliberating about completion time for a task (a less accessible target attribute), people may, therefore, draw inferences from a seemingly diagnostic cue - the total time available (a more accessible related attribute).

Longer (vs. shorter) external time limits might either spontaneously bring to mind aspects of explicit task scope (e.g., number of completion steps, greater difficulty, or higher complexity), or just prompt a general sense that the task takes longer independent of time limits (i.e., implicit task scope). Consequently, irrespective of whether the time limit is normatively informative, people may more readily imagine a scope of work consistent with the time limit, based on an over-learned association between time limit and amount of work. This could result in a higher estimate of task completion time when time limits are longer (Goswami \& Urminsky, 2018).

In a typical demonstration of the "Scope Perception Bias" (Goswami \& Urminsky, 2018), when judges were told that deadlines were not known to the workers (and therefore, could not affect workers' effort or motivation), the judges nevertheless estimated a longer task completion time when these "hidden" (and therefore objectively irrelevant) deadlines were longer. This psychology of scope perception is consistent with 
recent research showing that longer (vs. shorter) imposed deadlines for achieving a goal might lead to inferences about greater goal difficulty (Zhu, Bagchi, \& Hock, 2018).

An effect of time limits on expected completion time estimates could also be consistent with incidental anchoring (Critcher \& Gilovich, 2008; Wilson et al., 1996), in which numerical cues in the decision context may affect numerical estimates without any deliberate prompting or inferential reasoning. However, the evidence for such anchoring effects is limited (Brewer \& Chapman,2002; Mussweiler \& Strack, 2001). While incidental anchoring could further contribute to the proposed effect of time limits on compensation decisions, our studies are designed to rule out incidental anchoring as an artifact (e.g, by having participants make their compensation choice before, and even without, making numerical time estimates and by exposing participants to all possible time limits).

Next, we demonstrate the presence of a flat-rate bias in employment settings (involving judgments of others' behavior) that is psychologically distinct from prior findings of flat-rate bias in consumers' choice of service contracts (which relate to their own behavior). We contribute to this literature by identifying a novel misestimationbased route, via which decision makers exhibit a bias for flat-rate contracts that is specific to employment contexts with salient deadlines. The misestimations of others' task completion times is caused by how an external deadline biases beliefs, both about workers' behavior and about the scope of the task.

Across fourteen studies, we test the effects of deadlines on consequential one-shot choices between metered (e.g., paying per unit of time) and flat-fee employee compensation schemes and document a strong non-optimal preference for flat-fee 
compensation schemes. We limit our investigation to one-shot interactions to minimize the effect of long-term relationship motives on manager's choices. The preference for paying flat fee compensation results in lower earnings when hiring an actual worker to do a task in which the quality of the outcome is fixed (e.g., solving jigsaw puzzles; Study 1a). The behavior persists even when potential informational cues from deadlines are eliminated (Study 1b) and when task quality and the resulting value of the completed task to managers can vary (Study 2). Post-choice self-reports indicate that concern about slacking is common, yet only partially explains observed compensation scheme choices as we also find beliefs consistent with an implicit scope of work account (Study 3).

Delving deeper into the potential process explanations, we replicate the effect when the workers were all paid a flat fee (which eliminates the slacking concern for managers), but managers have the option of either paying a per-minute or flat fee (Study 4, pre-registered). This confirms that concerns about slacking alone cannot explain the observed findings, pointing to a potential mechanism that involves an association between time limits and the perceived scope of the work. Finally, we show that the effect persists when managers are given the full distribution of workers' completion time under no time limits, which defines the scope of work (Study 5, pre-registered). This confirms that the effect of deadlines on scope perception alone cannot explain the observed findings. Overall, the full set of results suggest that the effect of time limits on completion time misestimation and consequent preferences for paying flat fee compensation is jointly determined by both slacking concerns and scope perception, and very robust. 
Across the studies, we find consistent mediation of compensation choices by estimated worker completion time (in Studies 1a, 1b, 2, 4, and 5). We rule out multiple alternative accounts, including general risk aversion (Studies 1a and 1b), employmentspecific risk aversion (Study 4), and incidental anchoring (Studies 1b, 4 and 5). We report all studies conducted, sample sizes and exclusions were determined in advance, all data collected (as well as pre-registrations for Studies 4 and 5) are reported and made publicly available via OSF, and details of all stimuli are provided in Online Appendix A.

\section{Study 1a: The Effect of Deadlines on Contract Choices and Earnings}

Participants played a consequential game, either as a "worker" completing a task with a specific time limit (phase 1), or as a "manager" making contract choices about workers, under different time limits (phase 2). "Workers" were given a standardized task (a digital jigsaw puzzle) in which completed work does not vary in quality or in value to the manager. "Managers" could maximize their earnings by simply choosing the hiring plan that minimized the cost of their hired worker.

\subsection{Method - Phase 1: Workers}

\subsubsection{Participants}

Participants $(\mathrm{N}=55)$ were recruited in a research lab in a large Midwestern city, and played the role of workers. Workers were randomly assigned to one of two conditions (time limit: shorter $=5$ minutes vs. longer $=15$ minutes $)$ and were paid a rate of 25 cents per minute (rounded up to the nearest minute) for the time taken to solve the puzzle. Before starting work, workers were informed about their compensation scheme and time limit and then read about the puzzle-solving interface. Workers were told that they could either move on to participate in other studies in the lab or leave the lab as soon 
as they were done with the puzzle and had answered a few follow-up questions that were part of the survey. This instruction was given to correct any mistaken inferences workers might have made about reasons to delay finishing the task (e.g., that they need to be doing the work for the entire assigned time limit).

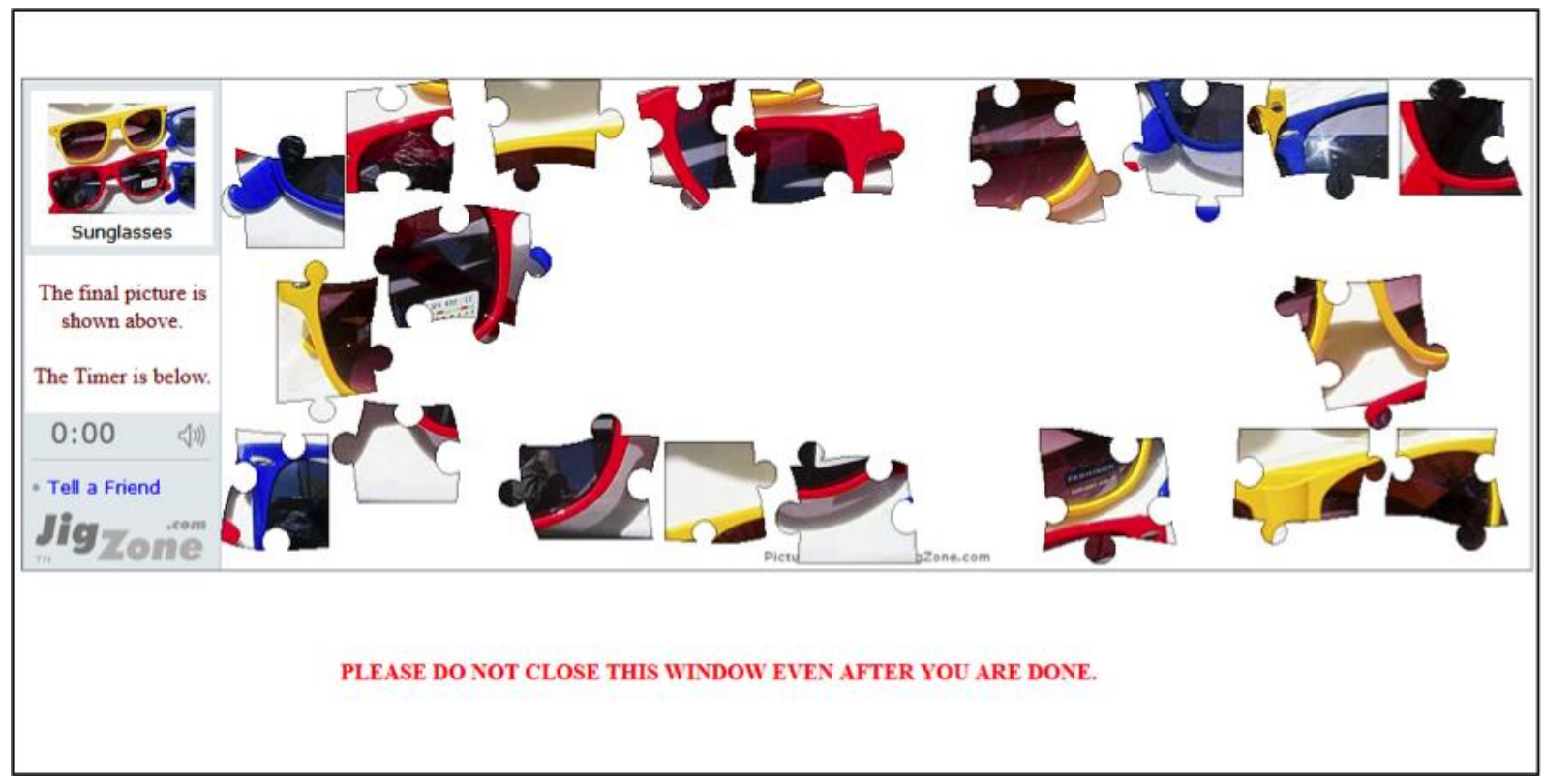

Figure 1: Interface used to administer the Jigsaw Puzzle task (Study 1a).

The jigsaw puzzle was then administered using a computer interface from the website $w w w . j i g z o n e . c o m$. The interface showed a timer which started counting immediately after the first piece was moved and stopped when all the pieces were in place. All participants solved the same puzzle, but each participant started off with a different initial random arrangement of the puzzle pieces (see Figure 1).

As participants moved the puzzle pieces on the screen, the pieces snapped together only when the two pieces were the correct fit. As a result, it was not possible to solve the puzzle incorrectly, and thus quality of outcome was held constant across workers. After each worker finished the puzzle, they answered questions about their experience and familiarity with jigsaw puzzles. A research assistant recorded the 
completion time (from the stopped clock on the screen) and paid the participants based on their actual time spent.

\subsection{Results - Phase 1: Workers' Completion Times}

Workers took only a little longer to solve the puzzle when time limits were longer, a non-significant difference $\left(\mathrm{M}_{\text {Shorter }}=2.81 \mathrm{vs} . \mathrm{M}_{\text {Longer }}=3.59, t(53)=1.35\right.$, $p=.183)^{2}$. As a result, there was no significant difference in the workers' earnings between the two time limits; even though the workers with longer time limits could have earned more if they had delayed completion to use more time (i.e., had intentionally slacked).

The workers' limited sensitivity to the deadline is not inconsistent with mixed predictions from the literature. While principal-agent theories expect workers to extract as much wage as possible (Alchian \& Demsetz, 1972; Fehr \& Goette, 2007), research in psychology suggest that the importance of others' self-interest is often overestimated (Ferraro et al., 2005) and the importance of others' intrinsic motivation is often underestimated (Heath, 1999).

Next, we investigate how well calibrated the managers are about the effect of the compensation scheme on workers' completion times under different time limits, and how that affected their choices.

\section{Method - Phase 2: Managers}

\subsubsection{Participants}

\footnotetext{
2 Three workers took over 5 minutes in the shorter time-limit condition, and these were truncated to 5 minutes. The results are the same using the untruncated numbers (see Online Appendix $\mathrm{C}$ for additional analysis for all studies including the complete distribution of workers' time).
} 
In phase 2, an adult online sample $(\mathrm{N}=171)$ recruited from Amazon Mechanical Turk played the role of managers. Managers were allotted a lump sum budget for getting a jigsaw puzzle completed, but they needed to "hire" and pay a worker to do the task for them. They could choose between hiring a per-minute worker or a flat-fee worker. When a manager opted for a flat-fee worker, the cost of hiring was fixed. However, if the manager opted for a per-minute worker, a real worker from phase 1 was randomly picked and paired with the manager, and the manager's cost of hiring the worker was based on the worker's actual time to complete the task. The remaining money, after deducting the cost of hiring from the allotted budget, was paid to the manager as their profit.

\begin{tabular}{|c|c|c|c|c|c|}
\hline \multirow[b]{2}{*}{ Time Limit } & \multirow[b]{2}{*}{ Terms } & \multicolumn{2}{|c|}{ If Flat Fee Selected: } & \multicolumn{2}{|c|}{ If Per-minute Fee Selected: } \\
\hline & & $\begin{array}{l}\text { Cost of } \\
\text { hiring } \\
\text { worker }\end{array}$ & $\begin{array}{l}\text { Profit earned } \\
\text { by manager } \\
\text { (fixed) }\end{array}$ & $\begin{array}{l}\text { Cost of } \\
\text { hiring } \\
\text { worker }\end{array}$ & $\begin{array}{c}\text { Profit earned } \\
\text { by manager } \\
\text { (variable) }\end{array}$ \\
\hline \multicolumn{6}{|c|}{ No Recruiting Fee Conditions: } \\
\hline $\begin{array}{l}5 \text { minutes } \\
\text { (shorter } \\
\text { time limit) }\end{array}$ & $\begin{array}{l}\text { Budget }=\$ 2 \\
\text { Flat Fee }=\$ 1 \\
\text { Per-Unit-Time rate }=\$ 0.25 / \mathrm{min}\end{array}$ & $\$ 1$ & $\$ 1$ & \multirow{2}{*}{$\begin{array}{l}25 \notin \text { per } \\
\text { minute } \\
\text { worked }\end{array}$} & $\$ 0.75$ to $\$ 1.75$ \\
\hline $\begin{array}{l}15 \text { minutes } \\
\text { (longer time } \\
\text { limit) }\end{array}$ & $\begin{array}{l}\text { Budget }=\$ 4 \\
\text { Flat Fee }=\$ 1.50 \\
\text { Per-Unit-Time rate }=\$ 0.25 / \mathrm{min}\end{array}$ & $\$ 1.50$ & $\$ 2.50$ & & $\$ 0.25$ to $\$ 3.75$ \\
\hline \multicolumn{6}{|c|}{ Recruiting Fee Conditions: } \\
\hline $\begin{array}{l}5 \text { minutes } \\
\text { (shorter } \\
\text { time limit) }\end{array}$ & $\begin{array}{l}\text { Budget }=\$ 2.10 ; \\
\text { Flat Fee }=\$ 1.10 \text { (including } \$ .10 \\
\text { recruiting fee); } \\
\text { Per-Unit-Time rate }=\$ 0.25 / \mathrm{min}\end{array}$ & $\$ 1.10$ & $\$ 1$ & \multirow{2}{*}{$\begin{array}{l}25 \phi \text { per } \\
\text { minute } \\
\text { worked }\end{array}$} & $\$ 0.85$ to $\$ 1.85$ \\
\hline $\begin{array}{l}15 \text { minutes } \\
\text { (longer time } \\
\text { limit) }\end{array}$ & $\begin{array}{l}\text { Budget }=\$ 4.60 ; \\
\text { Flat Fee }=\$ 2.10 \text { (including } \$ .60 \\
\text { recruiting fee); } \\
\text { Per-Unit-Time rate }=\$ 0.25 / \mathrm{min}\end{array}$ & $\$ 2.10$ & $\$ 2.50$ & & $\$ 0.85$ to $\$ 4.35$ \\
\hline
\end{tabular}

Table 1: Managers' potential profits in different conditions in Study 1a.

Managers were randomly assigned to one of the time-limit conditions (shorter=5 minutes vs. longer $=15$ minutes). We also varied whether the flat-rate contract included a "recruiting fee" or not (which was included to equalize the minimum potential earnings between choices of compensation schemes to address a potential confound). Thus, the 
study had a 2(time limit: shorter $=5$ minutes vs. longer $=15$ minutes $) \times 2$ (recruiting fee for flat-rate workers: present, absent) full-factorial design. Managers were informed that actual workers only did one task during the allotted time, and the workers were free to leave as soon as they completed the work. Managers were shown the exact puzzle interface instructions (including two pictures of the exact puzzle) that the workers had seen. Since the software only allowed correct solutions, managers also knew that there was only one way of completing the task and therefore the quality of the outcome could not vary with the type of compensation scheme chosen.

The cost of hiring workers (and the resulting potential profit) in each condition is shown in Table 1. The total budget available to the managers was either $\$ 2.00$ (shorter time limit) or $\$ 4.00$ (longer time limit). The cost of hiring a worker with a per-minute plan was the same in all four conditions: 25 cents per minute, rounded up to the nearest minute, for the time taken by the worker to solve the puzzle. Therefore, the total cost of hiring a per-minute worker ranged from $\$ 0.25$ to $\$ 1.25$ in the shorter time-limit condition, and from $\$ 0.25$ to $\$ 3.75$ in the longer time-limit condition.

The cost of hiring a flat-fee worker varied by condition. In the two no-recruitingfee conditions, the cost for hiring a flat fee worker was either $\$ 1.50$ (longer time limit) or $\$ 1$ (shorter time limit). Thus, managers in these conditions faced a tradeoff between a known fixed amount of profit if they chose the flat fee, or an unknown variable profit if they chose the per-minute fee. The profit from paying per-minute compensation could be either higher or lower than that from paying a flat fee, depending on how long the perminute worker took to complete the task. 
In the no-recruiting-fee conditions, the minimum potential earning from perminute compensation was less in the longer time-limit condition than in the shorter timelimit condition (\$0.25 vs. \$0.75). This introduces a "worst-case-scenario" confound, which was addressed in the recruiting-fee conditions. In the recruiting-fee conditions, the budgets were increased to either $\$ 2.10$ (shorter time limit) or $\$ 4.60$ (longer time limit), and either a $\$ 0.60$ (longer time limit) or $\$ 0.10$ (shorter time limit) recruiting fee for flat fee workers was added. As a result, the minimum profit from hiring a per-minute worker was the same for both longer and shorter time limits (85 cents) in the recruiting fee conditions.

To ensure comprehension of their hiring options, managers were prompted to reenter three crucial pieces of information before indicating their choice: the total time limit available, the total cost of hiring a flat fee worker, and the cost per minute of hiring a perminute worker. Managers then indicated whether they chose to pay flat fee or per minute compensation. After choosing, all managers (irrespective of the hiring option chosen) estimated the worker's completion time, both under the option they had chosen, as well as under the unchosen alternative compensation scheme.

After these questions, managers were presented with a hypothetical choice between a sure amount (equal to their profit from choosing the flat-fee option) and a gamble which, unbeknownst to them, was constructed from the results of phase 1 to match the actual distribution of profits under the per-minute compensation. Lastly, they answered a few questions measuring risk attitude, cognitive ability, and knowledge of jigsaw puzzles.

\subsection{Results - Phase 2: Managers' Compensation Choices}


We found no main effects of the recruiting fee manipulation and the manipulation did not interact with any other factors. Therefore, we conclude that hiring-option choices were not sensitive to the worst-case per-minute cost, and we collapsed across these conditions in the remaining analyses.
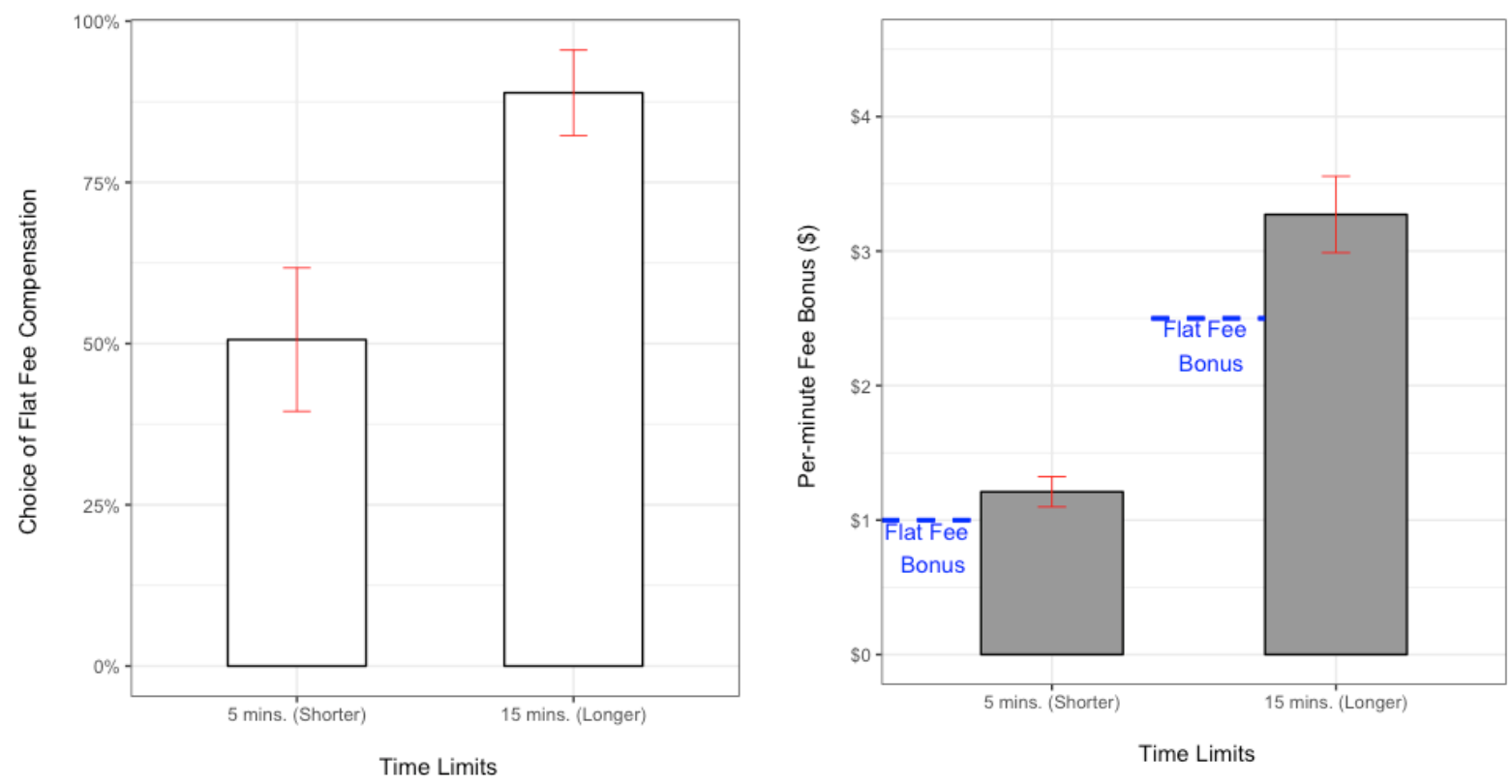

Figure 2: Choice of flat fee compensation (left-panel) and differences in expected bonuses from choosing different compensation options (right-panel) in Study 1a. The vertical lines are 95\% CI.

Based on the actual completion times of workers paid per-minute in phase 1 , unknown to the managers, the expected value of managers' earnings was significantly higher for choosing per-minute compensation than the fixed earnings from flat fee compensation, in both the shorter time-limit (MPer-minute Fee $=\$ 1.21$ vs. $\$ 1.00$ flat fee; $\Delta=$ $\$ 0.21 ; t(27)=3.84, p<.001)$ and the longer time-limit conditions (MPer-minute Fee $=\$ 3.27 \mathrm{vs}$. $\$ 2.50$ flat fee; $\Delta=\$ 0.77, t(26)=5.58, p<.001) .{ }^{3}$ Furthermore, the expected advantage of per-minute compensation was significantly higher in the longer time-limit condition

\footnotetext{
${ }^{3}$ These calculations are based on averaging bonuses from both the two possible budgets (with and without recruitment fee) for a particular time limit.
} 
$(t(53)=3.82, p<.001)$. Thus, well-calibrated managers would be expected to choose to pay per-minute compensation, particularly in the longer time-limit condition.

Nevertheless, close to three-fourth of the managers (71\%), chose the lower expected-value flat fee compensation. In particular, even though the expected payoff disadvantage of choosing the flat fee was higher in the longer time-limit condition, managers were more likely to choose the flat fee under the longer time-limit (89\%) than the shorter time-limit $(51 \%)$, a highly significant difference $\left(\chi^{2}(1)=30.18, \mathrm{p}<.001\right.$; see Figure 2).

Given that managers were less likely to choose the optimal per-minute option in the longer time-limit condition, they actually left significantly more money on the table (based on realized profits after being matched to a random per-minute worker) in the longer time-limit condition $\left(\mathrm{M}_{\text {Per-minute Fee }}=\$ 3.74, \mathrm{M}_{\text {Flat Fee }}=\$ 2.50 ; \Delta=-\$ 1.24, t(9)=9.26\right.$, $p<.001)$, compared to the shorter time-limit condition $\left(\mathrm{M}_{\text {Per-minute Fee }}=\$ 1.18, \mathrm{M}_{\text {Flat Fee }}=\right.$ $\$ 1.00 ; \Delta=-\$ 0.18 ; t(39)=4.08, p<.001)$; difference $t(48)=9.52, p<.001)$.

The suboptimal compensation scheme choices are largely explained by the managers' estimates of completion time. Managers who chose to pay a flat fee estimated a longer completion time for per-minute workers both in the shorter $\left(\mathrm{M}_{\text {Chose Flat Fee }}=4.41\right.$ vs. $\left.\mathrm{M}_{\text {Chose Per-minute Fee }}=3.26 ; t(79)=6.17, p<.001\right)$ and longer time-limit conditions $\left(\mathrm{M}_{\text {Chose }}\right.$ Flat Fee $=12.86$ vs. MChose Per-minute Fee $=5.45 ; t(88)=6.79, p<.001)$, but more so when the external time limits were longer $(F(1,167)=41.05, p<.001)$. In particular, the managers who chose flat fees overestimated the expected time per-minute workers would take, compared to the actual time taken (shorter time limit: 4.41 vs. $2.81, t(67)=6.11, p<.001$; longer time limit: 12.86 vs. $3.59, t(105)=13.27, p<.001)$. 


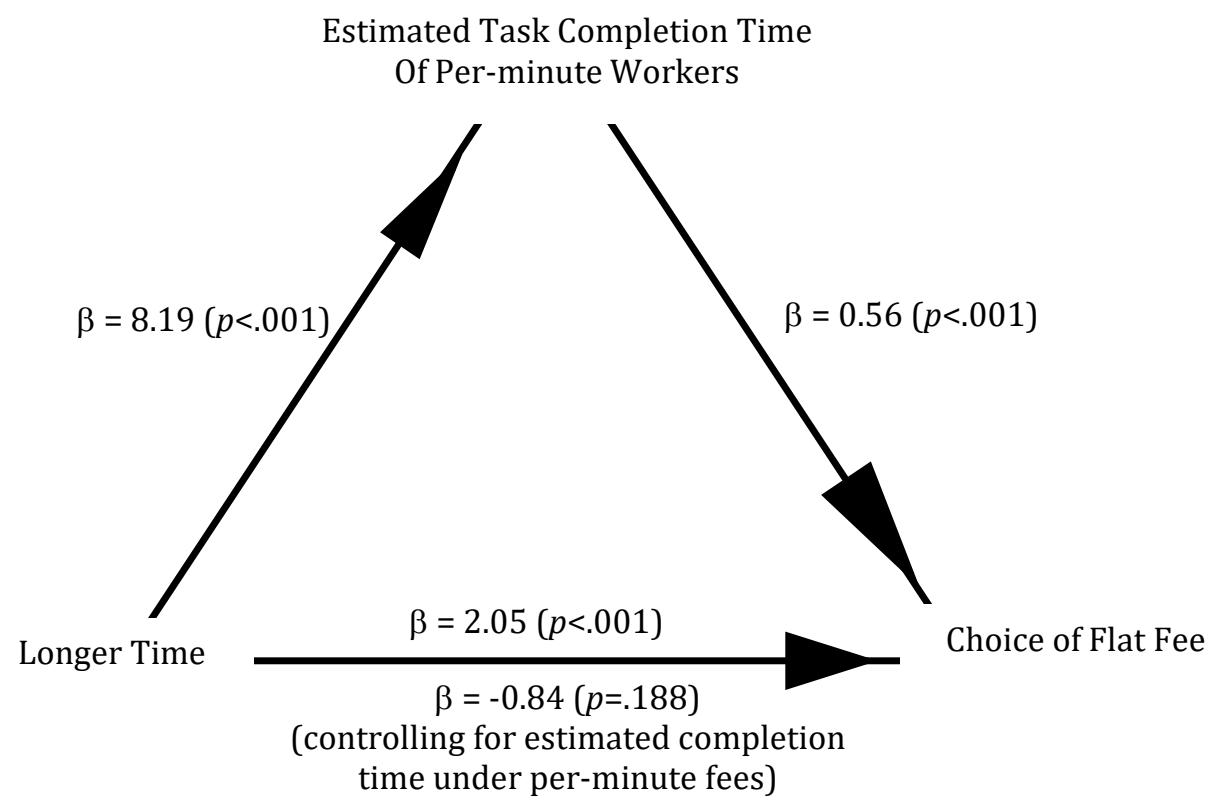

Figure 3: Mediation of the choice of flat-fee compensation by managers' estimated completion time for per-minute workers in Study 1a

In fact, managers' choices were largely rationalized by their estimates of workers' completion times. Most participants chose the option that would have provided a higher profit had their time estimates been correct (84\% in the shorter time condition; $91 \%$ in the longer time condition). Furthermore, controlling for managers' estimates of the time taken by per-minute workers, the effect of time limits on compensation scheme choices was no longer significant (Figure 3). The estimated time for per-minute workers completely mediated the effect of deadlines on managers' compensation scheme choices (indirect effect bootstrapped $95 \% \mathrm{CI}=[0.39,0.76])$. This provides further confirmation that managers' choices under different time limits were driven by their biased beliefs about task completion times.

Given that the compensation scheme choice can be thought of as a choice between a fixed profit or betting on an uncertain profit that could be either higher or lower (Grund \& Sliwka, 2010), it is important to consider the potential role of risk 
preferences. Might managers' preferences for paying a flat fee be explained by a general preference for avoiding risk, particularly in the longer time limit, where the payoffs for per-minute worker have high variance? To test this, we had the managers make a hypothetical choice between a fixed amount (equal to the profit from the flat-fee option), and a gamble equivalent to the actual distribution of payoffs from the per-minute compensation option (i.e., calculated from workers' times in phase 1, see Online Appendix B). The choice was presented as a separate hypothetical gamble, in order to measure risk preferences in an equivalent choice without managers' awareness that the gamble and earlier choices were equivalent, to avoid consistency motives.

Managers were less likely to choose the risk-free option in the gamble than the equivalent flat fee in both the time-limit conditions. In the shorter time-limit condition, managers were somewhat less likely to opt for the certain amount in the risky choice than to select the equivalent flat fee in the compensation scheme choice (37\% vs.51\%; McNemar's $\left.\chi^{2}(1)=4.17, p=.041\right)$. In the longer time-limit condition, managers were much less likely to choose the certain amount than to make the equivalent choice of the flat fee $\left(61 \%\right.$ vs. $\left.89 \% ; \chi^{2}(1)=21.55, p<.001\right)$. A logit model confirmed that managers' stronger preference for flat fees under the longer time limit than the shorter time limit still held $(\beta=1.89, z=4.51, p<.001)$ controlling for measured risk preferences (e.g., the equivalent gamble chosen; $\beta=1.51, z=3.64, p<.001)$. This suggests that the hiring-choice findings are not explained by managers' general risk aversion when facing a choice between certain and variable outcomes.

\subsection{Discussion}


Using a consequential hiring game, we find that lay people playing the role of managers show a preference for paying a flat fee (vs. time-metered compensation schemes), particularly under longer time limits, because of a deadline-induced bias in their estimates of other's task completion time. As a result, managers' actual profits suffered, earning $35 \%$ less than optimal in the longer time-limit condition, and $25 \%$ less than what they could have earned in the shorter time-limit condition, on average.

The bias for paying a flat fee was not explained by general risk aversion, and was robust to other factors, including the amount of time spent reading the instructions and making choices, and depth of processing (as measured by the Cognitive Reflection Test or CRT; Frederick, 2005). The results did not vary with self-reported knowledge about and experience with jigsaw puzzles.

In this study, workers' actual times did not differ significantly by time limit, but managers incorrectly believed that they would, resulting in biased compensation scheme choices. Of course, workers' times sometimes are affected by time limits (as we shall see in Studies 2 and 5). Our claim is that deadlines create a potential for managers to be systematically biased about workers' times in a specific direction, tending to overestimate the degree to which longer deadlines yield longer task completion times. When completion times are overestimated, the bias can affect consequential decisions, as demonstrated in this study.

This finding is very robust. In Study 1a, lay people made choices about hiring a single worker. Managers often hire multiple workers, and this may provide riskreduction benefits due to diversification (i.e., lower variance in cost when relying on multiple workers rather than a single worker). In another study, we generalized the 
findings to compensation scheme choices involving hiring multiple workers, further ruling out risk aversion as an explanation of the findings (Study A1, Online Appendix D). To test expertise as a potential boundary condition, we also replicated the findings among MBA students, the majority of whom had prior experience making decisions involving hiring and compensation (Study A2, Online Appendix D).

In the next study, we address a potential informational confound. In Study 1a, managers only knew about one of the time limits, and might have made additional inferences about the task based on the time limit. For example, managers might have assumed that the time limit was selected as a reasonable amount of time to complete the task, potentially even based on data about how long the task took workers. Such an inference, while non-optimal in the context of these studies, might be a normative strategy in general, if deadlines do typically convey diagnostic information.

Alternatively, the time limit might have acted merely as an implicit anchor (Critcher \& Gilovich, 2008), without participants engaging in additional inferences.

In Study 1b, we present an even more conservative test of the preference for flat fees under longer deadlines, which addresses both of these possibilities. We inform participants about both their workers' deadline and the alternative deadline that does not affect their workers, eliminating the potential for differential information across deadline conditions and holding constant the set of potential implicit anchors available across conditions.

\section{Study 1b: Contract Choices When Both Potential Deadlines Are Known}

\subsection{Method}

\subsubsection{Participants}


Amazon Mechanical Turk participants $(\mathrm{N}=178)$ played the role of managers in a consequential hiring game based on the two no-recruiting-fee conditions from Study 1a (time limit: shorter $=5$ minutes vs. longer $=15$ minutes) and the phase 1 worker data from Study 1a. However, unlike in Study 1a, all managers were informed that there were two potential time limits, and that workers had been randomly assigned to either the 5 minute or 15 minute time limit (which was, in fact, the case). Nearly all the managers (84\%) confirmed that workers were randomly assigned to a time limit, and the results are robust to excluding the managers who gave an incorrect response (see Online Appendix C).

\subsection{Results}

Replicating the prior results, overall most managers preferred to pay a flat fee $(81 \%)$, and they were more likely to choose so in the longer time-limit condition than in the shorter time-limit condition $\left(94 \%\right.$ vs. $\left.68 \%, \chi^{2}(1)=19.68, p<.001\right)$. Given that the hiring options were the same as in the no-recruiting fee conditions in Study 1a, the expected advantage of a per-minute fee was significantly higher in the longer time-limit condition. Managers' preference for flat fees therefore resulted in under-earning relative to optimal choices, particularly in the longer time-limit condition $(\Delta$ Longer time limit $=-\$ 0.85$, $\Delta$ Shorter time limit $=-\$ 0.13 ; t(31)=5.32, p<.001)$, as in Study $1 \mathrm{a}$.

Despite the fact that managers had been told about both time limits and knew that workers had been randomly assigned to a time limit, the same pattern of time misestimation as in Study la was observed, and the time estimates fully explained the compensation scheme choices. Managers who chose to pay a flat fee estimated a longer per-minute worker completion time, both for shorter time limits $\left(\mathrm{M}_{\mathrm{Chose} \text { Flat Fee }}=4.74 \mathrm{vs}\right.$. 
$\left.\mathrm{M}_{\text {Chose Per-minute Fee }}=2.93 ; t(87)=11.86, p<.001\right)$ and marginally more so for longer time limits $\left(\mathrm{M}_{\text {Chose Flat Fee }}=11.89\right.$ vs. $\mathrm{M}_{\text {Chose Per-minute Fee }}=7.60 ; t(87)=2.63, p=.009$; difference $F(1,174)=3.59, p=.059)$. Most managers' choices were consistent with their beliefs about estimated times (96\% in the shorter time-limit condition; 89\% in the longer time-limit condition), and the estimated time for per-minute workers fully mediated the effect of deadlines on compensation scheme choices (indirect effect bootstrapped $95 \% \mathrm{CI}=$ $[0.31,0.73])$. Finally, contrary to a general risk aversion explanation, managers were less likely to choose the certain amount in the matched risky choice than to select the equivalent flat fee compensation scheme choice in both the time-limit conditions.

\subsection{Discussion}

Findings of Study $1 \mathrm{~b}$ show that our results hold even though all managers were exposed to the same set of potential time limits, contrary to the predictions of an informational or implicit-anchoring accounts. Thus far, we have used a fixed-quality task (solving a jigsaw puzzle) in which there was no risk that faster workers would deliver lower quality (and therefore less valuable) work. The fixed-quality task also makes it easy for workers to tell when they have completed the task, which potentially reduces the effect of time limits on their actual completion times. This, in turn, also makes it simple for managers, at least in theory, who only need to take into account the task completion times and minimize labor costs in order to maximize profits.

However, in many employment contexts, the quality of the workers' final output may vary substantially, with consequences for the employers' revenue. In these settings, workers may take longer when given more time, in order to try to do a better job. Managers, in turn, need to consider the possibility that faster workers might do a worse 
job in such settings. Thus, when profits are dependent on the final quality of the completed task, the choice of compensation scheme might involve a tradeoff between speed and quality. If this is the case, managers facing longer time limits might view perminute fees as not merely costlier, but also as incentivizing higher quality work, potentially countering the bias for paying a flat fee that we have documented thus far. We investigate this possibility in the next study, using a spelling task in which the quality of the workers' output could vary with time spent, with a direct impact on managers' earnings.

\section{Study 2: Contract Choices When Worker Error is Costly}

This study was conducted in two phases. In phase 1, online participants assigned to be "workers" completed a proofreading task . In phase 2, a separate sample of "managers," drawn from the same online population, played a consequential hiring game. The managers' earnings depended on the productivity of the workers' proofreading (i.e., the number of correct answers), as well as on how long the worker took if the per-minute option was chosen. As in prior studies, managers were informed that workers were told to only do one task in the allotted time and were free to stop as soon as they completed the study.

\subsection{Method - Phase 1: Workers}

\subsubsection{Participants}

Online participants from Amazon Mechanical Turk serving as workers (N=429) were randomly assigned to one of eight conditions in a 2 (time limit: shorter $=5$ minutes vs. longer $=15$ minutes $) \times 2$ (compensation: flat fee vs. per-minute fee) $\times 2$ (task difficulty: easy vs. difficult) design. Workers in the flat fee conditions were paid either $\$ 1$ 
(in the shorter time-limit condition) or $\$ 1.50$ (in the longer time-limit condition), regardless of how long it took them. Workers in the per-minute conditions were paid a rate of 25 cents per minute (rounded up to the nearest minute) for the time taken to do the task. Workers' compensation in all conditions was independent of their accuracy in the task. The workers read about their compensation scheme and time limit before starting the task and were told that they could end the study as soon as they were done with the task and answered a few follow-up questions.

A list of 24-words was presented as an image (i.e. not as text) and separate openended text-boxes were provided on the same screen, in which the workers were asked to type the correct spelling of each word (see Online Appendix A). The workers were told to move on to the next page when they were finished. Otherwise, the online interface automatically advanced to the next page when the time limit was reached. Thus, workers could not take longer than the allotted time. The workers were randomly assigned to proofread either a set of 24 easy words (e.g., "arround") or 24 difficult words (e.g., "concensus"). Task difficulty was varied to test the possibility that managers would be more concerned about workers' quality, and therefore more reluctant to hire flat-fee workers, when the task is more difficult.

\subsection{Results - Phase 1: Workers' Completion Times and Productivity}

When assigned to proofread easy words, per-minute workers, averaging across time limits, took longer than flat fee workers $\left(\mathrm{M}_{\text {Flat Fee }}=1.49\right.$ vs. $\mathrm{M}_{\text {Per-minute Fee }}=3.22$, $t(206)=5.16, p<.001)$. The longer time they chose to spend was sufficient for the perminute workers to earn more ( $\$ 0.92$ vs. $\$ 1.24, \mathrm{t}(206)=3.72, \mathrm{p}<.001)$, although they could have earned even more, if they had taken even longer. 
Unlike Study 1a, in this task we also find a main effect of time limits, with workers proofreading easy words taking more time when deadlines were longer $\left(\mathrm{M}_{\text {Shorter }}=\right.$ 1.91 vs. $\left.M_{\text {Longer }}=2.70, t(206)=2.25, p=.026\right)$. In particular, workers spent more time while working under a per-minute fee compared to a flat fee, specifically when the time limit was longer (Shorter time limit: $M_{\text {Flat Fee }}=1.43$ vs. MPer-minute Fee $=2.48$, Longer time limit: $\mathrm{M}_{\text {Flat Fee }}=1.56$ vs. MPer-minute Fee $=4.01$; interaction $F(1.204)=4.49, p=.035$; see Figure 4).

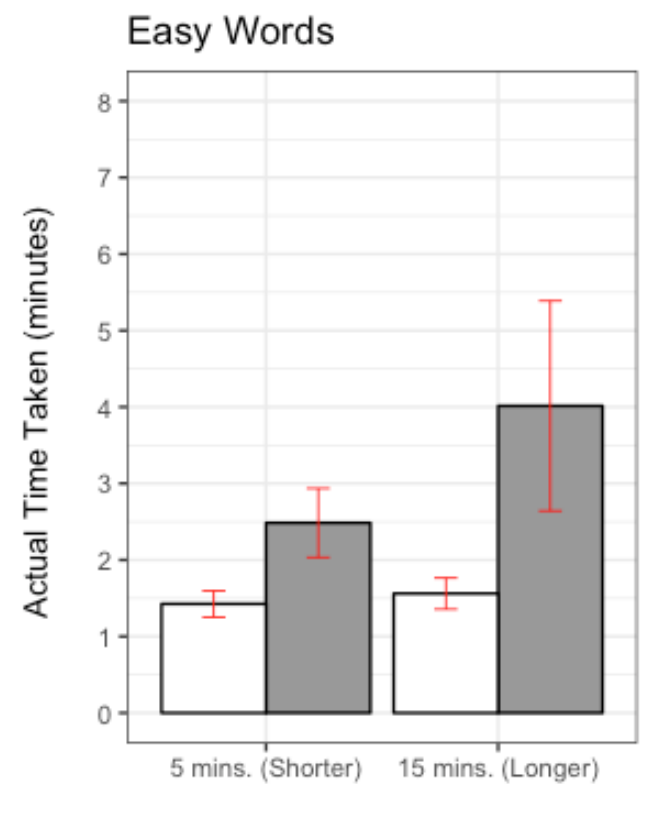

Time Limits

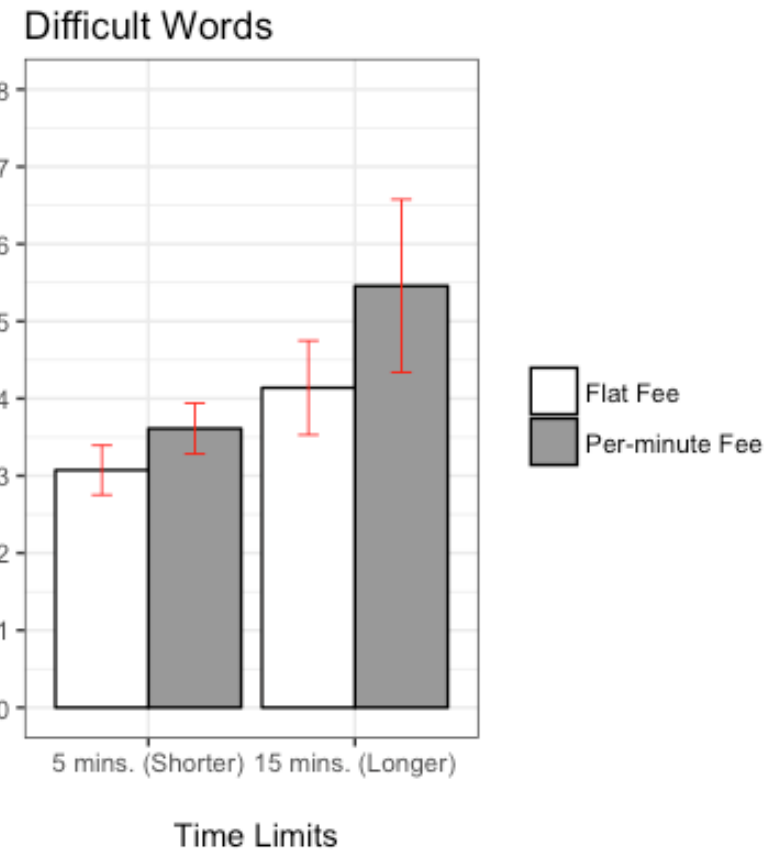

Figure 4: Time taken by workers to do the proofreading task under different time limits and compensation schemes in Study 2. The vertical lines are 95\% Confidence Intervals.

When assigned to proofread difficult words, per-minute workers, across time

limits, likewise took longer than flat fee workers $\left(\mathrm{M}_{\text {Flat Fee }}=3.58\right.$ vs. $\mathrm{M}_{\text {Per-minute Fee }}=4.55$, $t(219)=2.68, p=.008)$, but not long enough to earn more. Workers also took longer to finish the task when the time limit was longer $\left(\mathrm{M}_{\text {Shorter }}=3.35\right.$ vs. $\mathrm{M}_{\text {Longer }}=4.85$, $t(219)=4.26, p<.001)$. However, unlike proofreading easy words, compensation type did not moderate the effect of time limits on time taken by workers $(F(1,217)=1.25, p=.265)$. The fact that workers take longer with longer time limits and per-minute contracts in this 
setting is useful, because it enables us to test the efficiency of managers' compensation scheme choices when workers are affected by these factors, unlike in Study 1a. These differences can be interpreted as limited slacking, or as workers taking more time in order to try to do a better job.

As intended, there was a difference in accuracy (i.e., total correct answers) between the easy (96\% correct) and difficult (74\% correct; $p<.001)$ tasks. Longer time limits did not lead to a higher successful completion rate for easy proofreading tasks (22.87 vs. $23.04, t(206)=0.44, p=.658)$, but did increase the number of successes for difficult proofreading tasks (18.46 vs. $17.19 ; t(219)=2.03, p=.044$; interaction of time limit and difficulty $F(1,425)=3.79, p=.052)$. Compensation type had little effect on productivity for either easy $\left(\mathrm{M}_{\text {Flat Fee }}=22.68\right.$ vs. $\mathrm{M}_{\text {Per-minute Fee }}=23.29, t(206)=1.73$, $p=.085)$, or difficult tasks $\left(\mathrm{M}_{\text {Flat Fee }}=17.48\right.$ vs. $\mathrm{M}_{\text {Per-minute Fee }}=18.12, t(219)=1.01, p=.313$; difference $F(1,425)<1)$.

\subsection{Method - Phase 2: Managers}

\subsubsection{Participants}

An adult online sample $(\mathrm{N}=438)$, recruited from the same Amazon Mechanical Turk pool, played the role of managers in an incentivized hiring game. Participants would earn revenue for getting the proofreading task completed, but they needed to hire a worker to do the task for them and pay the cost of hiring out of their revenue. The managers earned the remaining profit as an actual bonus payment. Managers were randomly assigned to one of four conditions in a 2 (time limit: shorter $=5$ minutes vs. longer $=15$ minutes $) \times 2$ (proofreading task difficulty: low vs. high) experimental design . The managers were informed that the workers had been randomly assigned to contract 
types and time limits (as in Study 1b), were only doing the one task in the allotted time, and would finish the study as soon as they completed the proofreading task and answered a few follow-up questions. The managers then read about the compensation schemes and chose which compensation (flat fee or per-minute fee) to use to hire the worker.

\begin{tabular}{|c|c|c|c|c|}
\hline \multirow{2}{*}{ Time Limit } & \multirow{2}{*}{$\begin{array}{l}\text { Task } \\
\text { Difficulty }\end{array}$} & \multirow{2}{*}{ Revenue } & \multicolumn{2}{|c|}{ Cost of hiring worker } \\
\hline & & & Flat Fee Selected & $\begin{array}{c}\text { Per-minute Fee } \\
\text { Selected }\end{array}$ \\
\hline $\begin{array}{l}5 \text { mins. } \\
\text { (shorter time } \\
\text { limit) }\end{array}$ & Easy & $\begin{array}{l}\$ 1.20 \text { fixed plus } 10 \\
\text { cents for every correct } \\
\text { word }\end{array}$ & $\begin{array}{l}\$ 1 \text { earned by the worker } \\
\text { plus } 30 \text { cents "recruiting } \\
\text { fee" }\end{array}$ & 25 cents/minute \\
\hline $\begin{array}{l}5 \text { mins. } \\
\text { (shorter time } \\
\text { limit) }\end{array}$ & Difficult & $\begin{array}{l}\$ 1.20 \text { fixed plus } 10 \\
\text { cents for every correct } \\
\text { word }\end{array}$ & $\begin{array}{l}\text { \$1 earned by the worker } \\
\text { plus } 10 \text { cents "recruiting } \\
\text { fee" }\end{array}$ & 25 cents/minute \\
\hline $\begin{array}{l}15 \text { mins. } \\
\text { (longer time } \\
\text { limit) }\end{array}$ & Easy & $\begin{array}{l}\$ 3.70 \text { fixed plus } 10 \\
\text { cents for every correct } \\
\text { word }\end{array}$ & $\begin{array}{l}\$ 1.50 \text { earned by the worker } \\
\text { plus } 50 \text { cents "recruiting } \\
\text { fee" }\end{array}$ & 25 cents/minute \\
\hline $\begin{array}{l}15 \text { mins. } \\
\text { (longer time } \\
\text { limit) }\end{array}$ & Difficult & $\begin{array}{l}\$ 3.70 \text { fixed plus } 10 \\
\text { cents for every correct } \\
\text { word }\end{array}$ & $\begin{array}{l}\$ 1.50 \text { earned by the worker } \\
\text { plus } 40 \text { cents "recruiting } \\
\text { fee" }\end{array}$ & 25 cents/minute \\
\hline
\end{tabular}

Table 2: Managers' potential revenue and costs in different conditions in Study 2.

In the shorter time-limit condition, managers earned $\$ 1.20$ plus 10 cents for every correct word. They could either pay 25 cents per minute for a metered worker or pay a flat fee (the $\$ 1$ earned by the worker plus either a 30 cents "recruiting fee" in the easytask condition or a 10 cents recruiting fee in the difficult-task condition; see Table 2).

In the longer time-limit condition, managers earned $\$ 3.70$ plus 10 cents for every correct word. If they chose the metered contract, they paid 25 cents per minute that the worker they were paired with spent on the task. Managers who instead chose to pay a flat fee paid for the $\$ 1.50$ earned by the worker, as well as either an additional 50 cent recruitment fee (easy condition) or 40 cent recruitment fee (difficult condition). 
Therefore, as in prior studies, the managers received a bonus payment for the task, depending on their worker compensation decision. However, in this study, unlike the previous studies, the bonus also included an additional variable payment that depended on the number of correct answers (i.e., was based on the worker's performance in the task). Thus, the managers had an incentive to not sacrifice work quality while attempting to minimize costs. To help ensure that the managers understood the potential for quality problems, the list of 24 words along with the proportion of actual workers who got the spelling correct was shown to the managers (Figure 5).

\begin{tabular}{|c|c|c|c|c|}
\hline 1) & didn't (87\%) & 9) & somtimes (92\%) & 17) asked (91\%) \\
\hline 2) & arround $(92 \%)$ & 10) & prety $(94 \%)$ & 18 ) because $(91 \%)$ \\
\hline 3) & allways (91\%) & 11) & animals (93\%) & 19) wile (92\%) \\
\hline 4) & tride $(71 \%)$ & 12) & recieved $(74 \%)$ & $20)$ intresting $(91 \%)$ \\
\hline 5) & finaly $(92 \%)$ & 13) & boght (92\%) & 21) again (94\%) \\
\hline 6) & meny (95\%) & 14) & mony (91\%) & 22 ) once $(92 \%)$ \\
\hline 7) & people $(92 \%)$ & 15) & when $(89 \%)$ & 23) untill (93\%) \\
\hline 8) & children $(93 \%)$ & 16) & said $(94 \%)$ & $24)$ thought (92\%) \\
\hline
\end{tabular}

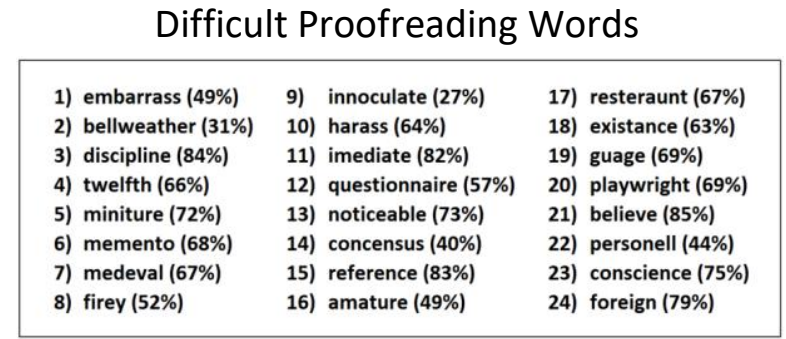

Figure 5: Words used in the easy and difficult proofreading tasks in Study 2. The proportion of actual workers in phase 1 of Study 2 who answered correctly (in parentheses) was shown to the managers.

After managers indicated their choice, they were asked to estimate the workers' completion time and productivity (i.e., total number of correct answers), both under the hiring scheme they had chosen, and under the unchosen alternative scheme. As in the prior studies, managers were also presented with a hypothetical choice between two options (a less risky and a riskier gamble) constructed to be equivalent to either the flat fee or the per-minute fee compensation outcomes, respectively, based on the actual results of the workers in phase 1, unbeknownst to the participants. Lastly, they answered a few questions measuring their knowledge of English spelling and experience with proofreading.

\subsection{Results - Phase 2: Managers' Compensation Choices}


Based on the workers' completion times in phase 1, paying per-minute compensation was a better deal, particularly when the time limit was longer. Averaging across task difficulty conditions, the expected value of managers' earnings was significantly higher when paying per-minute than when paying a flat fee, in both the shorter time limit $\left(\mathrm{M}_{\mathrm{Per}-\mathrm{minute}} \mathrm{Fee}=\$ 2.35\right.$ vs. $\left.\mathrm{M}_{\mathrm{Flat}} \mathrm{Fee}=\$ 1.98, t(219)=4.73, p<.001\right)$ and the longer time limit conditions $\left(\mathrm{M}_{\text {Per-minute Fee }}=\$ 4.45\right.$ vs. $\mathrm{M}_{\text {Flat Fee }}=\$ 3.79, t(206)=5.58$ $p<.001)$. The expected advantage of paying per-minute over flat fee was significantly higher in the longer time-limit condition $(\Delta=\$ 0.29, F(1,425)=4.29, p=.038)$. The relative advantage of paying per-minute held substantively for both easy (5 minutes: $\$ 2.82$ vs. $\$ 2.16, t(107)=9.07, p<.001 ; 15$ minutes: $\$ 4.88$ vs. $\$ 3.97, t(97)=5.62, p<.001$; difference $F(1,204)=2.23, p=.136)$ and difficult tasks (5 minutes: $\$ 1.94$ vs. $\$ 1.79$, $t(110)=1.41, p=.160 ; 15$ minutes: $\$ 4.10$ vs. $\$ 3.60, t(107)=3.36, p=.001$; difference $F(1,217)=3.86, p=.050)$ separately.

Notwithstanding the actual advantage of choosing to pay workers per-minute, many managers instead chose the flat fee $(63 \%)$ and were more likely to do so in the longer time-limit than shorter time-limit condition ( $83 \%$ vs. $\left.44 \%, \chi^{2}(1)=71.09, p<.001\right)$, consistent with prior results. The preference for paying a flat fee when the time limit was longer occurred both when the task was easy ( $78 \%$ vs. $\left.29 \%, \chi^{2}(1)=56.64, p<.001\right)$, as well as when the task was difficult ( $87 \%$ vs. $\left.59 \% ; \chi^{2}(1)=20.76, p<.001\right)$. In fact, there was no significant difference in the preference for flat fees under longer time limits based on task difficulty (interaction $\beta=0.664, \mathrm{z}=1.41, p=.158$ ).

The preference for paying a flat fee was costly. For easy tasks, managers who chose flat fee earned significantly lower profits, as in previous studies, both in the shorter 
time-limit condition $\left(\mathrm{M}_{\text {Per-minute Fee }}=\$ 2.77, \mathrm{M}_{\text {Flat Fee }}=\$ 2.12 ; \Delta=-\$ 0.65 ; t(112)=7.64\right.$, $p<.001)$, and even more so in the longer time-limit condition $\left(\mathrm{M}_{\text {Per-minute Fee }}=\$ 4.97, \mathrm{M}_{\text {Flat }}\right.$ Fee $=\$ 3.98 ; \Delta=-\$ 0.99, t(111)=7.88, p<.001$; difference $F(1,223)=4.91, p=.027)$.

Likewise, for difficult tasks, the profits earned by the managers were smaller when choosing the flat fee option, both in the shorter time-limit condition $\left(\mathrm{M}_{\text {Per-minute Fee }}=\$ 1.93\right.$ $\left.\mathrm{M}_{\text {Flat Fee }}=\$ 1.78 ; \Delta=-\$ 0.15 ; t(108)=1.37, p=.172\right)$, and more so in the longer time-limit condition $\left(\mathrm{M}_{\text {Per-minute Fee }}=\$ 4.18, \mathrm{M}_{\mathrm{Flat}} \mathrm{Fee}=\$ 3.63 ; \Delta=-\$ 0.55, t(99)=3.75, p<.001\right.$; difference $F(1,207)=4.79, p=.029$; Figure 6).

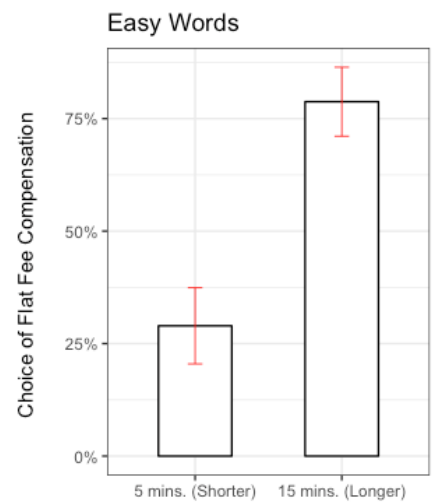

Time Limits

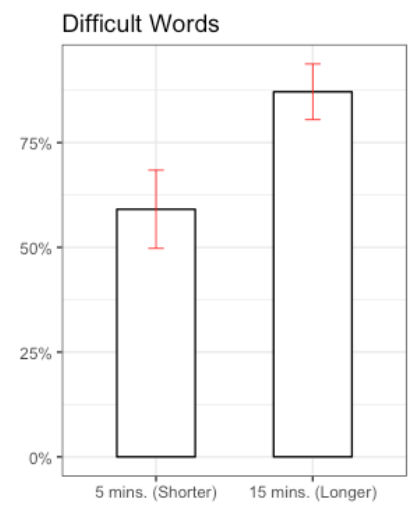

Time Limits

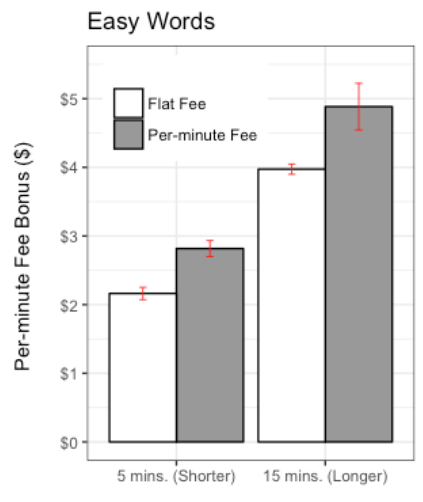

Time Limits

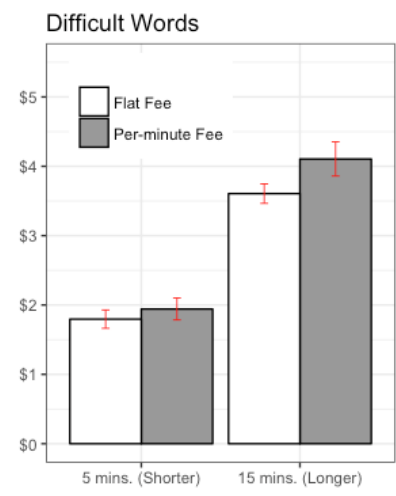

Time Limits

Figure 6: Choice of flat fee compensation (left-panel) and differences in expected bonuses from choosing different compensation options (right-panel) in Study 2. The vertical lines are 95\% CI.

While choosing to pay a flat fee earned the managers less money in actuality, the preference for flat fee was consistent with their beliefs about worker completion times.

As in the previous studies, managers who chose a flat fee (for either easy or difficult tasks) then estimated a longer completion time, on average, for workers paid per-minute, both for the shorter time limits $\left(\mathrm{M}_{\text {Chose Flat Fee }}=4.65\right.$ vs. $\mathrm{M}_{\text {Chose Per-minute Fee }}=4.25$; $t(222)=3.42, p<.001)$ and even more so for the longer time limits $\left(\mathrm{M}_{\text {Chose Flat Fee }}=13.74\right.$ vs. $\mathrm{M}_{\text {Chose Per-minute Fee }}=8.26 ; t(212)=11.68, p<.001$; difference $\left.F(1,434)=138.05, p<.001\right)$. A majority of managers' choices were consistent with selecting the hiring option that 
provided the higher payoff based on their own time estimates (66\% in the shorter timelimit condition, $88 \%$ in the longer time-limit condition). Finally, consistent with previous studies, the estimated time for per-minute workers partially mediated the effect of deadlines on compensation scheme choices (indirect effect bootstrapped 95\% CI= $[.56$, $.78])$.

Could incorrect beliefs about worker productivity (i.e., the expected rate of total correct answers) explain the effect of time limits on compensation choices? Managers who chose to pay per-minute (vs. those who chose the flat fee) expected per-minute workers to do better than flat-fee workers, both when the time limit was shorter (M $\mathrm{M}_{\text {Chose }}$ Per-minute Fee $=20.53$ vs. $\left.\mathrm{M}_{\text {Chose Flat Fee }}=12.32, \Delta=8.21 ; t(222)=16.56, p<.001\right)$ and somewhat less so when the time limit was longer ( $\mathbf{M}_{\text {Chose Per-minute Fee }}=19.29$ vs. $\mathbf{M}_{\text {Chose Flat }}$ Fee $=13.60, \Delta=5.69 ; t(212)=8.34, p<.001 ;$ difference $F(1,434)=9.01, p=.003)$. However, logistic regression analysis confirmed that managers' preference for paying a flat fee when time limits were longer persisted ( $\beta=1.18, z=2.52, p=.012)$ even controlling for the expected difference in productivity between per-minute workers and flat fee workers ( $\beta=$ $-0.45, z=-10.53, p<.001)$. Thus, the effect of time limits on choices of compensation schemes was not explained by beliefs about productivity.

Managers' worker-compensation choices were also not explained by general risk aversion, as managers were less likely to select the less risky option in the gamble choice than the equivalent flat fee worker compensation, both in the longer time limit (46\% vs. $83 \%$, McNemar's $\left.\chi^{2}(1)=53.37, p<.001\right)$ as well as in the shorter time-limit condition ( $30 \%$ vs. $44 \%$, McNemar's $\left.\chi^{2}(1)=8.18, p=.004\right)$. Further, preference for flat fees in the longer time limit persisted $(\beta=1.84, z=8.02, p<.001)$ controlling for general risk 
preferences (e.g., the equivalent gamble chosen; $\beta=-0.14, z=-0.60, p=.549$ ). Because managers were told that workers had been randomly assigned to one of two time limits, the results are not explained by information leakage or incidental anchoring. Likewise, time spent, knowledge of proofreading, and experience with proofreading tasks did not moderate the results.

\subsection{Discussion}

In this study, we used an open-ended task, for which the quality of the workers' outcomes could vary, and we also manipulated the level of objective task difficulty. As occurs in some employment contexts, when working on the difficult task, workers were indeed more productive when they had more time. However, even when managers' incentives were based on workers' productivity, the managers continued to show a preference for paying a flat fee when the time limit was longer, despite the fact that the per-minute compensation scheme had higher expected earnings, and in fact earned them more money, on average. The results suggest that our findings generalize to settings in which managers' incentives depend not only on containing labor costs, but also on the quality of the final output. This study also generalizes our findings to a setting in which workers' times did differ by time limits, unlike workers in Study 1a. We also replicated these findings in a second consequential study using the same task, with a sample of MBA students ( $\mathrm{N}=62$; Study A3, Online Appendix D), most of whom had prior managerial experience.

Thus far, we have demonstrated a robust and costly preference for paying workers a flat fee under relatively longer time limits. This bias is explained by managers' overestimation of worker completion times, rather than by risk aversion, information 
leakage, or incidental anchoring. So, what drives managers' misestimations of completion time?

Next, we consider the two types of psychological mechanisms discussed earlier, involving either managers' beliefs about the workers behavior (i.e, slacking), or manager's beliefs about the task scope. First, managers might be miscalibrated about the extent to which workers under longer time limits will strategically slack, taking longer when paid per-minute in order to earn more. Alternatively, managers may overestimate completion times if they associate longer time limits with tasks that involve greater scope of work. This could occur because managers simply associate longer time limits with tasks that generally involve greater scope of work, or because managers draw inferences about specific characteristics of the task (e.g., difficulty, effort required, thoroughness, etc.) based on the longer external time limit, and consequently infer a greater scope of work.

In the next study, we use a within-subjects design to elicit managers' preferences between hypothetical compensation schemes under different external time limits. A within-subjects design provides a conservative test, as it increases evaluability and prompts managers to examine the consistency of their preferences (i.e., for the two deadlines) potentially attenuating any biases. Then, in an exploratory analysis, we examine post-choice beliefs suggested by the above two potential accounts. This study tests generalizability in two ways, as managers may evaluate multiple tasks (i.e., "withinsubjects") with different deadlines in practice and by using a different worker task (i.e., a math task) in this study.

\section{Study 3: What Drives Managers' Misestimates?}




\subsection{Method}

\subsubsection{Participants}

A sample of online participants $(\mathrm{N}=140)$ were recruited from Amazon Mechanical Turk and played the role of managers. Managers were shown hiring game scenarios and decided which compensation to use for hiring a worker to complete a simple math task. The math task required workers to search for five pairs of numbers, such that each pair added to ten, from a 5 x 5 number grid that contained eight such valid pairs. Managers were shown an example number grid and a valid pair of boxes were highlighted to explain the task. (see Figure 7; details of instructions and stimuli are available in Online Appendix A).

Managers made two hiring decisions for two different tasks, one for each worker time limit (5 vs. 15 minutes; manipulated within-subjects). The two tasks were created by randomly shuffling the box numbers that contained the eight valid pairs in the grid. Both time limit and task order were counterbalanced, resulting in a four-cell mixed design. Managers were told that these workers' time limits were randomly selected. As in the previous studies, a fixed revenue (i.e., \$4.00) would be earned from a completed task, and the cost of hiring the worker would be deducted from the revenue, to compute the net profit, which was hypothetical in this study. Managers had two options: hire the worker with a flat fee ( $\$ 1.00$ in the 5 mins condition; $\$ 1.50$ in 15 mins) or pay at a rate of 25 cents per minute, with the maximum determined by the assigned time limit. Managers were informed that the game would only be played once and they would not need to build a long-term relationship with the hired worker. Finally, managers were also 
told that workers only knew about their own hiring terms (i.e., time limit and flat fee or per-minute fee) before starting their work.

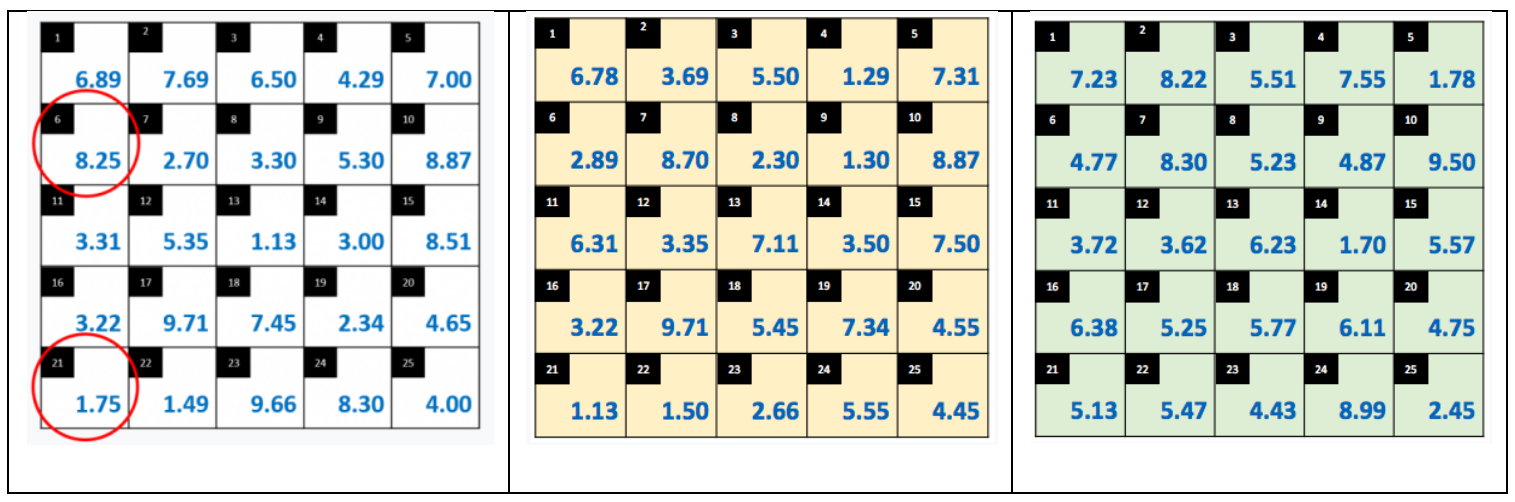

Figure 7: Example task (extreme left) and the two actual tasks (Task 1 and Task 2) used in Study 3. The two actual tasks were created by randomly shuffling the position of the valid pairs of correct responses.

After making compensation choices for both time limits, managers answered a series of follow-up questions on 7-point bipolar scales indicating which of the two tasks they thought took a longer time to complete, was more difficult, resulted in workers intentionally working slower (to measure slacking), was more interesting and enjoyable (as a measure of intrinsic motivation), and inspired a higher achievement motivation. After the managers answered these questions, managers were asked to indicate using a slider how much work (i.e., the scope of work) they thought there was in each of the two tasks $(1=$ a little work; $100=$ a lot of work $)$. To directly capture concerns about slacking, managers were asked directly, for each task, if they were worried that workers would take longer than necessary to make more money at their expense when they made their contract choices. Details of both the tasks (e.g., time limits, revenue, cost of flat fee and per-minute contracts) were displayed on the same screen as the follow-up questions.

Finally, managers also answered a 7-item empathy scale that captured individual differences in perspective taking (Davis, 1983) to examine if managers who scored high 
on this trait made better contract choices. Specifically, if managers who tend to put themselves in the workers' shoes are able to better predict the workers' behavior, they may exhibit a weaker preference for flat fees, particularly when times limits are longer.

\subsection{Results}

Estimates from a hierarchical regression strongly replicated the effect of external time limits on compensation decisions. More participants (83\%) preferred the flat fee in the longer time-limit condition than in the shorter time-limit condition $(60 \% ; \beta=1.15, z=$ $3.89, p<.001)$. The results were not moderated by the order of time limits or by the order of the two math tasks used in the study. Mid-point tests revealed that managers perceived the two tasks differently. Managers thought that workers would require more time to complete the 15 -minute deadline task than the 5 -minute deadline task $(M=+0.68, t(139)=$ 5.24, $p<.001$ ), a belief consistent with the time mis-estimation results in the prior studies. Thus, we replicate the prior findings in a within-subjects study, even when managers evaluated both time limits in the same study and did not make numerical estimates of the time taken.

Managers were more concerned about workers slacking in the 15-minute condition. They thought that in the 15 -minute task workers would be more likely to intentionally work slower and take longer than necessary $(M=+0.99, t(139)=6.72$, $p<.001$ ), and were more likely to indicate a concern about slacking in the 15 -minute deadline task (76\%) than in the 5-minute deadline task (46\%; McNemar's $\chi^{2}(1)=25.81$, $p<.001$ ). Managers also rated a significantly higher scope of work for the task (using the slider scale) that was assigned a random time limit of 15 minutes $\left(M_{5}=60.32\right.$ vs. $M_{15}=$ 
65.54; paired $t(139)=3.01, p=.003)$, consistent with inferring the scope of work from the deadline.

While we found evidence for both beliefs about slacking and scope inferences from deadlines, none of the self-report measures significantly mediated (or moderated) the effect of deadline on choice of compensation schemes. There was no difference in managers' judgments of workers' intrinsic motivation as a function of time limits, and likewise, perspective taking did not moderate the effect of time limits on contract choices (see Online Appendix C).

\subsection{Discussion}

Study 3 demonstrates that the effect of deadlines generalizes to managers making repeated compensation choices in a within-subjects design. This indicates that managers do not recognize their preference for flat fees under longer time limits as a bias, even when the comparison is made highly evaluable. Furthermore, this finding provides even stronger evidence against an incidental anchoring account, as participants are not only presented with both deadlines (as in Studies $1 \mathrm{~b}$ and 2), but actually make choices involving both deadlines (without making any prior numerical completion time estimates).

Participants' self-reported beliefs are broadly consistent with inferences about both slacking and task scope. In two additional studies (Studies A6 and A7 in Online Appendix D), we replicate the within-subjects effect of deadlines on hiring-option choices, and find document effects of time limits on beliefs about both slacking and scope, although none of the beliefs mediate the effect on compensation choices. 
These results suggest that the effect of time limits on misestimation of completion times and consequent choices of compensation schemes are driven by multiple psychological processes. In the last two studies, we test diverging predictions of the slacking and scope-perception accounts about how contextual factors would moderate the observed effects.

Next, we focus on a prediction of the slacking account. For beliefs about slacking to determine managers' contract preferences, the time limits must be relevant for workers' incentives. Accordingly, in Study 4, we had managers make choices involving time limits that were relevant only for the managers and which could not impact the workers. If we replicate the effect of time limits on compensation choices in this setting, the findings cannot be explained solely by beliefs about workers slacking.

We use the same math task as in Study 3, but have actual workers complete the task so that we can identify any bias in time estimation and choice, as we did in Studies 1 and 2. In addition, we control for a potential self-generated validity confound (Feldman \& Lynch, 1988), and introduce a context-specific test of risk aversion as an alternative explanation.

\section{Study 4: Contract Choices When Workers Do Not Have Deadlines}

In this study, we simulated a real-world situation in which the manager choosing a compensation option faces incentives (related to time limits) that do not affect the workers, in order to disassociate the manager's preference from the workers' motives. Consider an intermediary firm (such as a temp-agency, law firm, or piecework service) that has a full-time staff of workers. These workers may be paid a flat rate (e.g., as salaried employees), regardless of how long they spend on given tasks. However, the 
firm may contract their services to clients either at a flat rate (i.e. per task) or based on the time the workers spend on a client's project (e.g., billable hours). Thus, a manager who is in the market for such work may make decisions about whether to enter into a flat-fee or per-time billing arrangement, but this would not affect how the workers are paid. In particular, the arrangement may include time limits (e.g., the maximum amount of time billed to the client) that are irrelevant to the workers' compensation.

\subsection{Method - Phase 1: Workers}

\subsubsection{Participants}

In phase 1, online participants $(\mathrm{N}=102)$ from Amazon Mechanical Turk were recruited for a pre-registered study (http://aspredicted.org/blind.php? $\mathrm{x}=\mathrm{as} 83 \mathrm{nb}$ ). The participants were assigned to the role of "workers" and were all asked to complete the same math task as in Study 3 (Figure 8) at their own pace and were paid a flat fee.

\subsection{Results - Phase 1: Workers' Completion Times}

All workers completed the task. Overall, $77 \%$ of the workers took five minutes or less to complete the task (the complete distribution of time taken is presented in Online Appendix C). The median completion time was 3.55 minutes. We used this distribution of workers' completion times to compute Managers' payoffs in phase 2, based on the contract terms they chose. 


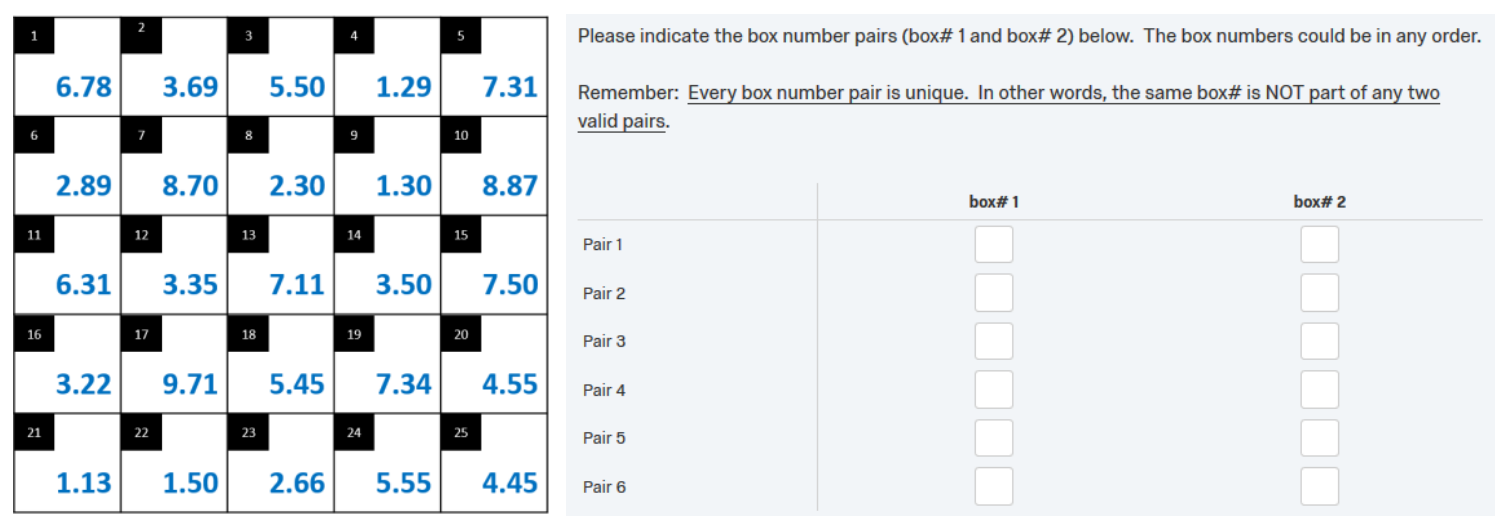

Figure 8: Interface used to administer the Math task (Study 4).

\subsection{Method - Phase 2: Managers}

\subsubsection{Participants}

In phase 2, a sample of online participants $(\mathrm{N}=287)$ were recruited from the same Amazon Mechanical Turk population (as the workers) and played the role of managers in a pre-registered study (http://aspredicted.org/blind.php? $\mathrm{x}=\mathrm{wm} 6 \mathrm{wx} 3$ ). The workers' terms in phase 1 were described to the "managers", who then decided how to hire a worker from an "agency" to get the math task completed. In particular, the managers were told that the agency recruited multiple workers from Amazon Mechanical Turk, and all of them were paid the same fixed amount. Managers were also told that the agency measured the time workers took to complete a task, but there were no time limits imposed on the workers and workers were not informed about the time they had taken.

The agency offered the managers a consequential choice between paying either a flat fee or a per-minute metered fee that was capped by a maximum time limit (between subjects; shorter time $=5$ minutes, longer time $=15$ minutes). As in Study $1 \mathrm{~b}$, managers were told that the time cap in their condition was chosen at random from one of two potential time caps: 5 minutes and 15 minutes. 


\begin{tabular}{|c|c|c|c|c|c|}
\hline \multirow[b]{2}{*}{ Time Limit } & \multirow[b]{2}{*}{ Terms } & \multicolumn{2}{|c|}{ If Flat Fee Selected: } & \multicolumn{2}{|c|}{ If Per-minute Fee Selected: } \\
\hline & & $\begin{array}{c}\text { Cost of } \\
\text { hiring } \\
\text { worker }\end{array}$ & $\begin{array}{l}\text { Profit earned } \\
\text { by manager } \\
\text { (fixed) }\end{array}$ & $\begin{array}{c}\text { Cost of } \\
\text { hiring } \\
\text { worker }\end{array}$ & $\begin{array}{c}\text { Profit earned } \\
\text { by manager } \\
\text { (variable) }\end{array}$ \\
\hline $\begin{array}{l}5 \text { minutes } \\
\text { version } 1 \\
\text { (shorter } \\
\text { time limit) }\end{array}$ & $\begin{array}{l}\text { Budget }=\$ 2.50 \\
\text { Flat Fee }=\$ 1.75 \\
\text { Per-Unit-Time rate }=\$ 0.40 / \mathrm{min}\end{array}$ & $\$ 1.75$ & $\$ 0.75$ & \multirow{3}{*}{$\begin{array}{l}40 \notin \text { per } \\
\text { minute }\end{array}$} & $\$ 0.50$ to $\$ 2.10$ \\
\hline $\begin{array}{l}5 \text { minutes } \\
\text { version } 2 \\
\text { (shorter } \\
\text { time limit) }\end{array}$ & $\begin{array}{l}\text { Budget }=\$ 6.00 \\
\text { Flat Fee }=\$ 1.75 \\
\text { Per-Unit-Time rate }=\$ 0.40 / \mathrm{min}\end{array}$ & $\$ 1.75$ & $\$ 4.25$ & & $\$ 4.00$ to $\$ 5.60$ \\
\hline $\begin{array}{l}15 \text { minutes } \\
\text { (longer time } \\
\text { limit) }\end{array}$ & $\begin{array}{l}\text { Budget }=\$ 6.50 \\
\text { Flat Fee }=\$ 2.25 \\
\text { Per-Unit-Time rate }=\$ 0.40 / \mathrm{min}\end{array}$ & $\$ 2.25$ & $\$ 4.25$ & & $\$ 0.50$ to $\$ 6.10$ \\
\hline
\end{tabular}

Table 3: Managers' potential profits in different conditions in Study 4.

When a manager opted for the flat fee, the cost of hiring was fixed. However, if the manager opted for a metered fee, the manager was randomly paired with a real worker from phase 1 and the manager's cost of hiring was based on the worker's actual time (rounded up) to complete the task, capped at the pre-determined time limit.

Managers were allotted a lump sum budget from which the cost of hiring was deducted, and the remaining money was paid to the manager, as their profit. The exact cost of hiring workers (and the resulting potential profit) in each condition is shown in Table 3. As seen in the table, there were two versions of the shorter time-limit condition in order to control for the worst-case per-minute outcomes ${ }^{4}$ (version 1) and the flat-fee profits ${ }^{5}$ (version 2) between the two time limits. The equal flat-fee profits between the 15-minute version 2 of the 5-minute conditions tests whether people satisfice, simplifying their decision by choosing flat-fees whenever the profits are sufficiently attractive (e.g., Nunes, 2000).

\footnotetext{
4 Minimum profit earnable with metered fee choice is 50 cents in both time-limit conditions

5 Maximum profit earnable with flat fee choice is $\$ 4.25$ in both time-limit conditions
} 
Unlike in the previous studies, half the managers first estimated the task completion time before (vs. after, as in the previous studies) indicating their preferred worker compensation option. This counterbalancing was done to test whether managers' biased completion time estimates were merely an attempt to rationalize their prior decision about the compensation scheme, when asked after the choice. Managers were then asked a few recall questions about the scenario.

Managers were also presented with a second hiring scenario, which tested their risk preferences specifically in an employment context (as opposed to the gamble context used in Studies 1a, 1b, and 2). In this scenario, managers chose between a certain fixed cost or an uncertain cost (presented as a list of potential costs and associated probabilities) to recruit a worker (see online appendix A for details of the stimuli). Managers were told that the cost would be deducted from a fixed revenue to determine their profit. Unbeknownst to the managers, the costs were constructed from the results of phase 1 to match the actual distribution of profits under the per-minute fee. This question was included to examine if context-specific risk preferences (i.e., about employment specifically) could explain the pattern of compensation scheme choices.

\subsection{Results - Phase 2: Managers' Choices}

Based on the actual completion times of workers in phase 1, the expected value of managers' earnings was significantly higher from choosing to pay per-minute fee than the fixed earnings from paying a flat fee, in all the conditions (Shorter time limit, version 1:

$\mathrm{M}_{\text {Per-minute Fee }}=\$ 0.90$ vs. $\$ 0.75$ flat fee; $\Delta=\$ 0.15 ; t(101)=3.92, p<.001$; Shorter time

limit, version 2: $M_{\text {Per-minute Fee }}=\$ 4.40$ vs. $\$ 4.25$ flat fee; $\Delta=\$ 0.15 ; t(101)=3.92, p<.001$;

Longer time limit: $\mathrm{M}_{\text {Per-minute Fee }}=\$ 4.58$ vs. $\$ 4.25$ flat fee; $\Delta=\$ 0.33 ; t(101)=3.27$, 
$p=.001$ ). Averaging across the two shorter time-limit conditions, the expected advantage of per-minute fees was significantly higher in the longer time-limit condition $(t(101)=2.27, p=.025)$.

Preferences for paying a flat fee differed across the three experimental conditions $\left(\chi^{2}(2)=109.36, p<.001\right)$. In the two shorter time-limit conditions, relatively few participants chose the flat fee $\left(25 \%\right.$ and $\left.38 \% ; \chi^{2}(1)=2.69, p=.100\right)$. In contrast, when the time limit was longer, an overwhelming majority (91\%) of managers chose the suboptimal flat fee option, which was significantly higher than the corresponding choice in both the shorter time limit versions (both $p$ s $<.001$ ). The higher choice of flat fees in the longer time limit condition than in version 2 is inconsistent with a simplifying heuristic (Nunes 2000) which would predict similar choices of flat fees based on a "satisficing" choice of the sure bonus of $\$ 4.25$ in both cases).
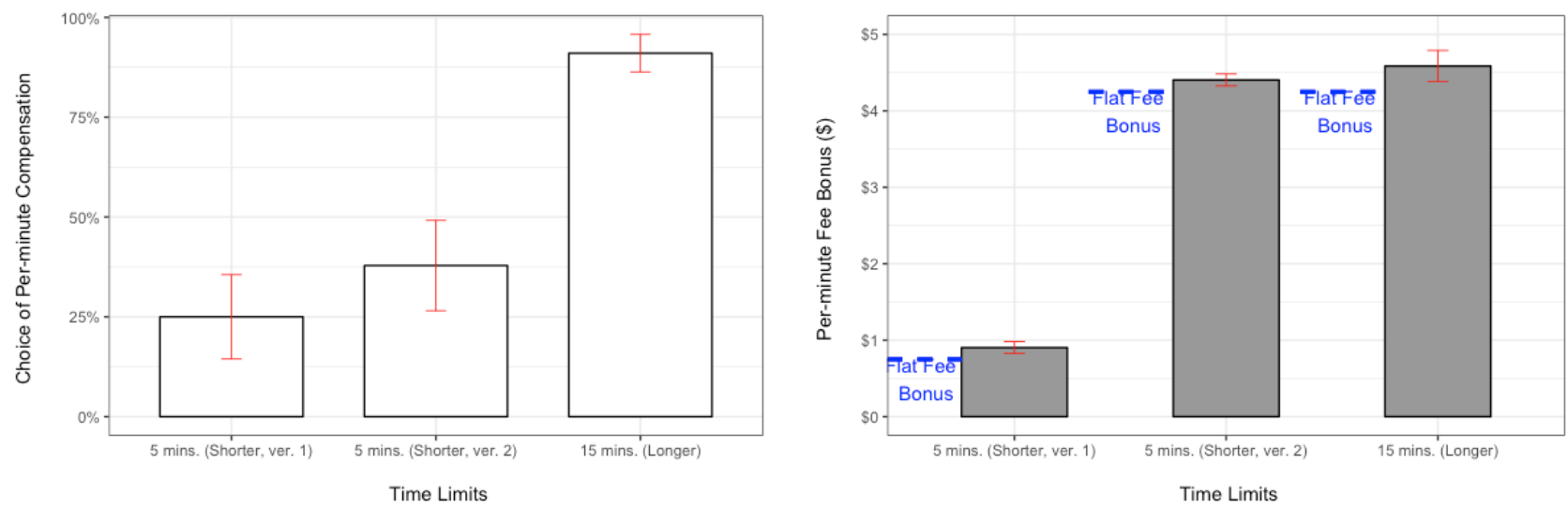

Figure 9: Choice of flat fee compensation (left-panel) and differences in expected bonuses from choosing different compensation options (right-panel) in Study 4. The vertical lines are 95\% CI.

Given that there was an expected payoff advantage of choosing to pay per-minute, particularly in the longer time-limit condition, managers actually left significantly more money on the table (based on realized profits after being matched to a random worker) in the longer time-limit condition $\left(\mathrm{M}_{\text {Per-minute Fee }}=\$ 4.93, \mathrm{M}_{\text {Flat Fee }}=\$ 4.25 ; \Delta=-\$ 0.68\right.$, 
$t(12)=4.88, p<.001)$, compared to either of the shorter time-limit conditions: version $1\left(\mathrm{M}_{\text {Per-minute Fee }}=\$ 0.81, \mathrm{M}_{\text {Flat Fee }}=\$ 0.75 ; \Delta=-\$ 0.06 ; t(50)=1.05, p=.298 ;\right.$ difference vs . longer time $t(62)=4.44, p<.001)$ and version $2\left(\mathrm{M}_{\text {Per-minute Fee }}=\$ 4.41, \mathrm{M}_{\text {Flat Fee }}=\$ 4.25 ; \Delta=\right.$ $-\$ 0.16 ; t(45)=2.69, p=.009$; difference vs. longer time $t(57)=3.92, p<.001$; see Figure 9).

The suboptimal compensation scheme choices are largely explained by the managers' estimates of task completion time. Managers who chose a flat fee estimated a longer task completion time in both the combined shorter time-limit conditions (MChose Flat Fee $=4.93$ vs. $\left.M_{\text {Chose Per-minute Fee }}=3.57 ; t(140)=3.25, p=.001\right)$ as well as in the longer timelimit condition $\left(\mathrm{M}_{\text {Chose Flat Fee }}=8.93\right.$ vs. $\left.\mathrm{M}_{\text {Chose Per-minute Fee }}=6.38 ; t(143)=1.93, p=.055\right)$. This was not significantly affected by order of elicitation (before vs. after choice of contract) for any of the conditions (interaction $p=.083$ and .403 respectively in the shorter and longer time limit conditions), suggesting that managers' estimates of workers completion time were not due to ex-post rationalization by managers of their preceding choices. Comparing the estimates of managers who chose flat fees with the actual time taken by workers in phase 1 , there was no difference in the combined shorter time-limit conditions ( 4.93 vs. $4.59, t(145)=0.49, p=.622)$ but there was a significant overestimation when the time limit was longer ( 8.93 vs. $4.59, t(232)=7.54, p<.001)$.

Indeed, managers' choices were largely rationalized by their estimates of workers' completion times, regardless of the question order. Most participants chose the option that would have provided a higher profit had their time estimates been correct (78\% in the combined shorter time conditions; $72 \%$ in the longer time condition). Furthermore, the estimated time for per-minute workers mediated the effect of deadlines on managers' contract choices (indirect effect bootstrapped 95\% $\mathrm{CI}=[0.03,0.28]$ ) and 
this held even when completion time estimates were made before choosing compensation schemes (indirect effect bootstrapped $95 \% \mathrm{CI}=[0.02,0.30])$.

The observed contract choices were not explained by context-specific risk preferences. In the longer time-limit condition, managers were much less likely to choose the per-minute fee than the equivalent uncertain employment cost (9\% vs. 39\%; McNemar's $\left.\chi^{2}(1)=40.33, p<.001\right)$, although there was no difference in the shorter timelimit condition $(\mathrm{p}=.273)$. Further, preference for flat fees in the longer time limit persisted $(\beta=3.27, z=8.28, p<.001)$ controlling for context-specific risk preferences (e.g., the equivalent employment cost; $\beta=2.45, z=6.51, p<.001)$. This strongly suggests that the compensation scheme choices under the longer time limit cannot be explained by managers' context-specific risk aversion.

\subsection{Discussion}

In Study 4, we again strongly replicate our basic result, that managers prefer flat fees more under longer time limits, because managers who see longer time limits estimate longer worker completion times. This finding cannot be explained by a concern that workers under longer time limits would slack more, because in this study, workers were all paid a flat fee and did not even know about the time limit, which only affected the managers' (but not the workers') incentives. Thus, the results of Study 4 rule out the possibility that the findings are explained solely by managers' beliefs about workers slacking.

The finding that judges were biased towards choosing flat fees when the external deadlines were longer, even without any difference in workers' incentives, is consistent with time limits affecting the perceived scope of the task (Goswami \& Urminsky, 2018). 
In Study 4, even though the time limits in this context logically could not affect workers' motivation, longer external time limits could still prompt a perception of the work as larger in scope, and therefore as taking workers longer to finish. This in turn would make time-metered based compensation schemes less attractive to managers, particularly when time limits are longer.

In the next study, we test information about scope as a moderator predicted by the scope perception account, by providing managers with the distribution of completion times among flat fee workers without any deadline. The distribution of completion times when workers do not have an incentive to slack provides information about the scope of the task but is irrelevant to the degree of slacking that will occur when such incentives are present. If providing this scope information eliminates the effect of time limits, we can conclude that our findings are likely to be driven by scope perception alone. However, if the effects of time limits persist when scope information has been provided, scope perception alone cannot explain the results.

\section{Study 5: Choice with Full Information about Completion Time Distribution}

In phase 1, online workers were paid per minute to complete the same math task used in Studies 3 and 4 with a known external time limit of either 5 minutes or 15 minutes. In phase 2, online participants, playing the role of managers, made a consequential decision to hire either a flat fee worker (whose completion time is irrelevant for their profits) or a per-minute worker to get the work done under an assigned external deadline. To remove any uncertainty about workers not being able to complete the task in the assigned deadline, managers were further told that only workers who had successfully completed the task in the provided time limit were available for hiring. 
Accordingly, we only include these workers in our analysis below, although all participating workers were paid, as promised, irrespective of whether they successfully completed the task.

\subsection{Method - Phase 1: Workers}

\subsubsection{Participants}

In phase 1, online participants $(\mathrm{N}=125)$ from Amazon Mechanical Turk were recruited for a pre-registered study (http://aspredicted.org/blind.php?x=qm4es5) and were paid a nominal base payment with the possibility of earning a bonus payment. The participants were assigned to the role of "workers" and were all asked to complete a simple math task. The task along with the instructions were the same as in Study 4 (i.e., find six valid pairs from eight valid pairs).

Workers were randomly assigned to either a shorter (5 minutes) or a longer (15 minutes) time-limit condition. All workers were told that they would get an additional payment (as a bonus) at a rate of 25 cents per minute (rounded up to the nearest minute) they took to complete the task, and confirmed the terms, including their time limit.

\subsection{Results - Phase 1: Workers' Completion Times}

Overall, 102 of the 125 workers (82\%) completed the task in the assigned time limit. These successful workers took significantly more time when the time limit was longer $\left(\mathrm{M}_{\text {Longer }}=6.05\right)$ than when it was shorter $\left(\mathrm{M}_{\text {Shorter }}=3.56, t(100)=4.71, p<.001\right.$; see Online Appendix $\mathrm{C}$ for the complete distribution of completion times in the two timelimit conditions). Therefore, as in Study 2, per-minute workers indeed earned significantly more when they were assigned to do the task under a longer external time limit, potentially because of slacking. 


\subsection{Method - Phase 2: Managers}

\subsubsection{Participants}

A sample of online participants $(\mathrm{N}=546)$ played the role of managers in a preregistered study (http://aspredicted.org/blind.php? $\mathrm{x}=\mathrm{nr} 4 \mathrm{py} 6)$. Managers were told that they would play a hiring game and that the decisions of five randomly selected managers would be implemented, such that any profits earned by these managers, based on their decisions, would be given as additional bonuses at the end of the study.

Managers were shown both the example task and the exact task that the workers had seen in phase 1. Managers were then randomly assigned to a cell in a 2(Time Limit: Shorter $=5$ minutes, Longer $=15$ minutes $) \times 2($ Scope Information: Yes, No) betweensubjects design. In particular, managers were told that workers had been randomly assigned to one of three time-limit conditions: unlimited time (or no time limits), 5 minutes, and 15 minutes; and that they would only use workers who were randomly assigned to a maximum time of 5 minutes (15 minutes) and who had successfully completed the task.

Two compensation schemes for hiring workers were available: a flat fee $(\$ 1.00$ in 5 minutes; $\$ 2.00$ in 15 minutes) or a metered fee of 25 cents per minute worked (rounded to the nearest integer) up to the maximum determined by the time limit. Managers were allotted a lump sum budget (i.e., \$4.00) from which the cost of hiring was deducted, and the remaining money was accrued to the managers as their profit.

In the scope information condition, the true distribution of flat-fee worker completion-times under no time limits (i.e., the information reported in phase 1of Study 3) was provided to managers in the form of a histogram before they made their choice. 
Five comprehension questions were asked in this information condition, on the same page where the chart was displayed, to ensure participants comprehended the additional completion-time information.

All managers then indicated their choice between a flat fee and a per-minute fee. After this, the managers estimated the task completion time of their worker under the chosen compensation scheme, as well as under the alternative compensation scheme. Finally, managers were asked a few recall questions.

\subsection{Results - Phase 2: Managers' Choices}

In the analysis below, we use the entire sample of managers. The results are substantively unchanged if we include only those managers who pass the various comprehension checks (see online Appendix C).

Based on the actual completion times of workers operating under a per-minute fee in phase 1, the expected value of managers' earnings was nearly identical for choosing to pay per-minute or a flat fee in the shorter time limit (\$3.00), but there was an advantage of choosing to pay per-minute in the longer time limit (MPer-minute Fee $=\$ 2.35$ vs. $\$ 2.00$ flat fee; $\Delta=\$ 0.35, t(54)=3.01, p=.004)$, a significant difference by time limit in the incentive to choose the per-minute fee $(t(100)=2.65, p=.009)$.

When no scope information was provided, managers were significantly more likely to choose the flat fee under the longer time limit (77\%) than the shorter time-limit $\left(60 \% ; \chi^{2}(1)=8.59, p=.003\right)$, replicating the prior studies. Accordingly, managers who chose to pay a flat fee left more money on the table (based on realized profits after being matched to a random per-minute worker) particularly when the time limit was longer $\left(\mathrm{M}_{\mathrm{Per}-\mathrm{minute}} \mathrm{Fee}=\$ 2.33, \mathrm{M}_{\mathrm{Flat}} \mathrm{Fee}=\$ 2.00 ; \Delta=-\$ 0.33, t(28)=2.16, p=.039\right)$ though there was 
no difference in the shorter time-limit condition $(p=.183)$. Therefore, like in previous studies, managers lost significantly more money in when time limits were longer $(t(81)=2.36, p=.020)$.

However, providing completion-time information, which informs the task scope, did not moderate the effect of time limits on choices of compensation schemes. In the scope information conditions, the biased preference towards flat fees persisted, with more choices of flat fee compensation schemes under the longer than the shorter time limits $\left(68 \%\right.$ vs. $\left.55 \%, \chi^{2}(1)=4.10, p=.042\right)$, not significantly different from the no-scope information conditions (interaction $\beta=0.303, z=0.82, p=.412$ ). Indeed, even when scope information was provided, managers choosing per-minute fees earned significantly less in the longer time-limit condition $\left(\mathrm{M}_{\text {Per-minute Fee }}=\$ 2.45, \mathrm{M}_{\text {Flat Fee }}=\$ 2.00 ; \Delta=-\$ 0.45\right.$, $t(45)=4.02, p<.001)$, although there were no difference in the shorter time-limit condition $(p=.31)$. Therefore, providing information about scope did not arrest the loss in managers' earnings when time limits were longer $(t(106)=3.95, p<.001)$. In fact, the twoway interaction of time limits and completion-time information on bonuses earned was not significant $(\beta=0.125, t=0.77, p=.441)$, suggesting, overall, the additional information regarding the scope of work did not attenuate the effect of longer time limit on flat fee choices.

As in the prior studies, whether or not scope information was presented, longer time limits biased estimates of completion times, which explained compensation choices, which were mostly rationalized by participants' time estimates (see online Appendix C).

\subsection{Discussion}


We replicated our basic findings that time limits biased choices of compensation scheme, whether or not addition information about task scope was presented. This result is inconsistent with a purely scope-based account of the findings, and supports the conclusion that time limits also affect beliefs about workers' slacking behavior when workers have the incentive to slack. Further evidence that beliefs about slacking contributes to the effect of time limits can be seen by looking at the subset of managers (across conditions) who estimated no difference in completion times between per-minute workers and flat-fee workers $(\mathrm{N}=169)$. Among this subset of managers who did not believe that workers would slack, external time limits had no effect on choices of compensation schemes ( $\beta=0.04, z=0.11, p=.909)$.

Studies 4 and 5, taken together, suggest that the robust effect of time limits on misestimations of others' task completion times, and consequent choice of hiring schemes, is multiply determined - driven by the effect of time limits on perceived scope of work and by beliefs about how external time limits affect workers strategic slacking behavior.

\section{General Discussion}

In many employment contexts, hiring workers under temporary contracts is crucial to the bottom-line. How efficiently do managers make such decisions when faced with different time limits? In this paper, we investigate this question using consequential economic games. Our findings reveal that many managers prefer suboptimal flat-fee compensation schemes over higher expected-profit time-metered plans. In particular, managers show a biased preference for flat fees (i.e., a lump sum 
cost to get a task done) when external time limits are longer, even when the expectedprofit advantage of time-metered fees is stronger for the longer time limits.

Across fourteen studies (six studies in the paper, eight in the Online Appendix) we show robust evidence for biased contract preferences, using both lay participants playing the role of managers (Studies 1a \& 1b) as well as experienced managers with prior hiring experience (Studies A2 \& A3; details in Online Appendix D). The preference for flat-fee compensation schemes persist when profits are dependent on the quality of the finished task (Study 2, Studies A4 \& A5 in Online Appendix D) and when managers hire multiple workers under the same contract scheme (Study A1). The misestimation of completion times on account of time limits was found to be multiply determined, involving both managers' perception of task scope under longer time limits (Studies $3 \&$ 4, Studies A6 \& A7 in Online Appendix D) as well as their beliefs about workers strategically slacking under longer time limits (Studies 3 \& 5, Studies A6, A7, \& A8 in Online Appendix D).

Prior research has documented flat fee biases for ongoing service usage, where decision makers are shown to prefer a fixed payment schedule for unlimited usage of telephone minutes (Train et al., 1987) and gym access (DellaVigna \& Malmendier, 2006). Such preferences have been attributed to risk aversion (Lambrecht \& Skierra 2006), or the motivational benefits of pre-commitment (DellaVigna \& Malmendier, 2006). In this paper, we document a parallel bias in a novel domain, which cannot be explained by any of these factors. Specifically, we find that decision makers prefer paying a flat fee when hiring temporary workers and we provide evidence that this is due 
to misestimating completion time, and cannot be explained by risk aversion, satisficing, or self-control motivations.

Instead, our evidence suggests that longer time limits overly affect managers' beliefs about workers' strategic slacking, taking more time in order to earn more money, which makes time-based compensation schemes unattractive. Previous work on industrial psychology has documented examples of "holding back" behavior (e.g., "goldbricking") in order to restrict production to manage future quotas. However, in our studies, managers are concerned about a quite different strategic response, per-minute workers "holding back" to increase their completion time, and resulting wages, which has not been previously studied empirically, to the best of our knowledge. Our evidence suggests that although such slacking behavior may happen in practice, people in the role of managers are not well-calibrated and tend to overestimate the incidence of such behavior. As a result, they might unnecessarily avoid paying metered compensation to hire temporary workers in one-shot interactions, and consequently, leave money on the table.

Our findings are also consistent with recent research showing external deadlines, even when incidental, can change the perceived scope of tasks on account of overgeneralized beliefs about deadline-difficulty association (Zhu, Bagchi, \& Hock, 2018; Goswami \& Urminsky, 2018). Consequently, even objectively non-diagnostic but salient environmental cues of scope, like external time limits, can systematically affect decision makers' judgments about others' task completion times, also contributing to the erroneous preference for flat fees, yielding significant economic losses and inefficiencies. 
However, biased time estimates may not lead to a preference for paying a flat fee when the cost differernce between flat fees and metered fees is large enough to compensate for the bias. In additional conditions run with Study 1a (reported in Appendix C), we doubled the cost of flat fees (from $\$ 1.50$ to $\$ 3.00$ ) in the longer timelimit condition, which significantly reduced the preference for flat fees to lower than that in the shorter time-limit condition, reversing the effect of time limits on compensationscheme choices. This suggests a conditionally rational interpretation: managers were largely basing their decision on expected profits conditional on their beliefs (rather than a more general avoidance of metered fees) and used per-minute fees when it seemed more profitable to do so. If the preference for flat fees was instead due to the general preferences studied in prior research on flat-fee bias (e.g., because of risk aversion or motivational benefits), the preference should have persisted regardless of the cost of the flat fee. Thus, our findings should be seen as an existence proof - bias in time estimation results in biased choices of compensation schemes under specific conditions.

More broadly, our results hint at a general problem that managers may face in contemporary employment settings, where complete control is often impossible and success instead relies on conditional cooperation (Bewley \& Brainard, 1995; Fehr \& Falk, 2002). Managers may tend to overestimate the necessity of explicit control (such as constraining pay to be fixed) and underestimate the extent of workers' internal motives or indirect external incentives to perform well (Heath, 1999; Goswami \& Urminsky, 2018). While we focus on a one-shot interaction between workers and managers in this research, it would be interesting to study how managers' behavior might change when there are opportunities to interact with the workers repeatedly (Eriksson \& Villeval, 2008). Would 
managers give sufficient weight to workers' motivation to build reputation capital for securing future opportunities?

In this paper, we focus on how a person predicts other people's completion times, rather than one's own times. Prior research has shown that the way people make completion time predictions for themselves may be different from how they reason about the times of others (Buehler, Griffin \& Deslauriers, 2012; also see Roy et al., 2013), particularly for the effect of deadlines (Buehler et al., 1994). Because we investigate estimates of task completion times specifically for others, our results cannot be explained by biases in belief formation from other factors that arise in predicting one's own future behavior, such as attribution (Jones \& Nisbett, 1971), motivated reasoning (Kunda, 1990), self-presentation motives (Leary, 1996) and strategic goal setting (Locke, Latham, Smith, Wood, \& Bandura, 1990). That said, future research might investigate the potential implications for how people make decisions when managing their own time. In particular, our results suggest that people may also choose suboptimal options to unnecessarily prevent perceived "time traps" (Mackenzie and Peterson 1972) in their own behavior, based on erroneous predictions of future time spending.

Given the pervasiveness of deadlines in both our daily life as well as in the dayto-day workings of organizations, investigating how this environmental factor influences managerial and economic decisions is an important and underdeveloped research endeavor. While some research has looked at the effect of external deadlines on negotiations and settlements in managerial settings (Gneezy, Haruvy, \& Roth 2003) and on auction outcomes (Katok \& Kwasnica, 2008), to the best of our knowledge this research is the first to identify effects of deadlines on choice of hiring options in 
employment settings. The slacking and scope perception mechanisms through which this effect of deadlines on hiring-option preference operates are distinct from the factors that result in preferences for flat fees in non-employment settings.

Our research provides a counterpoint to prior work on employment decisions, which has emphasized the role of rational factors (e.g., ease and cost of monitoring, uncertainty in the environment, workers' type) in contract choices. These findings may provide a starting point for investigating other belief-based biases that can influence managerial choices of contracts under incomplete information, as well as the unintended consequences of pervasive time limits on other commonly observed managerial practices. 


\section{References}

Alchian, A. A., \& Demsetz, H. (1972). Production, information costs, and economic organization. The American Economic Review, 62(5), 777-795.

Amabile, T. M., DeJong, W., \& Lepper, M. R. (1976). Effects of externally imposed deadlines on subsequent intrinsic motivation. Journal of Personality and Social Psychology, 34(1), 92.

Aranda, J., \& Easterbrook, S. (2005). Anchoring and adjustment in software estimation (Vol. 30).

Ariely, D., \& Wertenbroch, K. (2002). Procrastination, deadlines, and performance: Self-control by precommitment. Psychological Science, 13(3), 219-224.

Bewley, T. F., \& Brainard, W. (1995). A depressed labor market as explained by participants. American Economic Review, 85(2), 250-254.

Block, R. A. (1992). Prospective and retrospective duration judgment: The role of information processing and memory. Time, Action and Cognition: Towards Bridging the Gap, 141152.

Bohnet, I., \& Zeckhauser, R. (2004). Trust, risk and betrayal. Journal of Economic Behavior \& Organization, 55(4), 467-484.

Brunswik, E. (1943). Organismic achievement and environmental probability. Psychological Review, 50(3), 255.

Bryan, J. F., \& Locke, E. A. (1967). Parkinson's Law as a goal-setting phenomenon. Organizational Behavior and Human Performance, 2(3), 258-275.

Buehler, R., Griffin, D., \& Ross, M. (1994). Exploring the" planning fallacy": Why people underestimate their task completion times. Journal of Personality and Social Psychology, 67(3), 366. 
Buehler, Roger, Griffin, D., Lam, K. C., \& Deslauriers, J. (2012). Perspectives on prediction: Does third-person imagery improve task completion estimates? Organizational Behavior and Human Decision Processes, 117(1), 138-149.

Critcher, C. R., \& Gilovich, T. (2008). Incidental environmental anchors. Journal of Behavioral Decision Making, 21(3), 241-251.

Dai, X., Wertenbroch, K., \& Brendl, C. M. (2008). The value heuristic in judgments of relative frequency. Psychological Science, 19(1), 18-19.

Davis, M. H. (1983). Measuring individual differences in empathy: Evidence for a multidimensional approach. Journal of Personality and Social Psychology, 44(1), 113.

DellaVigna, S., \& Malmendier, U. (2006). Paying not to go to the gym. The American Economic Review, 694-719.

Dumond, J., \& Mabert, V. A. (1988). Evaluating project scheduling and due date assignment procedures: An experimental analysis. Management Science, 34(1), 101-118.

Fehr, E., \& Falk, A. (2002). Psychological foundations of incentives. European Economic Review, $46(4), 687-724$.

Fehr, E., \& Goette, L. (2007). Do workers work more if wages are high? Evidence from a randomized field experiment. American Economic Review, 97(1), 298-317.

Feldman, J. M., \& Lynch, J. G. (1988). Self-generated validity and other effects of measurement on belief, attitude, intention, and behavior. Journal of Applied Psychology, 73(3), 421.

Ferraro, F., Pfeffer, J., \& Sutton, R. I. (2005). Economics language and assumptions: How theories can become self-fulfilling. Academy of Management Review, 30(1), 8-24.

Francis-Smythe, J., \& Robertson, I. (1999). Time-related individual differences. Time \& Society, 8(2-3), 273-292. 
Frederick, S. (2005). Cognitive reflection and decision making. The Journal of Economic Perspectives, 19(4), 25-42.

Gjesme, T. (1975). Slope of gradients for performance as a function of achievement motive, goal distance in time, and future time orientation. The Journal of Psychology, 91(1), 143-160.

Gneezy, U., Haruvy, E., \& Roth, A. E. (2003). Bargaining under a deadline: Evidence from the reverse ultimatum game. Games and Economic Behavior, 45(2), 347-368.

Grimstad, S., \& Jørgensen, M. (2007). Inconsistency of expert judgment-based estimates of software development effort. Journal of Systems and Software, 80(11), 1770-1777.

Grund, C., \& Sliwka, D. (2010). Evidence on performance pay and risk aversion. Economics Letters, 106(1), 8-11.

Gruschke, T. M., \& Jørgensen, M. (2008). The role of outcome feedback in improving the uncertainty assessment of software development effort estimates. ACM Transactions on Software Engineering and Methodology (TOSEM), 17(4), 20.

Halkjelsvik, T., \& Jørgensen, M. (2012). From origami to software development: A review of studies on judgment-based predictions of performance time. Psychological Bulletin, $138(2), 238$.

Heath, C. (1999). On the social psychology of agency relationships: Lay theories of motivation overemphasize extrinsic incentives. Organizational Behavior and Human Decision Processes, 78(1), 25-62.

Hölmstrom, B. (1979). Moral hazard and observability. The Bell Journal of Economics, 74-91.

Hull, C. L. (1932). The goal-gradient hypothesis and maze learning. Psychological Review, 39(1), 25.

Jones, E. E., \& Nisbett, R. E. (1971). The actor and the observer: Divergent perceptions of the causes of behavior. 
Jørgensen, M., \& Sjøberg, D. I. (2001). Impact of effort estimates on software project work. Information and Software Technology, 43(15), 939-948.

Jørgensen, M., Teigen, K. H., \& Moløkken, K. (2004). Better sure than safe? Over-confidence in judgement based software development effort prediction intervals. Journal of Systems and Software, 70(1), 79-93.

Kahneman, D., \& Frederick, S. (2002). Representativeness revisited: Attribute substitution in intuitive judgment. Heuristics and Biases: The Psychology of Intuitive Judgment, 49-81.

Kivetz, R., Urminsky, O., \& Zheng, Y. (2006). The goal-gradient hypothesis resurrected: Purchase acceleration, illusionary goal progress, and customer retention. Journal of Marketing Research, 39-58.

König, C. J. (2005). Anchors distort estimates of expected duration. Psychological Reports, 96(2), $253-256$.

Kunda, Z. (1990). The case for motivated reasoning. Psychological Bulletin, 108(3), 480-498.

Lambrecht, A., \& Skiera, B. (2006). Paying too much and being happy about it: Existence, causes and consequences of tariff-choice biases. Journal of Marketing Research, 43, 212-223.

Leary, M. R. (1996). Self-presentation: Impression management and interpersonal behavior.

Lo, D., Ghosh, M., \& Lafontaine, F. (2011). The Incentive and Selection Roles of Sales Force Compensation Contracts. Journal of Marketing Research, 48(4), 781-798.

Locke, E. A., Latham, G. P., Smith, K. J., Wood, R. E., \& Bandura, A. (1990). A theory of goal setting \& task performance (Vol. 21).

Lowry, S. M., Maynard, H. B., \& Stegemerten, G. J. (n.d.). Time and motion study and formulas for wage incentives. 1940. New York. McGraw-Hill Book Co. 
MacPherson, J. (2014). Hourly vs. Flat Rate for Auto Techs. Retrieved from http://careeradvice.monster.com/salary-benefits/salary-information/hourly-vs-flat-rate-for-autotechs/article.aspx

Madhani, P. M. (2010). Realigning fixed and variable pay in sales organizations: An organizational life cycle approach. Compensation \& Benefits Review, 42(6), 488-498.

Meyvis, T., Ratner, R. K., \& Levav, J. (2010). Why don't we learn to accurately forecast feelings? How misremembering our predictions blinds us to past forecasting errors. Journal of Experimental Psychology. General, 139(4), 579.

Neter, J. (1970). Measurement errors in reports of consumer expenditures. Journal of Marketing Research, 11-25.

Nunes, J. C. (2000). A cognitive model of people's usage estimations. Journal of Marketing Research, 397-409.

Parkinson, N. (1955). Parkinson's law, Economist. November.

Pendleton, A., Lupton, B., Rowe, A., \& Whittle, R. (2019). Back to the Shop Floor: Behavioural Insights from Workplace Sociology. Work, Employment and Society, 0950017019847940.

Prelec, D., \& Loewenstein, G. (1998). The red and the black: Mental accounting of savings and debt. Marketing Science, 17(1), 4-28.

Prendergast, C. (2000). The tenuous tradeoff between risk and incentives. Retrieved from National Bureau of Economic Research

Roy, D. (1952). Quota restriction and goldbricking in a machine shop. American Journal of Sociology, 57(5), 427-442.

Roy, M. M., Christenfeld, N. J., \& Jones, M. (2013). Actors, observers, and the estimation of task duration. The Quarterly Journal of Experimental Psychology, 66(1), 121-137.

Sugden, R., Williams, A., \& others. (1978). The principles of practical cost-benefit analysis. 
Taylor, F. W. (1896). A piece rate system. Economic Studies, 1(2), 89.

Thomas, K. E., \& Handley, S. J. (2008). Anchoring in time estimation. Acta Psychologica, 127(1), $24-29$.

Train, K. E., McFadden, D. L., \& Ben-Akiva, M. (1987). The demand for local telephone service: A fully discrete model of residential calling patterns and service choices. The Rand Journal of Economics, 109-123.

Waller, M. J., Zellmer-Bruhn, M. E., \& Giambatista, R. C. (2002). Watching the clock: Group pacing behavior under dynamic deadlines. Academy of Management Journal, 45(5), 1046-1055.

Williamson, O. E. (1981). The economics of organization: The transaction cost approach. American Journal of Sociology, 548-577.

Wilson, T. D., Houston, C. E., Etling, K. M., \& Brekke, N. (1996). A new look at anchoring effects: basic anchoring and its antecedents. Journal of Experimental Psychology: General, 125(4), 387.

Yeung, C. W., \& Soman, D. (2007). The duration heuristic. Journal of Consumer Research, 34(3), $315-326$.

Zauberman, G., Levav, J., Diehl, K., \& Bhargave, R. (2010). 1995 Feels So Close Yet So Far The Effect of Event Markers on Subjective Feelings of Elapsed Time. Psychological Science, 21(1), 133-139.

Zhu, M., Bagchi, R., Hock, S. J., \& Diehl, K. (2018). The Mere Deadline Effect: Why More Time Might Sabotage Goal Pursuit. Journal of Consumer Research. 
ONLINE APPENDICES

DON'T FEAR THE METER: HOW LONGER TIME LIMITS BIAS MANAGERS TO PREFER HIRING WITH FLAT FEE COMPENSATION

Online Appendix A: Study Stimuli

Online Appendix B: Details of the Consequential Hiring Game

Online Appendix C: Additional Analysis

Online Appendix D: Additional Studies

Online Appendix E: Pre-registrations (Study 4 and Study 5) 


\section{Online Appendix A: Study Stimuli}

Study 1a, Phase 1 (15 minutes condition is shown)

We will ask you to solve a jigsaw puzzle. Clicking on the thumbnail icon below will take you to the puzzle, and will start the timer.

Before you begin please make note of the following instructions:

1. You will have to arrange the jigsaw pieces to get a complete picture which will be shown to you on the left.

2. If the pieces are adjacent and they fit together, you will hear a 'snap' sound.

3. Once you are ready just start moving the jigsaw pieces and the system will automatically record your time.

4. You will have a total time of 15 minutes from the moment you start working. This means 15 minutes from the time you move your first piece. You will be paid 25 cents per minute for the time you spend doing this task.

5. Once you are done the timer clock will automatically stop. PLEASE DO NOT CLOSE THE POP-UP. The experimenter will record your time at the end of the study.

6. If 15 minutes are over and if you are not done with solving the puzzle, the experimenter will ask you to stop and proceed to the followup questions. If you are done solving the puzzle before 15 minutes, you can immediately proceed to the followup questions.

7. As soon as you are done with this study (the puzzle task along with the followup questions), you can move on to participate in another study or go home, as you wish.

If you have read and understood the instructions, please click on the icon below to begin.

\section{CLICK THE SUNGLASSES BELOW TO BEGIN:}

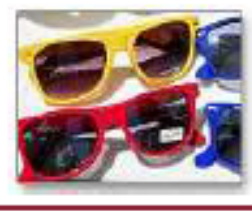


Study 1a, Phase 2 (15 minutes and $\$ 4.00$ budget condition is shown)

\section{THE EMPLOYER GAME}

In this survey, you will play a game, from which you can get REAL monetary rewards, based on your decisions. In the game, you are an employer making choices about how to compensate workers.

In the game, your "company" would be paid $\$ 4.00$ for a completed jigsaw puzzle.

From that $\$ 4.00$, however, you need to deduct the cost of having a worker complete the puzzle for you. The remaining money, after paying for the worker, will be yours to keep, and you will receive that money for real via Mechanical Turk, after the study is over.

The job your worker needs to do for you is to complete the 20 piece digital jigsaw puzzle shown below.

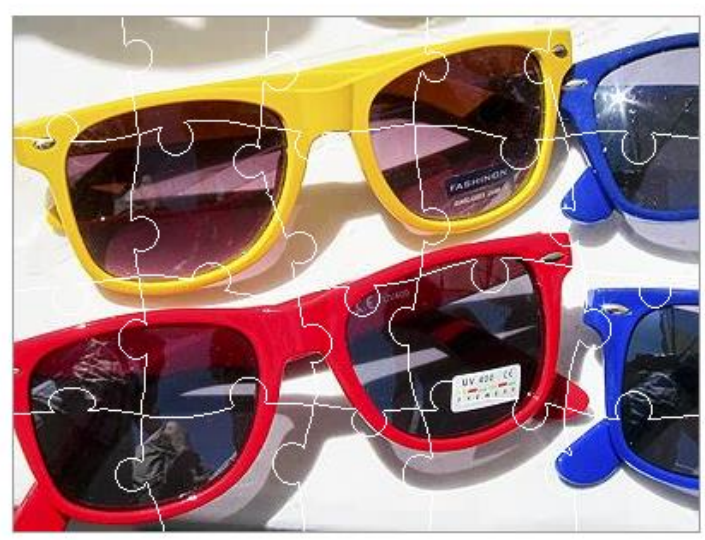

\section{GETTING A WORKER TO SOLVE YOUR PUZZLE}

Please read the following information carefully - this will be important to the choice you make, and we will check your recall at the end of the survey.

The workers are actual participants in a research lab in downtown Chicago, primarily students at local commuter colleges.

Workers are given the puzzle, and have a maximum of 15 minutes to solve it. In the past, all the workers have been able to solve it in the 15 minutes provided.

Workers are compensated for the time they spend on solving the puzzle. As an employer you will choose the contract which determines how the worker is paid.

The workers are told before they begin exactly how they will be paid (either per minute or a fixed fee).

Workers work on their own pace and solve the puzzle. As soon as a worker finishes the puzzle, that worker is paid the amount due based on the time it took, and then could either leave or participate in other unrelated paid studies in that lab.

Each worker does only one puzzle, and the workers have not done any jigsaw puzzle studies in this lab before. 
The interface the workers used looked similar to the picture below. (The initial layout of the puzzle pieces was random and differed for each person).

When matching pieces are moved next to each other, they join together with a 'snap' sound. As a result it was clear to the workers when a puzzle piece had been put in the right location.

The time taken to solve the puzzle was automatically measured by the timer on the left hand panel. As soon as the last piece was put into place, the timer stopped, and it could not be reset or changed by the worker.

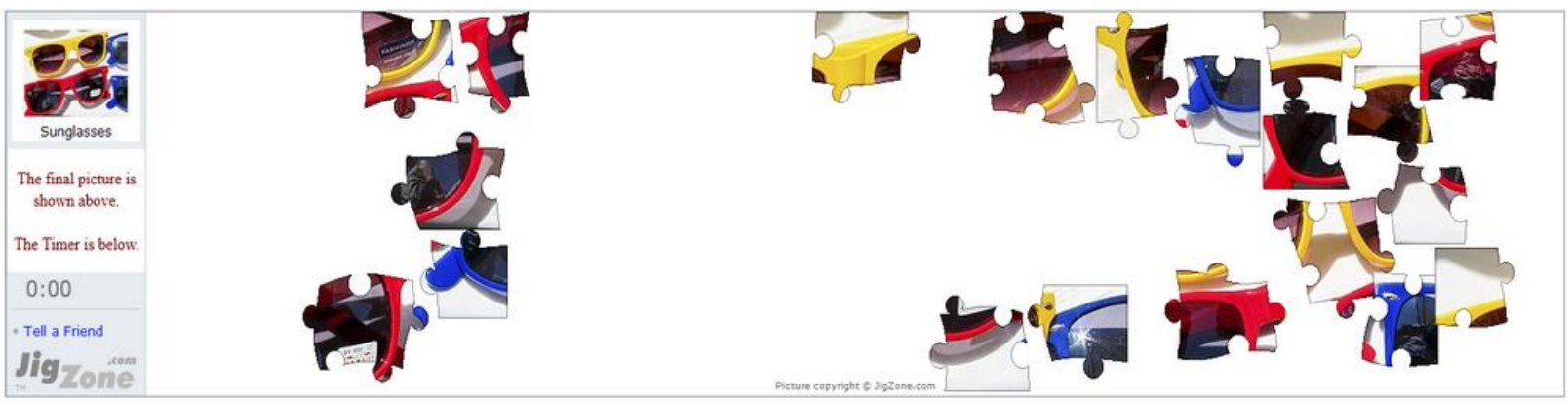

CHOOSING YOUR WORKER'S PAYMENT

IMPORTANT: THE FOLLOWING CHOICE IS YOUR DECISION IN THE GAME AND WILL DETERMINE YOUR REAL PAYMENT.

Remember, your "company" will be paid $\$ 4.00$ for the completed puzzle, but from that the cost of having the worker complete the puzzle for you will be deducted. The remaining profit will be yours, and you will receive that amount via Mechanical Turk, after the survey (within three days).

Also remember that the worker has a maximum of 15 minutes to solve the puzzle.

Now, you need to choose the kind of contract you want to have with the worker.

\section{AVAILABLE CONTRACTS:}

OPTION A: FLAT FEE

You would pay the worker a $\$ 1.50$ flat fee. If you choose this, your cost will be $\$ 1.50$.

So, you will make $\$ 4.00$ minus $\$ 1.50$, which comes to $\$ 2.50$.

\section{OPTION B: PER-MINUTE FEE}

You would pay $\mathbf{2 5}$ cents for each minute the worker takes to solve the puzzle. If you choose this, your cost will be 25 cents for each minute the worker spends, rounded UP to the nearest minute.

So, you will make $\$ 4.00$ minus the cost of the person's time ( 25 cents per minute times the number of minutes, between $\$ 0.25$ and $\$ 3.75$ ). So, you can make anywhere between $\$ 4.00$ minus $\$ 0.25$ to $\$ 4.00$ minus $\$ 3.75$ i.e. between $\$ 3.75$ to $\$ 0.25$.

Remember that the workers know exactly how they will be paid (either per minute or a fixed fee) before they start working.

One of the actual workers who was randomly assigned to do the job based on the contract option you chose will be picked for you completely at random. Your cost of hiring the worker will be calculated based on that specific worker's time and the terms of the contract you chose. 
Study 1b (15 minutes condition is shown)

\section{GETTING A WORKER TO SOLVE YOUR PUZZLE}

Please read the following information carefully - this will be important to the choice you make, and we will check your recall at the end of the survey.

The workers are actual participants in a research lab in downtown Chicago, primarily students at local commuter colleges. Workers are given the puzzle, and are randomly assigned a maximum of either $\mathbf{5}$ minutes or 15 minutes to solve it.

You are only going to use workers who are given a maximum of 15 minutes to solve the puzzle. In the past, all the workers have been able to solve it in the time provided.

Workers are compensated for the time they spend on solving the puzzle. As an employer you will choose the contract which determines how the worker is paid.

The workers are told before they begin exactly how they will be paid (either per minute or a fixed fee).

Workers work on their own pace and solve the puzzle. As soon as a worker finishes the puzzle, that worker is paid the amount due based on the time it took, and then could either leave or participate in other unrelated paid studies in that lab.

Each worker does only one puzzle, and the workers have not done any jigsaw puzzle studies in this lab before. 
Study 2, Phase 1 (A sample of the easy proofreading task on the left and the difficult proofreading task on the right are shown. The list of words were displayed as images to prevent workers from simply copying and pasting them into the textboxes)

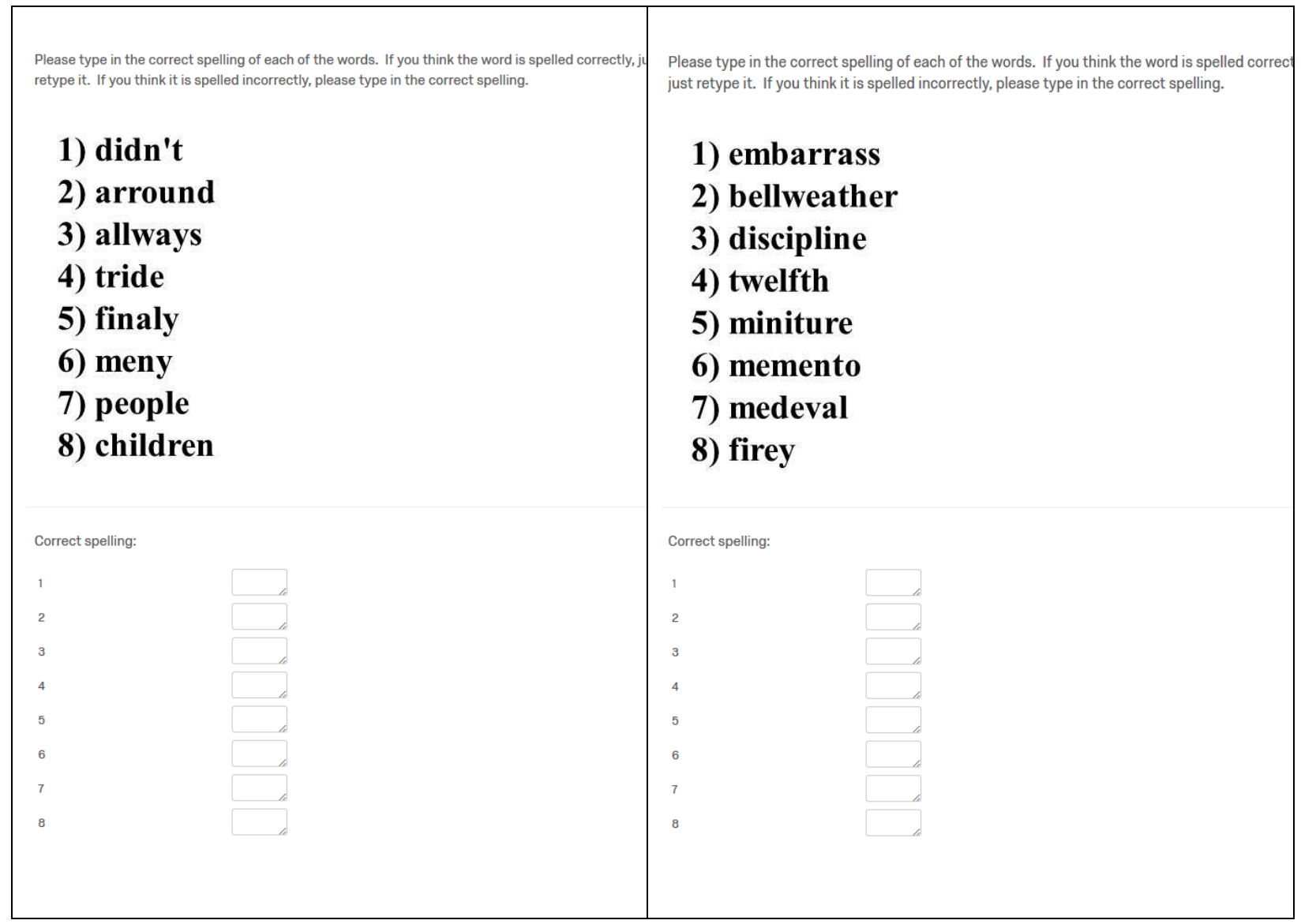


Study 2, Phase 2 (15 minutes and Easy proofreading task condition is shown)

\section{THE EMPLOYER GAME}

In this survey, you will play a game, in which you can get REAL monetary rewards, based on your decisions. In the game, you are an employer making choices about how to compensate a worker for completing a proofreading task for you.

The proofreading job your worker does for you is to examine and correct the spelling of a set of 24 words as shown below. Beside each word, the percentage of people who get the word spelled correctly, on average, is indicated.

In the task, a text-box is provided for each of the words, and workers are instructed to correct the spelling or simply copy the word if they think the spelling is already correct.

The set of 24-words were chosen from a list of easy words that most people often get correct.
1) didn't (87\%)
9) somtimes (92\%)
17) asked (91\%)
2) arround (92\%)
10) prety $(94 \%)$
18) because (91\%)
3) allways (91\%)
11) animals (93\%)
19) wile (92\%)
4) tride (71\%)
12) recieved $(74 \%)$
20) intresting (91\%)
5) finaly (92\%)
13) boght (92\%)
21) again (94\%)
6) meny (95\%)
14) mony (91\%)
22) once (92\%)
7) people (92\%)
15) when (89\%)
23) untill (93\%)
8) children (93\%)
16) said (94\%)
24) thought (92\%)

\section{YOUR REVENUE AND PROFITS}

Please read the following information carefully - this will be important to the choice you make, and we will check your recall at the end of the survey.

In the game, your "company" starts out with a budget of $\$ 3.70$ for completing an entire proofreading task. You will hire a worker who will do the proofreading for you.

Your company will earn 10 cents for each of the 24 tasks the worker does correctly (i.e., for every word for which the correct spelling is identified by the worker). Therefore the maximum revenue your company can potentially earn is $\$ 3.70$ + \$2.40, or $\$ 6.10$. Of course, the revenue would depend on the number of spelling tasks that your worker gets correct.

From that revenue, however, you need to deduct the cost of having the worker do the proofreading task for you, as discussed next. The remaining money, after paying for the worker, will be yours to keep (as net profit), and you will receive this net profit for real via Mechanical Turk, after the study is over. 


\section{HIRING A WORKER TO DO THE TASK}

Please read the following information carefully - this will be important to the choice you make, and we will check your recall at the end of the survey.

The workers are actual Amazon MTurk participants. Workers are given the task, and have a maximum of 15 minutes to finish it. In the past, most workers have been able to finish the task in the time provided.

Workers are compensated for the task. As an employer you will choose the contract which determines how the worker is paid (either paid per minute based on the total time spent or paid a fixed fee). All workers are told before they begin exactly how they will be paid.

Workers work at their own pace to finish the task. As soon as a worker finishes the task and answers a few questions, the worker is done.

The actual time taken to finish the task is accurately recorded by the computer.

\section{CHOOSING YOUR WORKER'S PAYMENT}

\section{IMPORTANT: THE FOLLOWING CHOICE IS YOUR DECISION IN THE GAME AND WILL DETERMINE YOUR} BONUS payment.

Now, you need to choose the kind of contract you want to have with the worker. This will determine your cost and profits.

\section{AVAILABLE CONTRACTS:}

\section{OPTION A: FLAT FEE}

You pay the worker a $\$ 1.50$ flat fee, plus an additional 50 cents fee (by the "employment agency"). If you choose this, your cost will be $\$ 1.50+0.50=\$ 2.00$.

\section{OPTION B: PER-MINUTE FEE}

You pay 25 cents for each minute the worker takes to finish the task. If you choose this, your cost will be variable -- 25 cents for each minute the worker spends to complete the task, rounded up to the nearest minute. If you choose this, your cost will be between $\$ 0.25$ to $\$ 3.75$.

Remember that the workers know exactly how they will be paid (either per minute or a fixed fee) before they start working, and has a maximum of 15 minutes to complete the task. Also, your "company" can earn a maximum revenue of $\$ 3.70+\$ 2.40$, or $\$ 6.10$ from a completed proofreading task, from which you have to pay the cost.

A group of MTurk workers were already given this task to complete and were randomly assigned to one of the contracts. One of the actual workers who was randomly assigned to do the job based on the contract option you chose will be picked for you completely at random. Your cost of hiring the worker will be calculated based on that specific worker's time and the terms of the contract you chose. 


\section{Study 3}

\section{Basic instructions (5 minutes condition for a task shown).}

In this survey, you will play a hiring game. In the game, you will be a manager deciding on how to hire workers to get a task done.

Below, we will describe a few scenarios that requires hiring a worker. Please read carefully and answer the questions that follow.

In all scenarios, assume the job is temporary, and you will not need to build a long-term relationship with the hired worker.
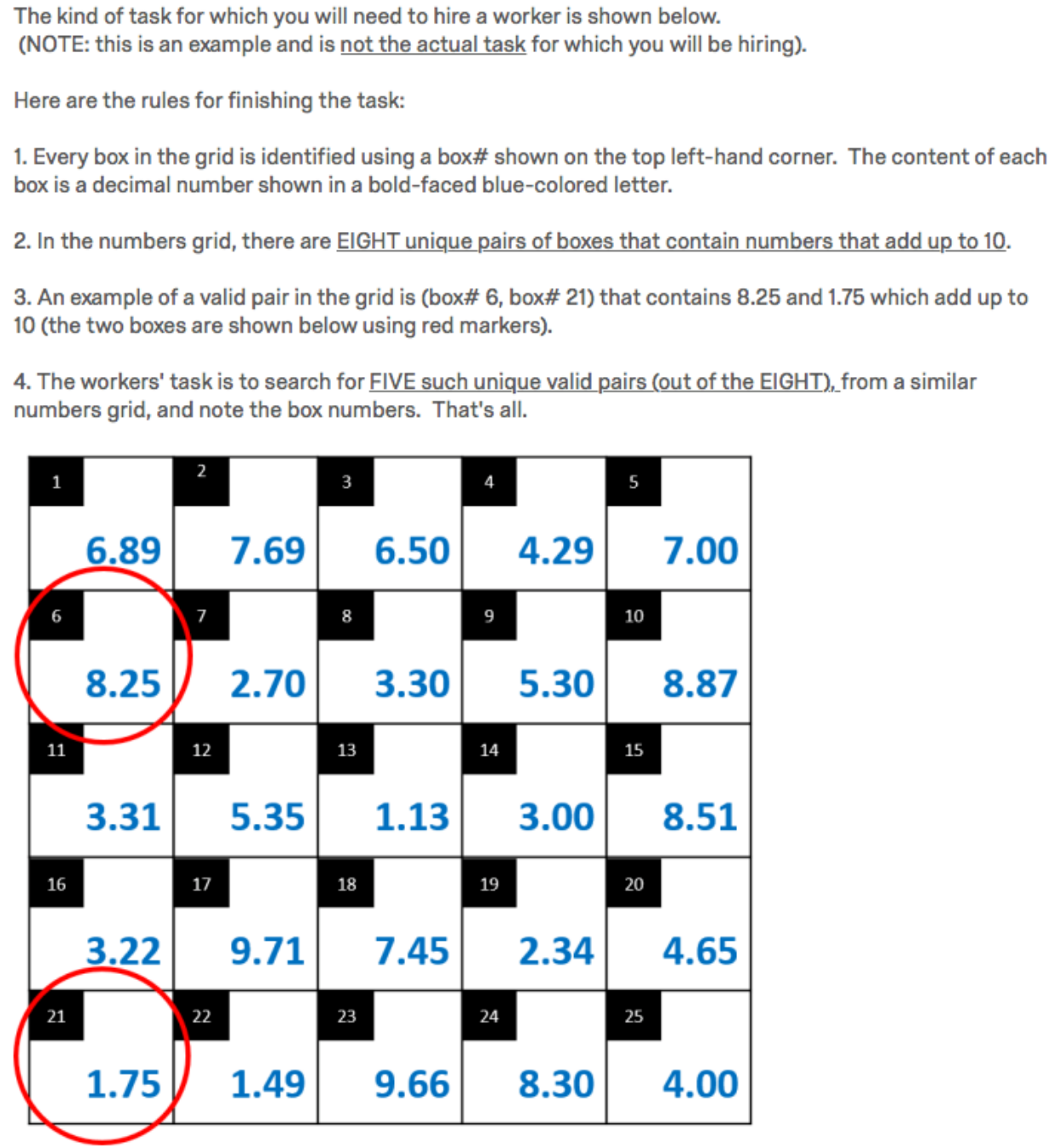

Below is another task for which you will need to hire a worker. This is a different numbers grid from what you saw earlier. 


\begin{tabular}{|c|c|c|c|c|}
\hline , & & & 4 & \\
\hline 6.78 & 3.69 & 5.50 & 1.29 & 7.31 \\
\hline 6 & & 8 & 9 & 10 \\
\hline 2.89 & 8.70 & 2.30 & 1.30 & 8.87 \\
\hline 11 & 12 & 13 & 14 & 15 \\
\hline 6.31 & 3.35 & 7.11 & 3.50 & 7.50 \\
\hline 16 & 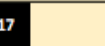 & 18 & 19 & 20 \\
\hline 3.22 & 9.71 & 5.45 & 7.34 & 4.55 \\
\hline 21 & 22 & 23 & 24 & 25 \\
\hline 1.13 & 1.50 & 2.66 & 5.55 & 4.45 \\
\hline
\end{tabular}

Following are additional details about the hiring situation. PLEASE READ VERY CAREFULLY.

1. You will need to hire just one worker for getting the task done.

2. The worker will get a maximum of 5 minutes to finish the task. This time limit was randomly selected between two options ( 5 minutes and 15 minutes), based on a coin toss.

3. In the past, most workers could complete the task in the assigned time limit.

4. The completed task sells for $\$ 4.00$. So, this is your revenue. From this, you will need to subtract the cost of hiring a worker to compute your profit. As a manager, your objective is to maximize profit.

5. For hiring a worker, you have two options: (a) pay the worker a flat fee of $\$ 1.00$. (b) pay the worker @ 25 cents per minute worked (rounded to the nearest integer) up to a maximum of the time limit.

6. Therefore, if you choose option (a) your profit is fixed at $\$ 3.00(\$ 4.00-\$ 1.00)$. If you choose option (b) your profit can vary between $\$ 2.75(\$ 4.00-\$ 1.25)$ and $\$ 3.75(\$ 4.00-\$ 0.25)$ depending on the time taken by the worker.

7. Workers know only about their assigned time limit, and the terms of hiring (flat fee or per-minute fee) before starting their work.

Which option would you choose to hire a worker for this task?

Option A - I will pay a flat rate of $\$ 1.00$

Option B - I will pay the rate of 25 cents per minute for a maximum of 5 (five) minutes 
Follow-up questions used in the Study 3 (a particular order of Task 1 and Task 2, along with a few illustrative examples provided)

Recall that you made hiring decisions about these two tasks.

\begin{tabular}{|c|c|c|c|c|c|c|c|c|c|}
\hline 7.23 & 8.22 & 5.51 & 7.55 & 1.78 & 6.78 & 3.69 & 5.50 & 1.29 & 7.31 \\
\hline 6 & , & 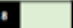 & , & 10 & 6 & 7 & 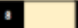 & & \\
\hline 4.77 & 8.30 & 5.23 & 4.87 & 9.50 & 2.89 & 8.70 & 2.30 & 1.30 & 8.87 \\
\hline u & $\mathrm{x}$ & 3 & u & is & u & 12 & $\infty$ & & \\
\hline 3.72 & 3.62 & 6.23 & 1.70 & 5.57 & 6.31 & 3.35 & 7.11 & 3.50 & 7.50 \\
\hline u & $n$ & 4 & 18 & $\$$ & 16 & & 18 & & $\infty$ \\
\hline 6.38 & 5.25 & 5.77 & 6.11 & 4.75 & 3.22 & 9.71 & 5.45 & 7.34 & 4.55 \\
\hline un & $n$ & $z$ & 24 & 8 & a & & 2 & 24 & \\
\hline 5.13 & 5.47 & 4.43 & 8.99 & 2.45 & 1.13 & 1.50 & 2.66 & 5.55 & 4.45 \\
\hline $\begin{array}{l}\text { Task } 1 \\
\text { Maximun } \\
\text { Revenue } \\
\text { Flat Fee } \\
\text { Per Minu }\end{array}$ & $\begin{array}{l}\text { Randor } \\
=\$ 4 \\
=\$ 1.50 \\
\text { te Fee = }\end{array}$ & $0.25 \mathrm{pe}$ & $\min$. & mins & $\begin{array}{l}\text { Task } 2 \\
\text { Maximum } \\
\text { Revenue } \\
\text { Flat Fee = } \\
\text { Per Minut }\end{array}$ & $\begin{array}{l}\text { Randon } \\
=\$ 4 \\
\$ 1 \\
\text { Fee = }\end{array}$ & $0.25 \mathrm{pe}$ & $\mathrm{r} \min$. & nins \\
\hline
\end{tabular}

For which task, did you feel, workers would take more time to complete?

\begin{tabular}{ccccccc} 
1. Task 1 would & \multicolumn{9}{c}{$\begin{array}{c}\text { 4. Task 1 and } \\
\text { Task 2 would }\end{array}$} \\
take more time & 2 & 3 & take similar time & 5 & 6 & 7. Task 2 would \\
take more time
\end{tabular}

For which task, did you feel, workers would be more likely to intentionally take more time than necessary to complete it?
1. For Task 1
2
3
4. Neither for
Task 1 nor for
Task 2
5
6
7. For Task 2
O
$\bigcirc$
$\bigcirc$
○
$\bigcirc$
○
$\bigcirc$

Which task, did you feel, workers would find more interesting and enjoyable?

\begin{tabular}{|c|c|c|c|c|c|c|}
\hline \multicolumn{7}{|c|}{ 4. Task 1 and } \\
\hline & & & Task 2 were & & & \\
\hline $\begin{array}{l}\text { 1. Task } 1 \text { was } \\
\text { more interesting }\end{array}$ & & & $\begin{array}{c}\text { equally } \\
\text { interesting and }\end{array}$ & & & $\begin{array}{l}\text { 7. Task } 2 \text { was } \\
\text { more interesting }\end{array}$ \\
\hline and enjoyable & 2 & 3 & enjoyable & 5 & 6 & and enjoyable \\
\hline$\bigcirc$ & 0 & O & $\bigcirc$ & 0 & 0 & 0 \\
\hline
\end{tabular}


Recall that you made hiring decisions about these two tasks.

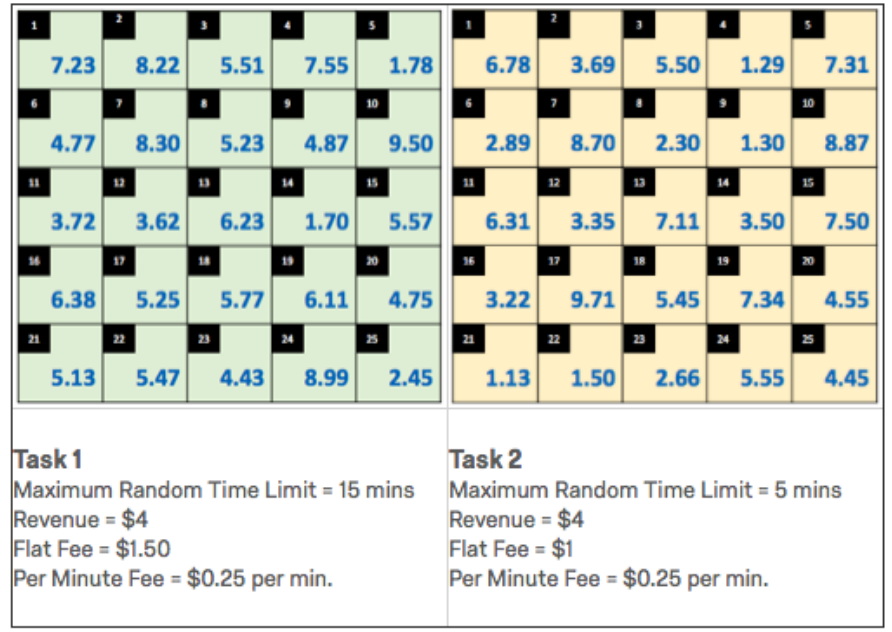

According to you, "how much work" is there in Task 1? Please drag the bar below to indicate your answer (1=A Little Work; 100= A Lot of Work).

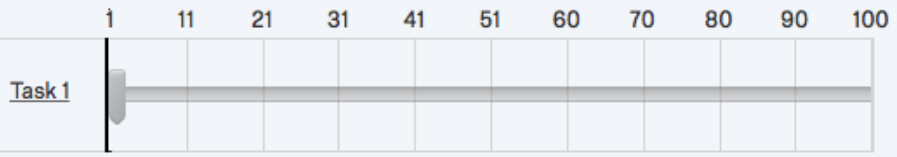

Recall that you made hiring decisions about these two tasks.

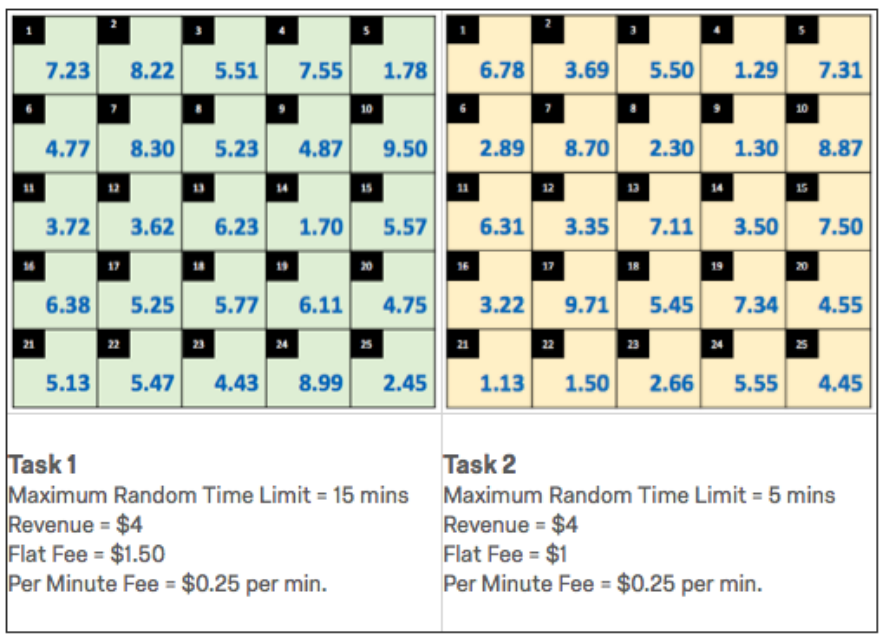

When you made your contract choice for Task 1, were you worried that workers would take longer than necessary to complete the task to make more money at your expense?
Yes
No
Don't know/Did not think about it 


\section{Study 4, Phase 1}

In this survey, you will be asked to complete a simple math task. The math task does not require any advanced skills beyond simple addition and counting.

After you're done with the task you will be finished with this survey and you can submit the HIT and move on to your other work.

On the next screen, you will see the instructions for the task along with an example.

\section{PLEASE READ THE INSTRUCTIONS SLOWLY AND CAREFULLY!}

In the actual task, you will see a number grid like this.

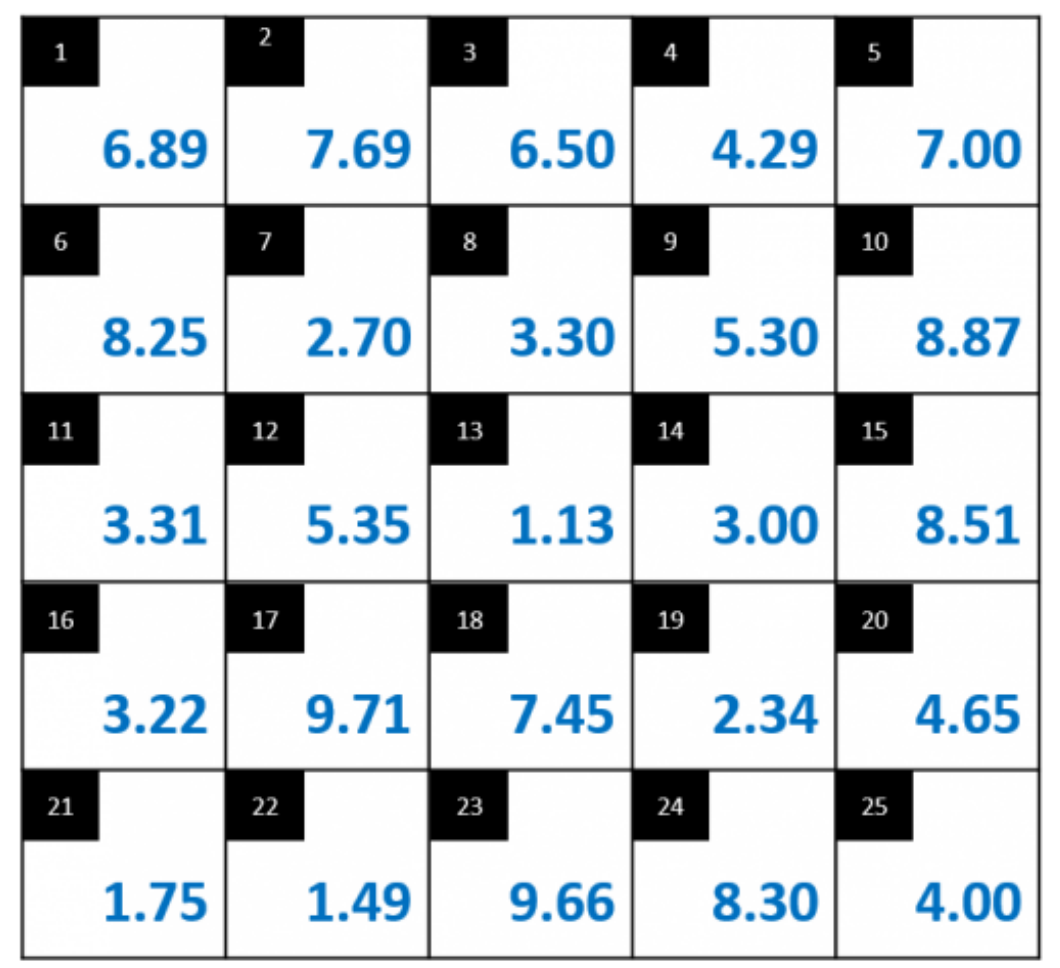

HERE ARE THE INSTRUCTIONS. PLEASE READ CAREFULLY.

1. Every box in the grid is identified using a box\# shown on the top left-hand corner.

2. The content of each box is a decimal number shown in a bold-faced blue-colored letter.

3. In the grid, there are several pairs of boxes that contain numbers that add up to 10.

4. Each such pair is unique; the same box\# is NOT part of any two valid pairs.

5. Your task is to find a certain number of such pairs in a similar number grid. 


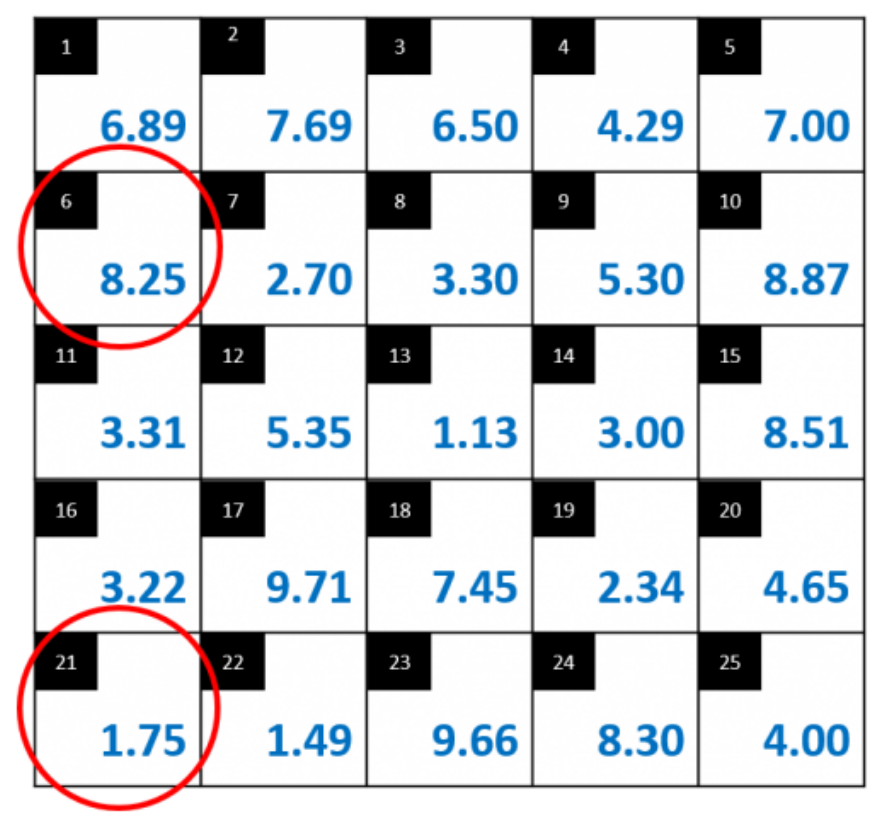

NOTE: THIS IS AN EXAMPLE AND NOT THE REAL TASK.

Once you identify such a pair, you indicate your answer by entering the box numbers, as shown below. Here box numbers 6 and 21 comprise a valid pair.

\begin{tabular}{l|l|}
\hline Pair 1 & box\# 1 \\
\hline Pair 2 & \\
$\ldots$ &
\end{tabular}

NOTE THE FOLLOWING:

1. The order of the box numbers in a pair is not important.

2. The same box\# is NOT part of any two valid pairs, so every valid pair is unique.

3. In the actual task, you will have to find several such valid pairs in a number grid.

On the next page, your actual task will be presented.

Please work at your own pace to complete the task as soon as you can and finish working on this HIT. 
In the number grid shown below, there are eight pairs of boxes that contain numbers that add up to 10 . Your task is to find SIX out these EIGHT pairs of boxes from this grid.

\begin{tabular}{|c|c|c|c|c|}
\hline 6.78 & 3.69 & 5.50 & 1.29 & 7.31 \\
\hline & & 8 & & 10 \\
\hline 2.89 & 8.70 & 2.30 & 1.30 & 8.87 \\
\hline & 2 & 13 & & 15 \\
\hline 6.31 & 3.35 & 7.11 & 3.50 & 7.50 \\
\hline & 7 & 18 & & 20 \\
\hline 3.22 & 9.71 & 5.45 & 7.34 & 4.55 \\
\hline & & 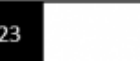 & & 25 \\
\hline 1.13 & 1.50 & 2.66 & 5.55 & 4.45 \\
\hline
\end{tabular}

Please indicate the box number pairs (box\# 1 and box\# 2) below. The box numbers could be in any order.

Remember: Every box number pair is unique. In other words, the same box\# is NOT part of any two valid pairs.

\begin{tabular}{l|l}
\hline Pair 1 & bair 2 \\
Pair 3 & \\
Pair 4 & \\
Pair 5 &
\end{tabular}

After you have entered all the answers, please click on the button below to check if they are correct. You will be taken to the next page if everything is okay.

CHECK ANSWERS 
Study 4, Phase 2 (15 minutes time-limit condition is shown)

In this survey, you will play a hiring game, in which you can get REAL monetary rewards, based on your decisions. These rewards will be paid as bonuses via the Amazon Mechanical Turk platform within a week.

In the game, you are a manager deciding on how to hire a worker from an agency to get a task done.

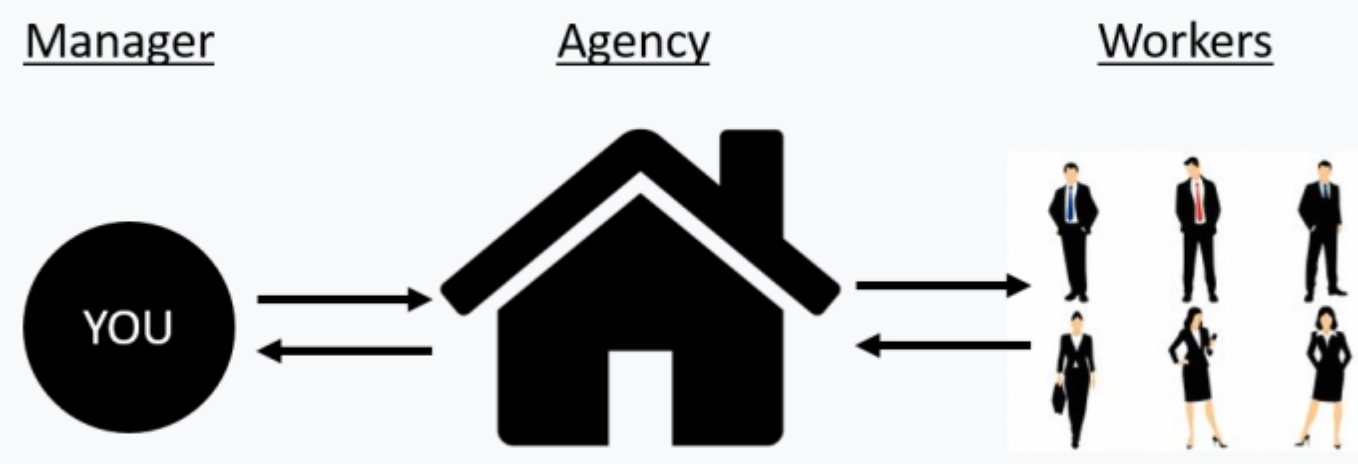

On the next screen you will learn more about the agency and the workers.

PLEASE READ CAREFULLY TO FIND OUT HOW YOU CAN MAKE MONEY IN THIS GAME.

\section{THE HIRING GAME}

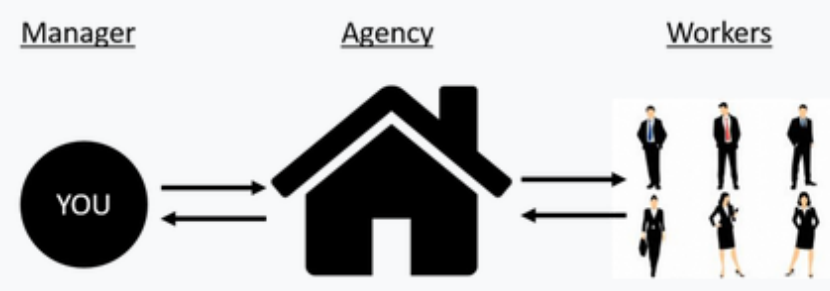

As a Manager, you know the following about the Agency and the Workers.

1. The agency employs multiple workers and pays all of them the same fixed amount (i.e., a fixed salary).

2. The workers are recruits from Amazon Mechanical Turk, just like you.

3. At the agency, the workers work on a task at their own pace and complete it. There are no time limits imposed on the workers when they are working on a task.

4. However, for its own records, the agency measures the time workers take to complete a task. Workers are not informed about the time they have taken and simply work at their own pace.

5. You will need to hire only one worker from the agency to get a task done.

On the next screen, you will learn more about the task.

PLEASE CONTINUE TO READ CAREFULLY. 


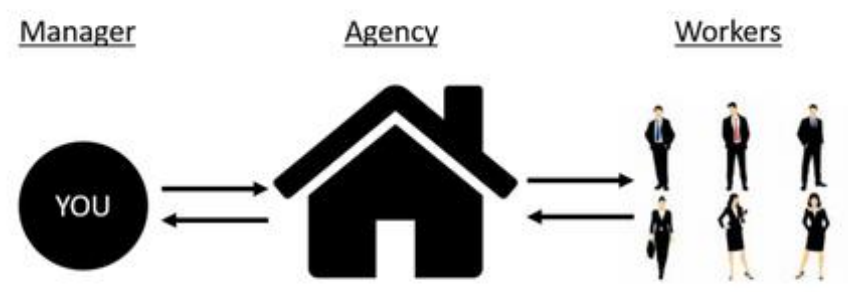

As a Manager, you know the following about the Task.

1. The task your worker needs to do for you is a math problem and the exact task is shown below. The task for the worker is to search six unique pairs of boxes that contain numbers that add up to 10.

2. Every box in the grid is identified using a box\# shown on the top left-hand corner. The content of each box is a decimal number shown in a bold-faced blue-colored letter.

3. An example of a valid pair in the grid is (box\# 24 , box\# 25) that contains 5.55 and 4.45 which add up to 10 . The grid contains eight such valid pairs, of which the workers only need to search six.

4. Assume that this is a one-time transaction, and as a manager, you will not be hiring workers from this agency for any other tasks.

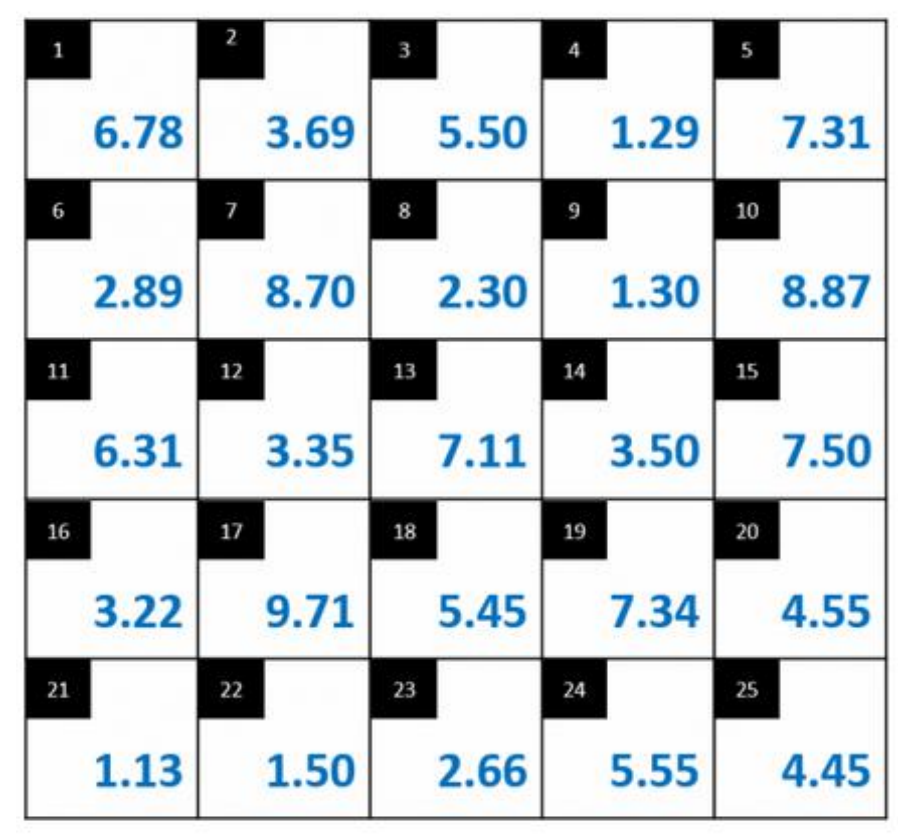

On the next screen, you will learn more about how you can hire a worker to get the task done and how you can earn bonuses based on the decisions you make as a Manager.

PLEASE CONTINUE TO READ CAREFULLY. 
In the game, your "company" would be paid $\$ 6.50$ for a completed task (i.e., 6 valid pairs that contains numbers that add up to 10 in the grid below).

From that $\$ 6.50$, however, you need to deduct the cost of hiring. The remaining money, after paying for the worker, will be yours to keep, and you will receive that money for real (as a bonus) via Mechanical Turk after the study is over (within a week).

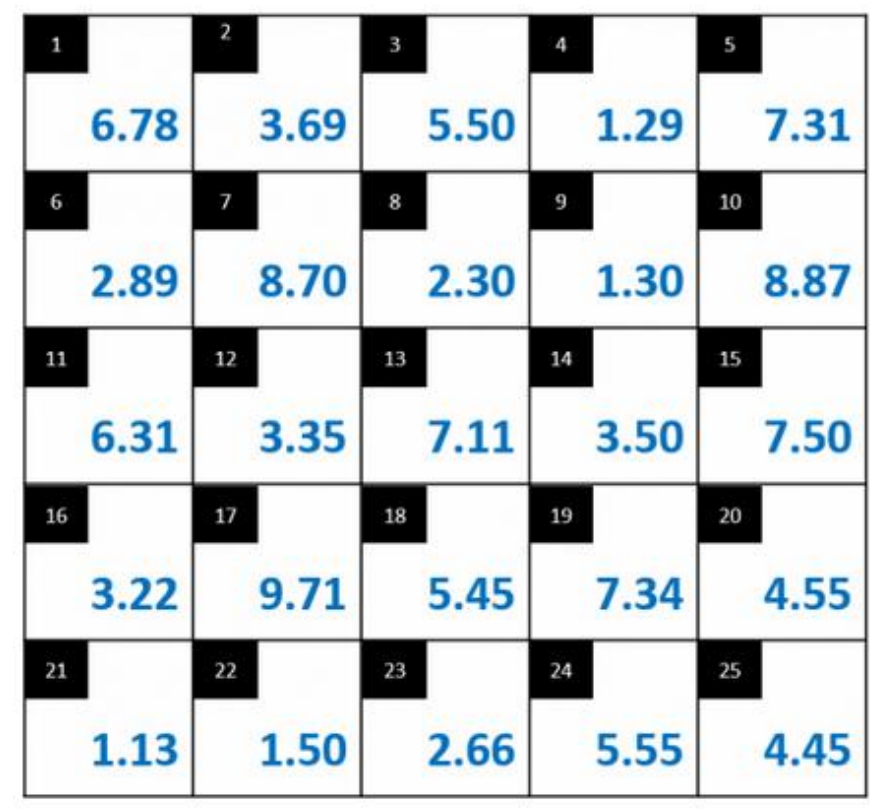

On the next screen, you will learn about your hiring options.

\section{THE HIRING GAME: YOUR OPTIONS}

\section{PLEASE READ CAREFULLY.}

The agency gives you two options (or offers) to hire a worker.

Option 1) You could pay a flat fee of $\$ 2.25$ to hire the worker.

Option 2) You could pay 40 cents per minute up to a maximum of 15 (fifteen) minutes. This means, if the worker takes longer than 15 minutes, the cost is capped at the 15-minutes cost.

Note: The 15-minutes time cap in Option 2 was chosen at random from one of two potential time caps: 5 minutes and 15 minutes.

Implementation details:

The workers work at the agency at their own pace. The agency randomly selects a worker and assigns him/her to work on your task and uses the actual time he/she takes to calculate your cost (it affects your cost only if you choose Option 2). 
Here is a recap of the hiring options you have.

PLEASE MAKE SURE YOU READ THIS CAREFULLY AND UNDERSTAND THIS BEFORE PROCEEDING. THIS WILL AFFECT YOUR BONUS PAYMENT IN THIS STUDY.

1. You will earn $\$ 6.50$ for the completed task, but the cost of having the worker complete the task for you will be deducted from that amount. The remaining profit will be yours, and you will actually be paid that amount as a bonus via Mechanical Turk, within one week of completing the survey.

2. If you choose the flat rate (hiring Option 1), your hiring cost will be $\$ 2.25$. So, you will earn $\$ 6.50$ minus $\$ 2.25$ (i.e., $\$ 4.25$ ), and you will be paid this $\$ 4.25$ as a bonus.

3. If you choose the per-minute rate (hiring Option 2), your hiring cost will be 40 cents for each minute the worker spends, rounded up to the nearest minute, up to a maximum of 15 minutes. So, your cost can vary between 40 cents and $\$ 6.00$. In effect, the bonus you earn will also vary. You will make between ( $\$ 6.50$ minus $\$ 0.40$ ) and ( $\$ 6.50$ minus $\$ 6.00$ ), i.e., between $\$ 0.50$ and $\$ 6.10$.

4. You will be randomly paired with an actual Mturk worker who will do the task. If you choose the perminute rate, your cost of hiring the worker will be calculated based on the real time that specific worker took to actually complete the task, up to a maximum of 15 minutes.

NOW, YOU ARE ALL SET.

\section{The condition when time estimates were asked before choice of compensation schemes is shown:}

Before you choose your preferred hiring option, we would like to know how much time you think a specific worker, randomly picked for you, took to finish the task.

As mentioned above, workers worked at their own pace and finished the task when they could.

Please enter your best guess of the time in minutes in the box below. Enter a NUMBER only.

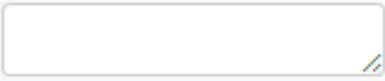

\footnotetext{
Now, it is time to indicate your preferred option to hire the worker.

Which option do you prefer?

(Option 1) I will pay the flat rate of $\$ 2.25$

(Option 2) I will pay the rate of 40 cents per minute for a maximum of 15 (fifteen) minutes
} 


\section{Study 5, Phase 1}

In this survey, you will be asked to complete a simple math task. The math task does not require any advanced skills beyond simple addition and counting. After you're done with the task (and a few followup questions) you will be finished with this survey and you can submit the HIT and move on to your other work.

Apart from the base payment, you can earn additional money for doing the task. Details about this will be provided in a short while.

In the actual task, you will see a number grid like this.

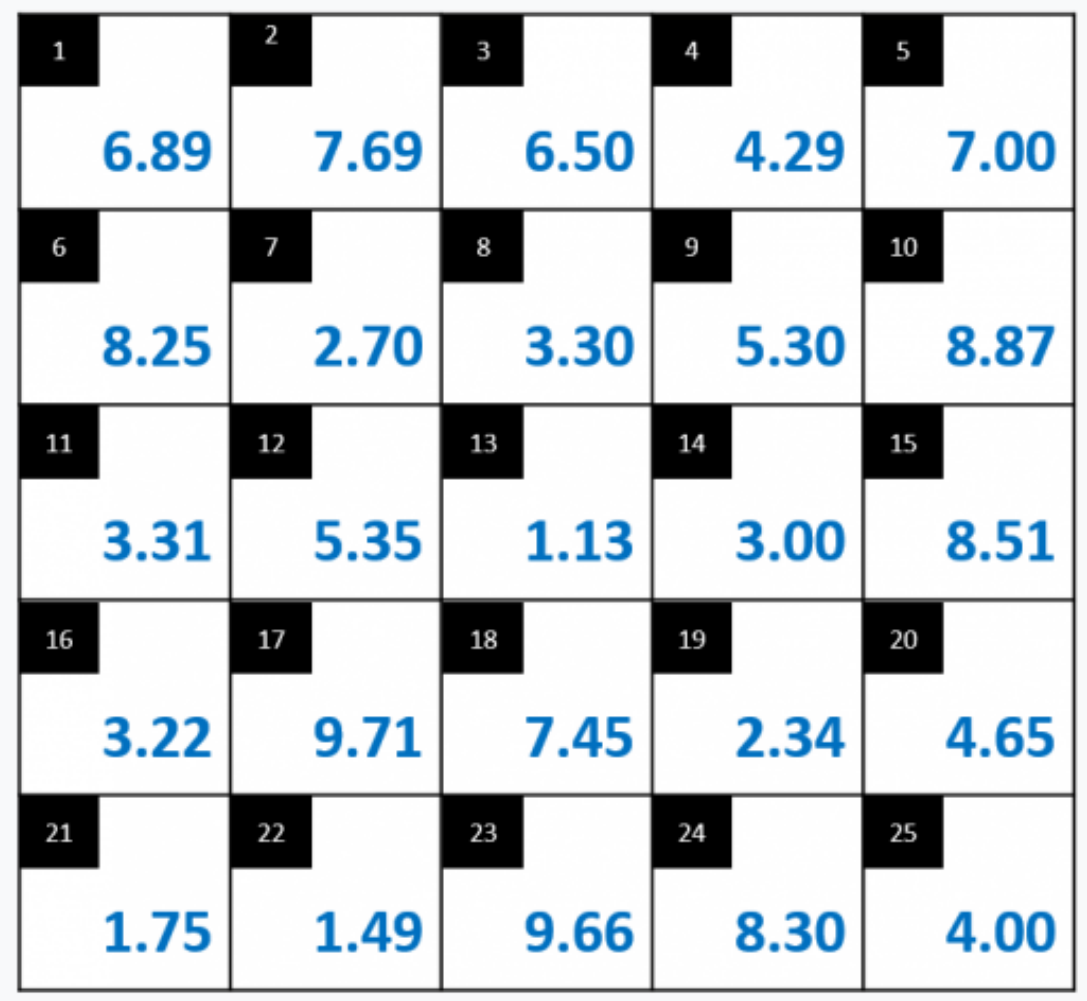

HERE ARE THE INSTRUCTIONS. PLEASE READ CAREFULLY.

1. Every box in the grid is identified using a box\# shown on the top left-hand corner.

2. The content of each box is a decimal number shown in a bold-faced blue-colored letter.

3. In the grid, there are several pairs of boxes that contain numbers that add up to 10 .

4. Each such pair is unique; the same box\# is NOT part of any two valid pairs.

5. Your task is to find a certain number of such pairs in a similar number grid. 
For example, a pair containing two numbers that add up to 10 is shown below.

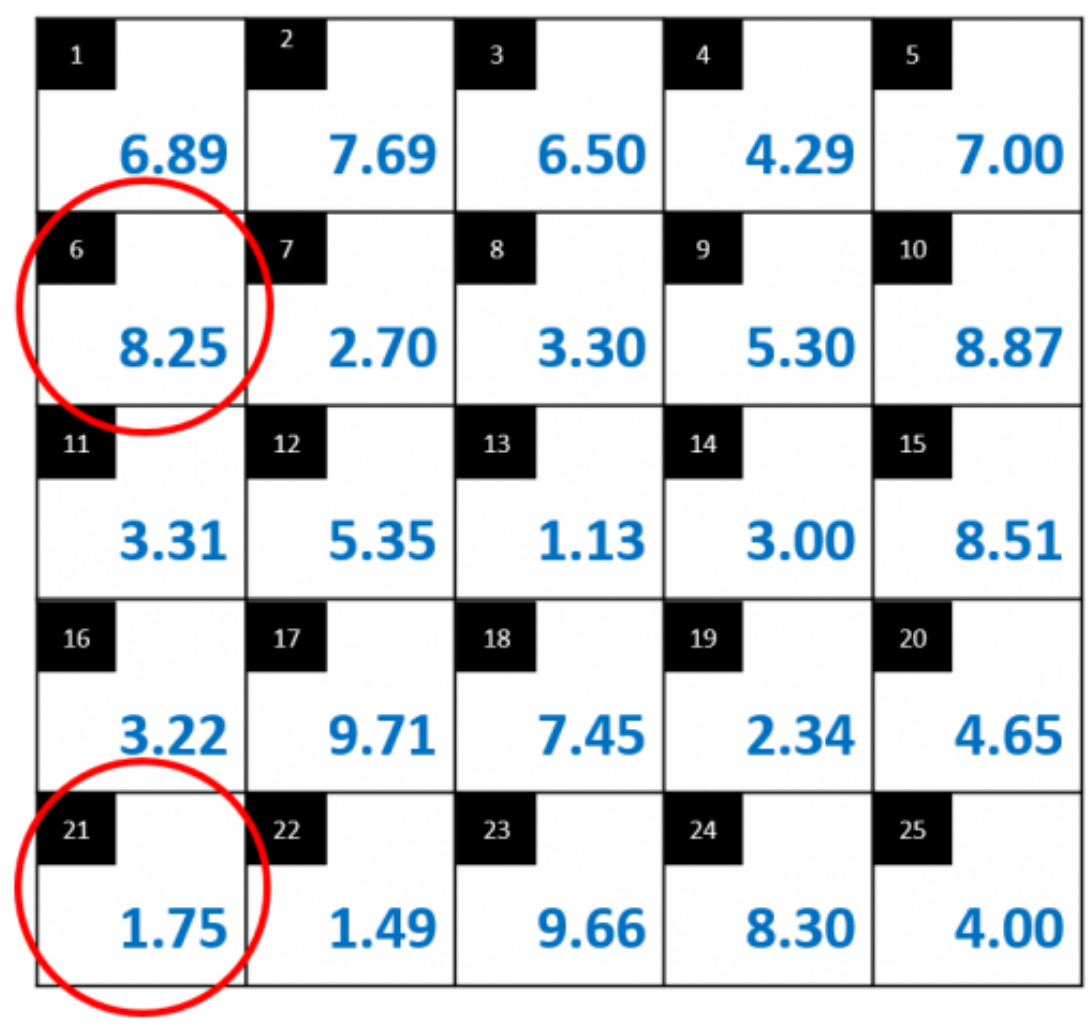

NOTE: THIS IS AN EXAMPLE AND NOT THE REAL TASK.

Once you identify such a pair, you indicate your answer by entering the box numbers, as shown below. Here box numbers 6 and 21 comprise a valid pair.

\begin{tabular}{llll} 
& box\# 1 & box\# 2 \\
Pair 1 & & \\
Pair 2 & & \\
\hline$\ldots$ & & \\
\hline
\end{tabular}

\section{NOTE THE FOLLOWING:}

1. The order of the box numbers in a pair is not important.

2. The same box\# is NOT part of any two valid pairs, so every valid pair is unique.

3. In the actual task, you will have to find several such valid pairs in a number grid. 
You will be paid at a rate of $\mathbf{2 5}$ cents per minute for completing this task.

We will multiply the total time in minutes it takes you to complete the task by 25 cents to compute your additional payment (over your base payment) for the task.

Your additional payment will be made via Amazon Mechanical Turk within 7 days after the completion of this survey.

Please confirm the additional compensation you will receive by retyping it below. Please enter ONLY a number in the box below.

(2)

When you do the task, your work will be timed by the computer. You will not be able to work on the task after the assigned time limit expires.

Display This Question:

If pay Is Equal to 1

You will have a time limit of 5 minutes to complete the task.

Display This Question:

If pay Is Equal to 2

You will have a time limit of 15 minutes to complete the task.

Please confirm your time limit by retyping it below. Please enter ONLY a number in the box below. 
Below the 15-minute condition is shown:

Display This Question:

If pay Is Equal to 2

This question lets you record and manage how long a participant spends on this page. This question will not be displayed to the participant.

\section{0}

In the number grid shown below, there are eight pairs of boxes that contain numbers that add up to 10 .

Your task is to find SIX out these EIGHT pairs of boxes from this grid.

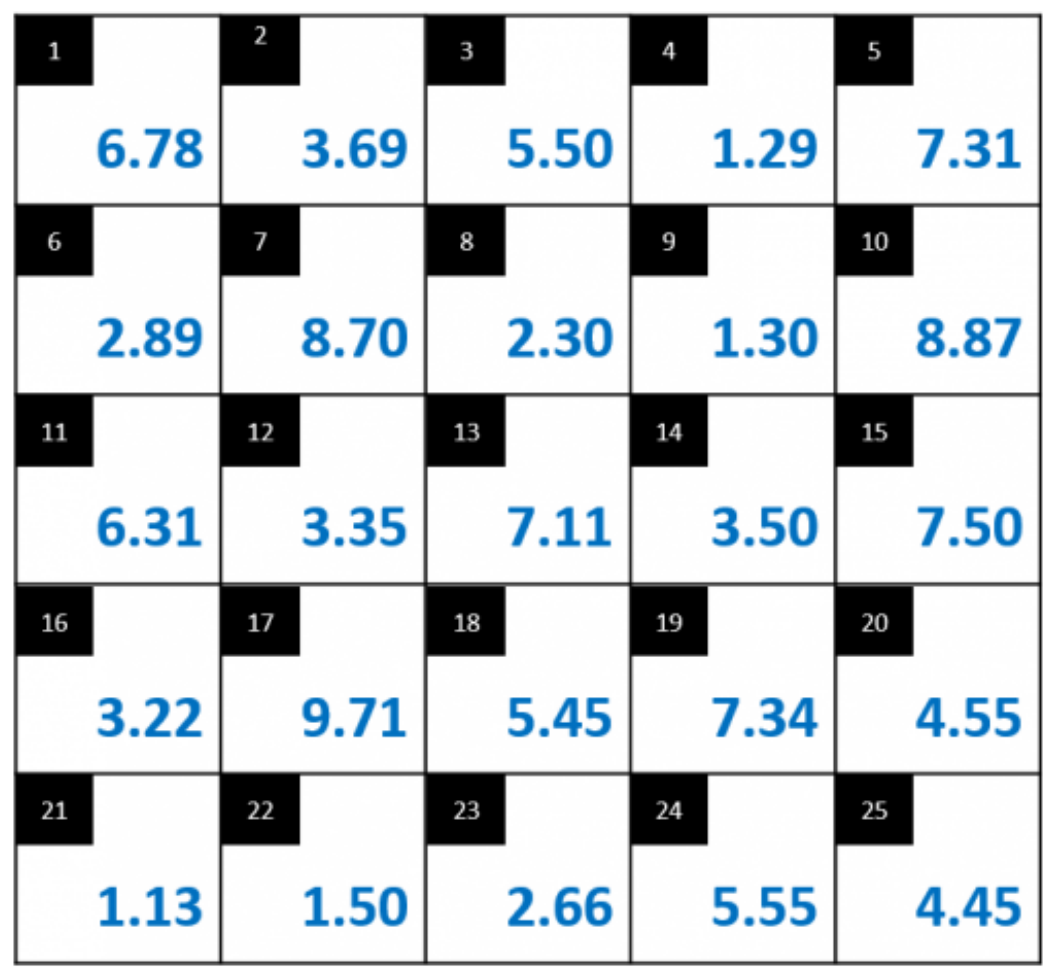




\section{Study 5, Phase 2}

In this survey, you will play a hiring game. In the game, you will be a manager deciding on how to hire a worker to get a task done.

FIVE participants will be randomly selected and THEY WILL WIN REAL BONUSES in addition to their base payments. The amount of these bonuses will depend on the decisions made in this survey. You could be one of those 5 participants, and therefore, please make your choices as if the consequences are real.

Below, we will describe a job situation that requires hiring a worker. Please read carefully. There will be recall questions to check your comprehension.

Please assume the job is temporary, and you will not need to build a long-term relationship with the hired worker.

\section{TASK INFORMATION}

The kind of task for which you will need to hire a worker is shown below.

(NOTE: this is an example and is not the actual task for which you will be hiring).

Here are the rules for finishing the task:

1. Every box in the grid is identified using a box\# shown on the top left-hand corner. The content of each box is a decimal number shown in a bold-faced blue-colored letter.

2. In the numbers grid, there are EIGHT unique pairs of boxes that contain numbers that add up to 10.

3. An example of a valid pair in the grid is (box\# 6 , box\# 21) that contains 8.25 and 1.75 which add up to 10 (the two boxes are shown below using red markers).

4. The workers' task is to search for SIX such unique valid pairs (out of the EIGHT), from a similar numbers grid, and note the box numbers. That's all.

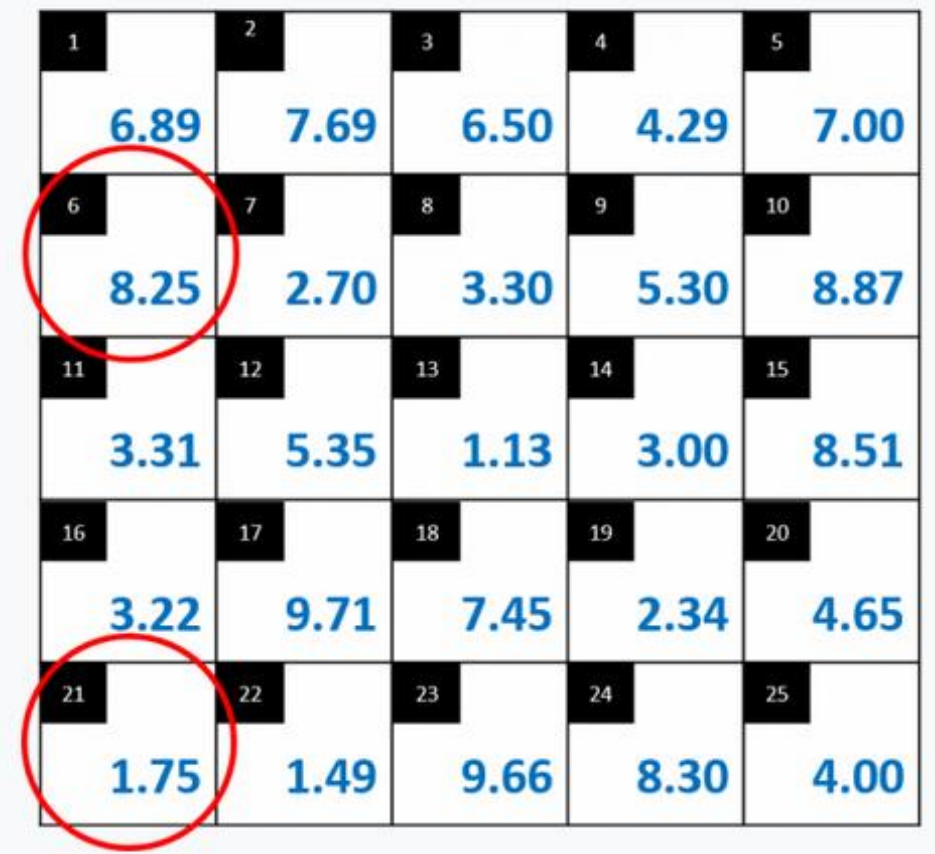

NOTE: THIS IS AN EXAMPLE AND IS NOT THE ACTUAL TASK. 


\section{WORKERS' INTERFACE \& INSTRUCTIONS}

Workers enter their answers (i.e., 6-pairs of box-numbers) in the following interface:

box\# 1 box\# 2

\begin{tabular}{l|l|l|} 
Pair 1 & 6 & 21 \\
\hline
\end{tabular}

Pair 2

Pair 3
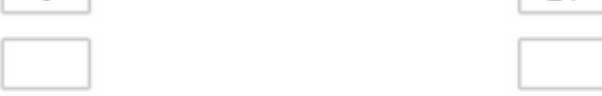

Pair 4

Pair 4

Pair 5

Pair 6

Workers read the following instructions:

1. Please indicate the box number pairs (box\# 1 and box\# 2) below.

2. The box numbers could be in any order.

3. Every box number pair is unique. In other words, the same box\# is NOT part of any two valid pairs.

\section{GETTING A WORKER TO WORK ON THE TASK}

We got actual workers to work on the task. Here are the details.

Recruited workers were randomly divided into three groups:

1) The first group was given a maximum time limit of $\mathbf{5}$ minutes to complete the task

2) The second group was given a maximum time limit of 15 minutes to complete the task

3) The third group had no maximum time limit to complete the task

Workers in all the groups were told to work at their own place to complete the task. As soon as a worker finished the task and answered a few follow-up questions, the worker was done.

However, workers in the timed conditions were stopped if the assigned time limit was over.

The actual time taken to finish the task was accurately recorded by the computer in all the conditions.

\section{Additional details for the TIMED conditions:}

As a worker started to work, a prominent countdown timer showed the time left to complete the task. The computer interface advanced to the next screen once the worker completed the task (and checked his/her answers by clicking a "CHECK ANSWERS" button), or if the assigned time limit expired.

\section{Additional details for the UNTIMED conditions:}

No countdown timer was shown and the computer interface advanced to the next screen once the worker completed the task (and checked his/her answers by clicking a "CHECK ANSWERS" button). 
Display This Question:

If time Is Equal to 5

TWO IMPORTANT POINTS TO NOTE:

POINT 1: IN THE GAME YOU WILL PLAY, YOU ARE GOING TO HIRE A WORKER ONLY AMONG THOSE WHO WERE TIMED AND GIVEN A MAXIMUM OF 5 MINUTES TO COMPLETE THE TASK.

TWO IMPORTANT POINTS TO NOTE:

POINT 1: IN THE GAME YOU WILL PLAY, YOU ARE GOING TO HIRE A WORKER ONLY AMONG THOSE WHO WERE TIMED AND GIVEN A MAXIMUM OF 15 MINUTES TO COMPLETE THE TASK.

TWO IMPORTANT POINTS TO NOTE:

POINT 2: ONLY WORKERS WHO HAVE COMPLETED THE TASK SUCCESSFULLY IN THE ASSIGNED TIME LIMIT ARE AVAILABLE FOR YOUR HIRING.

This will make sure that you will be able to get the task done in the assigned time limit.

Below is the actual task for which you would need to hire a worker.

\begin{tabular}{|c|c|c|c|c|}
\hline 6.78 & 3.69 & 5.50 & 1.29 & 7.31 \\
\hline 6 & & 3 & 9 & 10 \\
\hline 2.89 & 8.70 & 2.30 & 1.30 & 8.87 \\
\hline & & 3 & 14 & 15 \\
\hline 6.31 & 3.35 & 7.11 & 3.50 & 7.50 \\
\hline 6 & & 8 & 19 & 20 \\
\hline 3.22 & 9.71 & 5.45 & 7.34 & 4.55 \\
\hline & 2 & 3 & 24 & 25 \\
\hline 1.13 & 1.50 & 2.66 & 5.55 & 4.45 \\
\hline
\end{tabular}


Following are details about the hiring situation AND YOUR HIRING OPTIONS. This information will be important for your actual bonus in this survey. SO, PLEASE READ VERY CAREFULLY.

1. You will need to hire just one worker for getting the task done.

2. As mentioned earlier, the worker will get a maximum of 5 minutes to finish the task. This time limit was randomly selected for the worker.

3. Only workers who could complete the task in the assigned time limit are available for hiring.

4. The completed task sells for $\$ 4.00$. So, this is your revenue. From this, you will need to subtract the cost of hiring a worker to compute your profit. As a manager, your objective is to maximize profit.

5. For hiring a worker, you have two options: (a) pay the worker a flat fee of $\$ 1.00$. (b) pay the worker @ 25 cents per minute worked (rounded to the nearest integer) up to a maximum of the time limit.

6. Therefore, if you choose option (a) your profit is fixed at $\$ 3.00$ (\$4.00 - $\$ 1.00)$. If you choose option (b) your profit can vary between $\$ 2.75(\$ 4.00-\$ 1.25)$ and $\$ 3.75(\$ 4.00-\$ 0.25)$ depending on the time taken by the worker.

7. If you are one among the five randomly selected participants, you will be paid the earned profit for real as a bonus payment.

8. Workers know only about their assigned time limit, and the terms of hiring (flat fee or per-minute fee) before starting their work.

Display This Question:

If info Is Equal to 0

Which option would you choose to hire a worker for this task?

Option A - I will pay a flat rate of $\$ 1.00$

Option B - I will pay the rate of 25 cents per minute for a maximum of 5 (five) minutes 


\section{Follow-up questions asked to capture beliefs about task completion times (the questions asked if Managers chose the Flat Fee are shown for illustration):}

\section{Display This Question:}

If Which option would you choose to hire a worker for this task? Option A - I will pay a flat rate of $\$ 1.00$ Is Selected

You just decided to pay the worker a flat fee of $\$ 1.00$ for the work. The worker has 5 minutes to complete the work.

As you chose a flat-fee, you will get a fixed bonus amount of $\$ 3.00(\$ 4.00$ minus $\$ 1.00)$ irrespective of how much time your hired worker took to complete the task.

But, we would still like to know how much time (in minutes) do you think your hired worker would take to complete the task.

Please enter a NUMBER in the box below. (your answer can be a decimal number, but do not use any text such as units, etc.)

\section{Display This Question:}

If, instead, you had decided to pay the worker 25 cents per minute taken to complete the task (i.e. IF YOU HAD CHOSEN THE OTHER HIRING OPTION), we would have picked for you at random a worker assigned to do the job in 5 minutes and paid a rate of 25 cents per minute worked, and use the actual time taken by this worker to calculate your bonus.

How much time do you think this worker, paid at a rate of $\mathbf{2 5}$ cents per minute worked, would have ended up taking to complete the task?

Please enter a NUMBER in the box below. (your answer can be a decimal number, but do not use any text such as units, etc.) 


\section{Completion-time Information Intervention along with the comprehension questions (asked}

on the same page as the information):

To help you make your hiring decision we want to give you the actual time taken by workers who were randomly selected to do the task without any time limit.

So, this group had unlimited time, and they were told to work at their own pace to complete the work as soon as they could.

In this scenario, each worker was paid a flat fee (i.e., a fixed lump sum amount) for this work.

There were 102 such workers and the chart below shows the count of the various time taken by each of these workers.

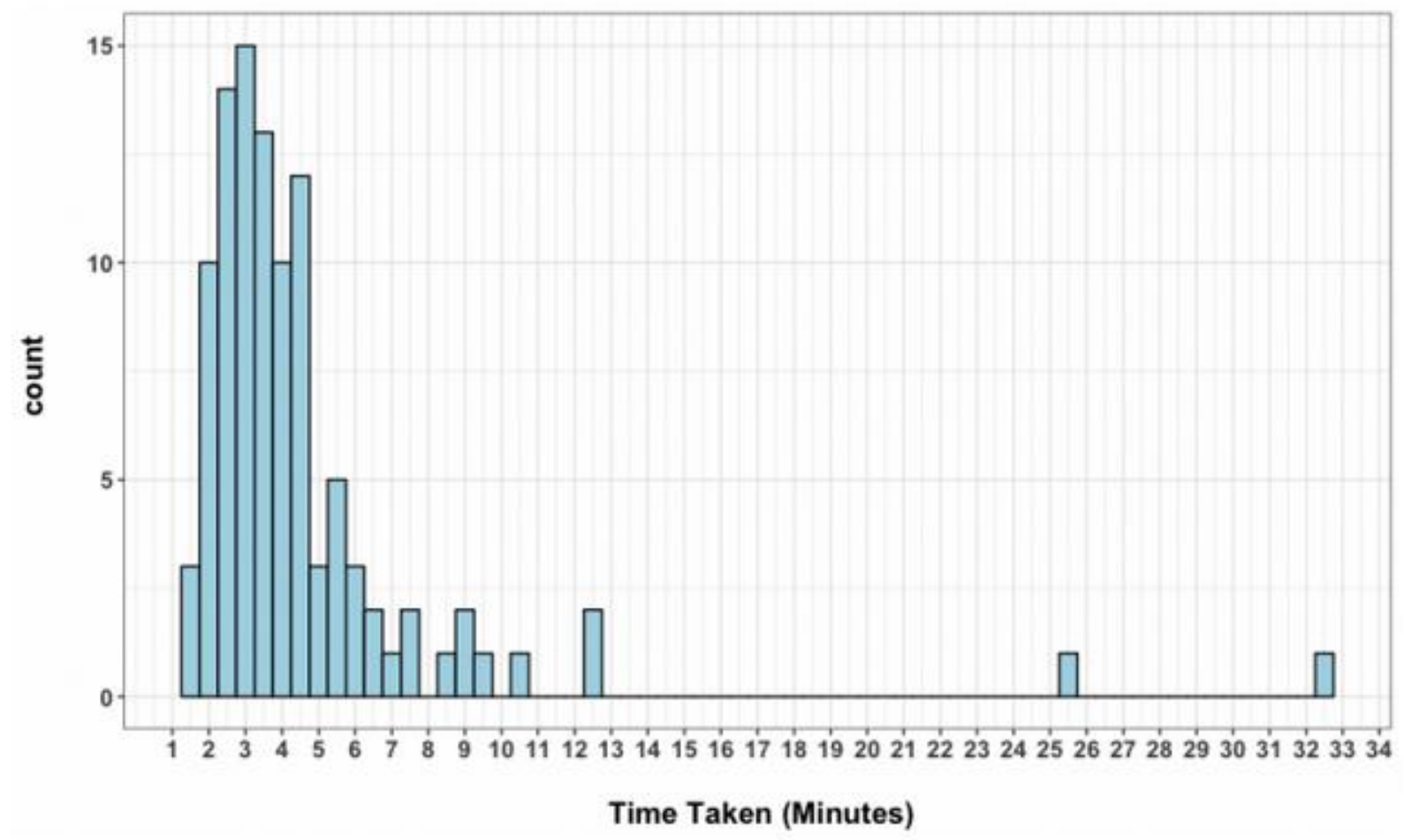

Each bar on the graph above tells you how many workers completed the task in each amount of time. A taller bar indicates that more workers completed the task in that amount of time.

Please spend a little time to browse this chart carefully and answer a few questions to indicate your comprehension. 
Look at the chart. How many workers (in \%) completed the task in $\mathbf{3}$ minutes or less?

$85 \%$

$35 \%$

$5 \%$

Look at the chart. How many workers (in \%) completed the task in $\mathbf{5}$ minutes or less?

○5\%

$75 \%$

$25 \%$

Look at the chart. How many workers (in \%) completed the task in 15 minutes or less?

- $98 \%$

$88 \%$

$78 \%$

How much time limit did this group of workers have?

5 Minutes

15 Minutes

$\bigcirc$ No Time Limits

How were these workers, working on the task without any time limits, paid?

They were paid a flat lump sum amount

They were paid at a certain rate per minute worked

$\bigcirc$ Don't know/Can't Say 


\section{End of Survey Recall Questions (all participants):}

Please answer a few recall questions. All the questions pertain to the specific hiring decision you made in this survey.

Please recall the maximum time limit a worker had to complete the task?

5 Minutes

15 Minutes

No Time Limits

Please recall how the maximum time limit was selected for a worker?

The time limit was selected randomly

The time limit was selected such that lesser skilled workers had more time

Please recall which of the following was true for the workers who were available for hire?

Only workers who completed the task in the assigned time limit were available for hire.

All workers (even those who failed to complete the task in the assigned time limit) were available for hire. 


\section{Online Appendix B: Details of the Consequential Hiring Game}

\section{Equivalent Gambles from Workers' Actual Times}

Studies 1a, 1b (and Study A1 in Online Appendix D)

\begin{tabular}{|c|c|c|}
\hline Condition & Option A & Option B \\
\hline $\begin{array}{l}\text { Time Limit = } 15 \\
\text { minutes (Longer) }\end{array}$ & $\begin{array}{l}\text { A fixed amount of } \$ 2.50 \text { for } \\
\text { sure }\end{array}$ & $\begin{array}{l}\text { Exactly one of the following } \\
\text { amounts: } \\
33 \% \text { chance of winning } \$ 3.50 \text {, or } \\
26 \% \text { chance of winning } \$ 3.25 \text {, or } \\
15 \% \text { chance of winning } \$ 3.00 \text {, or } \\
7 \% \text { chance of winning } \$ 2.50 \text {, or } \\
11 \% \text { chance of winning } \$ 2.25 \text {, or } \\
4 \% \text { chance of winning } \$ 2.00 \text {, or } \\
4 \% \text { chance of winning } 25 \text { cents }\end{array}$ \\
\hline $\begin{array}{l}\text { Time Limit }=5 \\
\text { minutes (Shorter) }\end{array}$ & A fixed amount of $\$ 1$ for sure & $\begin{array}{l}\text { Exactly one of the following } \\
\text { amounts: } \\
29 \% \text { chance of winning } \$ 1.50 \text {, or } \\
32 \% \text { chance of winning } \$ 1.25 \text {, or } \\
14 \% \text { chance of winning } \$ 1.00 \text {, or } \\
25 \% \text { chance of winning } 75 \text { cents }\end{array}$ \\
\hline
\end{tabular}


Study 2

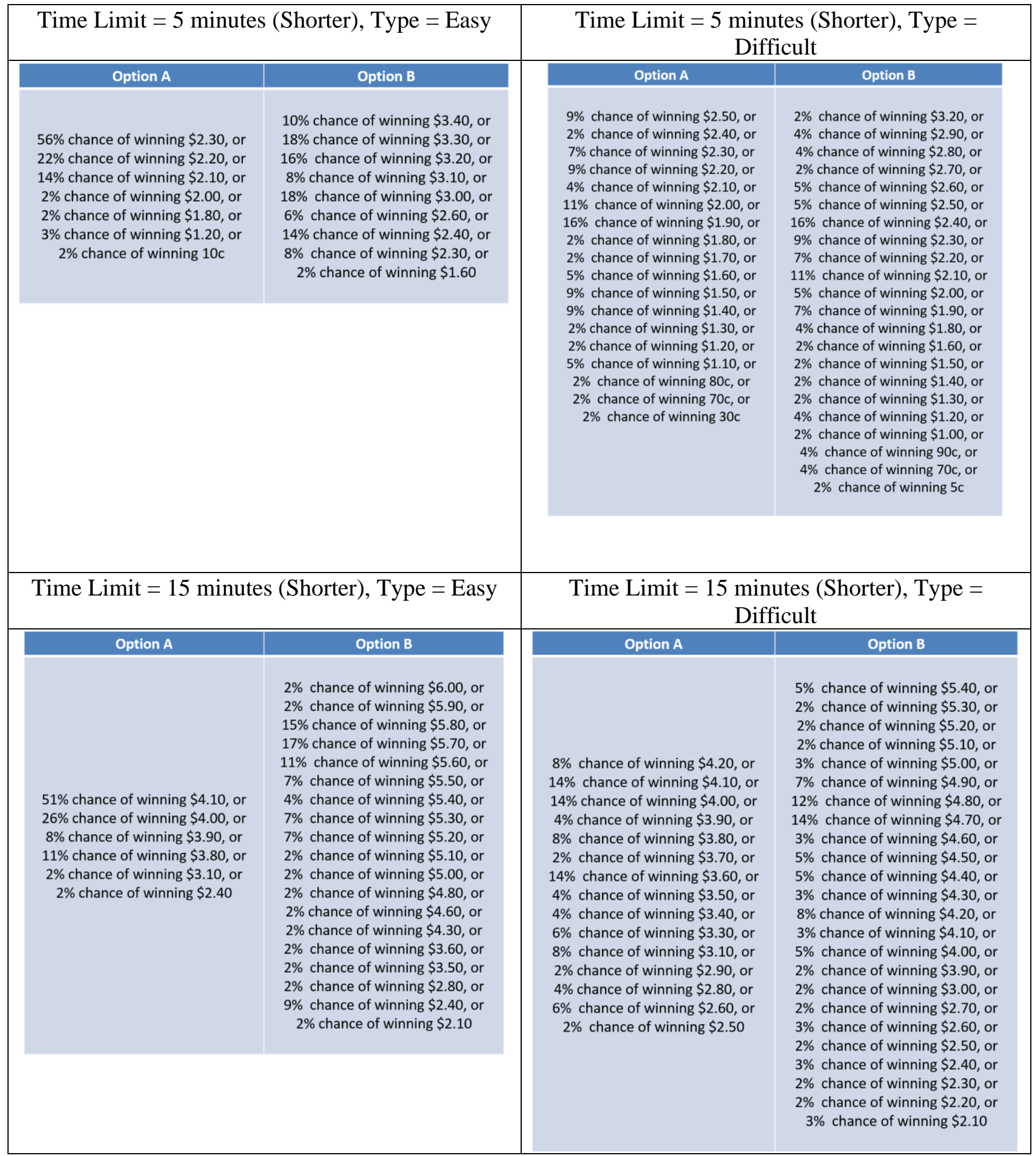




\section{Study 4}

\section{Common Information}

Imagine a new scenario, where you are again making a hiring decision to recruit a worker. In this

situation, you have a choice between a certain option where the cost of hiring is fixed and an uncertain

option where different costs of hiring are possible.

\section{Shorter time limit, Version 1}

From a fixed revenue of $\$ 2.50$, this incurred cost will be deducted to compute your profit.

In the table below, the probability of each cost outcomes is listed.

\begin{tabular}{|c|c|}
\hline Option A & Option B \\
\hline \multirow{3}{*}{ Incurring a fixed cost of $\$ 1.75$} & A variable cost which will be one of the following amounts: \\
\cline { 2 - 2 } & $41 \%$ chance of incurring a cost of $\$ 2.00$, or \\
\hline & $24 \%$ chance of incurring a cost of $\$ 1.60$, or \\
\hline & $28 \%$ chance of incurring a cost of $\$ 1.20$, or \\
\hline & $7 \%$ chance of incurring a cost of 80 cents. \\
\hline
\end{tabular}

\section{Shorter time limit, Version 2}

From a fixed revenue of $\$ 6.00$, this incurred cost will be deducted to compute your profit.

In the table below, the probability of each cost outcomes is listed.

\begin{tabular}{|c|c|}
\hline Option A & Option B \\
\hline \multirow{3}{*}{ Incurring a fixed cost of $\$ 1.75$} & A variable cost which will be one of the following amounts: \\
\cline { 2 - 2 } & $41 \%$ chance of incurring a cost of $\$ 2.00$, or \\
\hline & $24 \%$ chance of incurring a cost of $\$ 1.60$, or \\
\hline & $28 \%$ chance of incurring a cost of $\$ 1.20$, or \\
\hline & $7 \%$ chance of incurring a cost of 80 cents. \\
\hline
\end{tabular}

\section{Longer time limit}

From a fixed revenue of $\$ \mathbf{6 . 5 0}$, this incurred cost will be deducted to compute your profit.

In the table below, the probability of each cost outcomes is listed.

\begin{tabular}{|c|c|}
\hline Option A & Option B \\
\hline \multirow{4}{*}{ A variable cost which will be one of the following } \\
amounts:
\end{tabular}




\section{Managers' Payoff Details}

Study 2

\begin{tabular}{|c|c|c|c|c|c|c|}
\hline \multirow[b]{2}{*}{ Time Limit } & \multirow[b]{2}{*}{$\begin{array}{l}\text { Bonus or Reward } \\
\text { /correct spelling }\end{array}$} & \multicolumn{2}{|c|}{ Flat Fee Chosen } & \multicolumn{3}{|c|}{ Per-min Fee Chosen } \\
\hline & & $\begin{array}{l}\text { Cost of } \\
\text { hiring } \\
\text { worker }\end{array}$ & $\begin{array}{l}\text { Profit earned by } \\
\text { manager } \\
\text { (expected) }\end{array}$ & $\begin{array}{l}\text { Range of } \\
\text { costs for } \\
\text { hiring } \\
\text { worker } \\
\end{array}$ & $\begin{array}{c}\text { Expected cost } \\
\text { (based on average } \\
\text { completion times) }\end{array}$ & $\begin{array}{l}\text { Profit earned by manager } \\
\text { (expected) }\end{array}$ \\
\hline $\begin{array}{l}5 \text { minutes } \\
+ \text { Easy } \\
\text { Tasks }\end{array}$ & $\begin{array}{l}\text { Budget }=\$ 1.20 \text { (flat) }+ \\
10 \text { cents/correct } \\
\text { Average correct = } 23 \\
\text { (expected budget }= \\
\$ 3.50) \\
\text { Flat Fee }=\$ 1+\$ 0.30 \text { fee } \\
\text { Per-Unit-Time rate = } \\
\$ 0.25 / \mathrm{min}\end{array}$ & $\$ 1.30$ & $3.50-1.30=\$ 2.20$ & $\begin{array}{l}\$ 0.25- \\
\$ 1.25\end{array}$ & 60 cents & $\begin{array}{l}3.50-0.60=\$ 2.90 \\
\text { Extra profit compared to } \\
\text { hiring Flat Fee workers }= \\
2.90-2.20=70 \text { cents }\end{array}$ \\
\hline $\begin{array}{l}5 \text { minutes } \\
+ \text { Difficult } \\
\text { Tasks }\end{array}$ & $\begin{array}{l}\text { Budget }=\$ 1.20 \text { (flat) }+ \\
10 \text { cents/correct } \\
\text { Average correct=17 } \\
\text { expected budget = } \\
\$ 2.90) \\
\text { Flat Fee }=\$ 1+\$ 0.10 \text { fee } \\
\text { Per-Unit-Time rate = } \\
\$ 0.25 / \mathrm{min}\end{array}$ & $\$ 1.10$ & $2.90-1.10=\$ 1.80$ & $\begin{array}{l}\$ 0.25- \\
\$ 1.25\end{array}$ & 90 cents & $\begin{array}{l}2.90-0.90=\$ 2.00 \\
\text { Extra profit compared to } \\
\text { hiring Flat Fee workers }= \\
2.00-1.80=20 \text { cents }\end{array}$ \\
\hline $\begin{array}{l}15 \\
\text { minutes + } \\
\text { Easy Tasks }\end{array}$ & 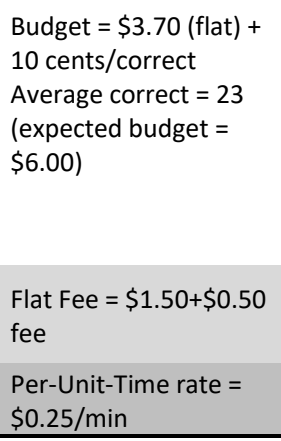 & $\$ 2.00$ & $6.00-2.00=\$ 4.00$ & $\begin{array}{l}\$ 0.25- \\
\$ 3.75\end{array}$ & $\$ 1.00$ & $\begin{array}{l}6.00-1.00=\$ 5.00 \\
\text { Extra profit compared to } \\
\text { hiring Flat Fee workers }= \\
5.00-4.00=\$ 1.00\end{array}$ \\
\hline $\begin{array}{l}15 \\
\text { minutes + } \\
\text { Difficult } \\
\text { Tasks }\end{array}$ & 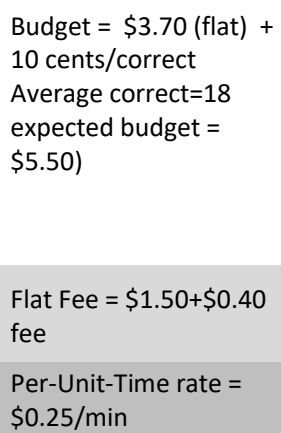 & $\$ 1.90$ & $5.50-1.90=\$ 3.60$ & $\begin{array}{l}\$ 0.25- \\
\$ 3.75\end{array}$ & $\$ 1.40$ & $\begin{array}{l}5.50-1.40=\$ 4.10 \\
\text { Extra profit compared to } \\
\text { hiring Flat Fee workers }= \\
4.10-3.60=50 \text { cents }\end{array}$ \\
\hline
\end{tabular}


Study A3, A4, and A5 (additional studies in Online Appendix D)

\begin{tabular}{|c|c|c|c|c|c|c|}
\hline \multirow[b]{2}{*}{ Time Limit } & \multirow[b]{2}{*}{$\begin{array}{l}\text { Bonus or Reward } \\
\text { /correct spelling }\end{array}$} & \multicolumn{2}{|c|}{ Flat Fee Chosen } & \multicolumn{3}{|c|}{ Per-min Fee Chosen } \\
\hline & & $\begin{array}{l}\text { Cost of } \\
\text { hiring } \\
\text { worker }\end{array}$ & $\begin{array}{l}\text { Profit earned by } \\
\text { manager } \\
\text { (expected) }\end{array}$ & $\begin{array}{l}\text { Range of } \\
\text { costs for } \\
\text { hiring } \\
\text { worker }\end{array}$ & $\begin{array}{c}\text { Expected cost } \\
\text { (based on average } \\
\text { completion times) }\end{array}$ & $\begin{array}{l}\text { Profit earned by manager } \\
\text { (expected) }\end{array}$ \\
\hline $\begin{array}{l}5 \text { minutes } \\
+ \text { Easy } \\
\text { Tasks }\end{array}$ & $\begin{array}{l}\text { Budget }=50 \text { cents (flat) } \\
+10 \text { cents/correct } \\
\text { Average correct }=23 \\
\text { (expected budget }= \\
\$ 2.80 \text { ) } \\
\text { Flat Fee }=\$ 1+\$ 0.10 \text { fee } \\
\text { Per-Unit-Time rate = } \\
\$ 0.25 / \text { min }\end{array}$ & $\$ 1.10$ & $2.80-1.10=\$ 1.70$ & $\begin{array}{l}\$ 0.25- \\
\$ 1.25\end{array}$ & 50 cents & $\begin{array}{l}2.80-0.50=\$ 2.30 \\
\text { Extra profit compared to } \\
\text { hiring Flat Fee workers }= \\
2.30-1.70=60 \text { cents }\end{array}$ \\
\hline $\begin{array}{l}5 \text { minutes } \\
+ \text { Difficult } \\
\text { Tasks }\end{array}$ & 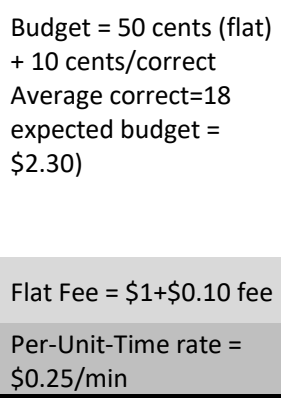 & $\$ 1.10$ & $2.30-1.10=\$ 1.20$ & $\begin{array}{l}\$ 0.25- \\
\$ 1.25\end{array}$ & 80 cents & $\begin{array}{l}2.30-0.80=\$ 1.50 \\
\text { Extra profit compared to } \\
\text { hiring Flat Fee workers }= \\
1.50-1.20=30 \text { cents }\end{array}$ \\
\hline $\begin{array}{l}15 \\
\text { minutes + } \\
\text { Easy Tasks }\end{array}$ & 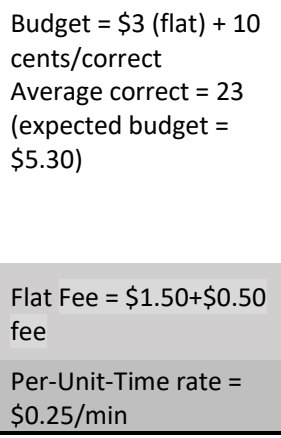 & $\$ 2.00$ & $5.30-2.00=\$ 3.30$ & $\begin{array}{l}\$ 0.25- \\
\$ 3.75\end{array}$ & $\$ 1.10$ & $\begin{array}{l}5.30-1.10=\$ 4.20 \\
\text { Extra profit compared to } \\
\text { hiring Flat Fee workers = } \\
4.20-3.30=90 \text { cents }\end{array}$ \\
\hline $\begin{array}{l}15 \\
\text { minutes + } \\
\text { Difficult } \\
\text { Tasks }\end{array}$ & 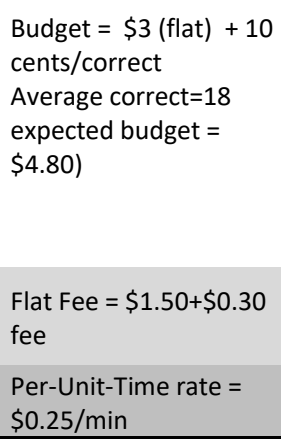 & $\$ 1.80$ & $4.80-1.80=\$ 3.00$ & $\begin{array}{l}\$ 0.25- \\
\$ 3.75\end{array}$ & $\$ 1.20$ & $\begin{array}{l}4.80-1.20=\$ 3.60 \\
\text { Extra profit compared to } \\
\text { hiring Flat Fee workers }= \\
3.60-3.00=60 \text { cents }\end{array}$ \\
\hline
\end{tabular}




\section{Online Appendix C: Additional Analyses}

\section{Study 1a, Phase 1}

Distribution of actual time taken by pre-minute workers (means indicated with red dots). In the 5-mins. condition, there were three workers who tool more time to complete the task than the time limit.

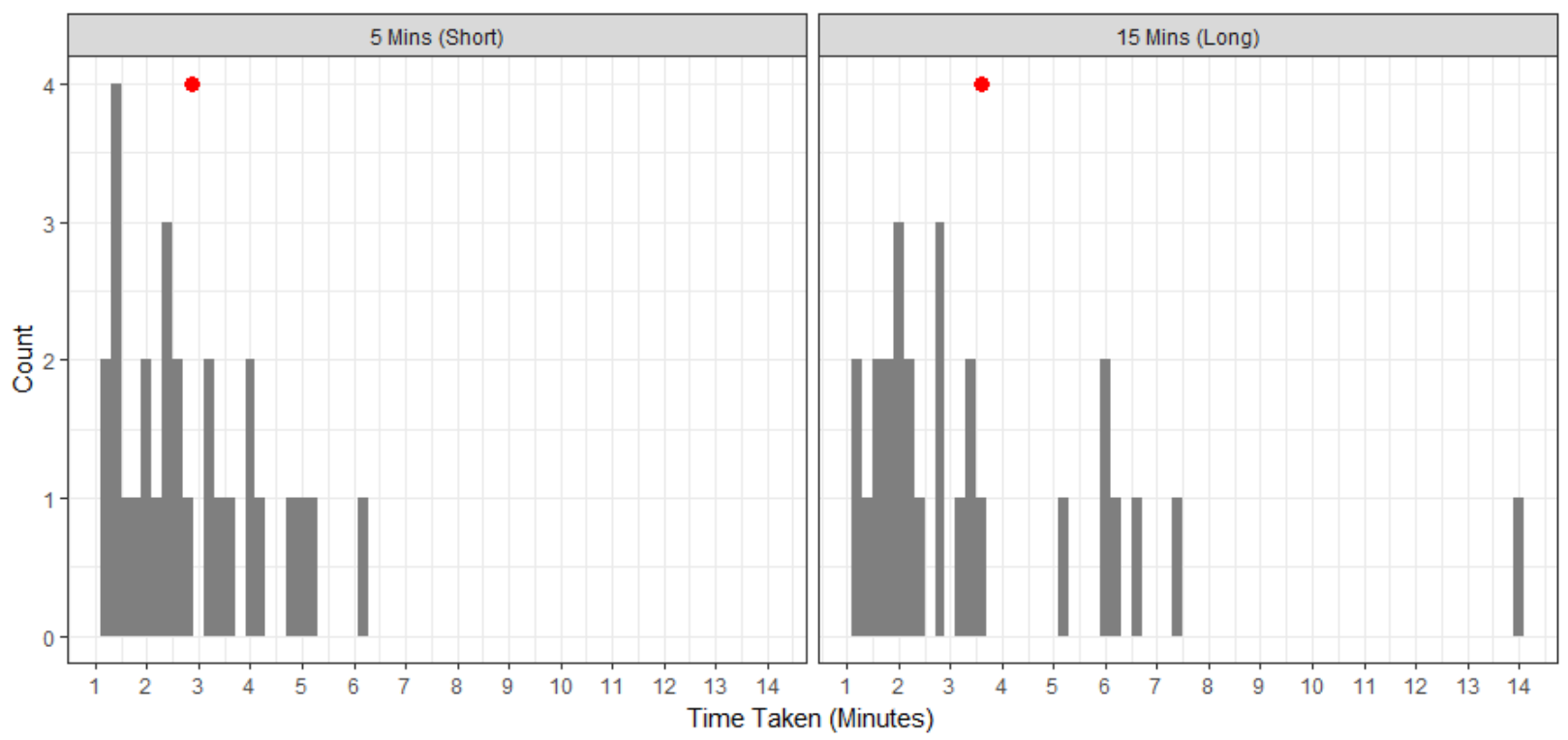

\section{Results without truncating time-taken for 3 workers:}

Three workers took over 5 minutes in the shorter time-limit condition, and their time taken was truncated to 5 minutes in the analysis reported in the paper. We find the same results without editing the data as shown here:

Workers took only a little longer to solve the puzzle when time limits were longer, a nonsignificant difference $\left(\mathrm{M}_{\text {Shorter }}=2.87\right.$ vs. $\left.\mathrm{M}_{\mathrm{Long}}=3.59, t(53)=1.23, p=.224\right)$. As a result, there was no significant difference in the workers' earnings between the two time limits; even though the workers with longer time limits could have earned more, if they had used all the available time. 


\section{Study 1a, Phase 2}

\section{Potential moderators (Managers' choices):}

Table 1: Moderation of Flat Fee Choices by Time Spent Reading Instructions

\begin{tabular}{lcccc}
\hline & $\beta$ & SE & $z$ & $p$ \\
\hline (Intercept) & 0.010 & 0.492 & 0.021 & 0.983 \\
Time Limit = 15 mins & 1.390 & 0.928 & 1.498 & 0.134 \\
Time Taken to Read Instructions & 0.0002 & 0.006 & 0.033 & 0.974 \\
Time Limit* Time Taken & 0.008 & 0.011 & 0.699 & 0.485 \\
\hline
\end{tabular}

$* * *<.001, * *<.01, *<.05$

Table 2: Moderation of Flat Fee Choices by Time Spent Making Choices

\begin{tabular}{lccccl}
\hline & $\beta$ & SE & $z$ & $p$ & \\
\hline (Intercept) & 0.612 & 0.541 & 1.130 & 0.259 & \\
Time Limit = 15 mins & 2.093 & 0.862 & 2.428 & 0.015 & $*$ \\
Time Taken to Make Choices & -0.005 & 0.005 & -1.180 & 0.238 & \\
Time Limit * Time Taken & 0.001 & 0.006 & 0.162 & 0.872 & \\
\hline
\end{tabular}

$* * *<.001, * *<.01, *<.05$

Table 3: Moderation of Flat Fee Choices by Time Spent Making Equivalent Gamble Choices

\begin{tabular}{lccccc}
\hline & $\beta$ & SE & $z$ & $p$ & \\
\hline (Intercept) & 0.040 & 0.401 & 0.100 & 0.920 & \\
Time Limit = 15 mins & 2.259 & 0.726 & 3.112 & 0.002 & $* *$ \\
Time Taken to Choose Gambles & -0.0005 & 0.011 & -0.046 & 0.963 & \\
Time Limit * Time Taken & -0.005 & 0.016 & -0.313 & 0.754 & \\
\hline
\end{tabular}

$* * *<.001, * *<.01, *<.05$

Table 4: Moderation of Flat Fee Choices by Depth of Processing (measured using CRT)

\begin{tabular}{lccccl}
\hline & $\beta$ & SE & $z$ & $p$ & \\
\hline (Intercept) & 0.325 & 0.358 & 0.909 & 0.363 & \\
Time Limit = 15 mins & 1.721 & 0.591 & 2.910 & 0.004 & $* *$ \\
CRT Score & -0.206 & 0.191 & -1.078 & 0.281 & \\
Time Limit * CRT Score & 0.236 & 0.355 & 0.663 & 0.507 & \\
\hline
\end{tabular}

$* * *<.001, * *<.01, *<.05$ 
Table 5: Moderation of Flat Fee Choices by Knowledge of Jigsaw Puzzles

\begin{tabular}{lcccc}
\hline & $\beta$ & SE & $z$ & $p$ \\
\hline (Intercept) & 1.727 & 0.910 & 1.898 & 0.058 \\
Time Limit = 15 mins & 0.352 & 1.600 & 0.220 & 0.826 \\
Knowledge of Jigsaw Puzzles & -0.539 & 0.279 & -1.931 & 0.054 \\
Time Limit * Knowledge & 0.539 & 0.496 & 1.086 & 0.278 \\
\hline$* * *<001 * *<01 * * 05$ & & & &
\end{tabular}

Table 6: Moderation of Flat Fee Choices by Frequency of Playing Jigsaw Puzzles (proxy for Experience)

\begin{tabular}{lcccc}
\hline & $\beta$ & $\mathrm{SE}$ & $\mathrm{z}$ & $\mathrm{p}$ \\
\hline (Intercept) & -1.245 & 1.036 & -1.202 & 0.229 \\
Time Limit = 15 mins & 1.873 & 1.563 & 1.198 & 0.231 \\
Frequency of playing Jigsaw & 0.502 & 0.400 & 1.255 & 0.209 \\
Time Limit * Frequency & 0.118 & 0.641 & 0.183 & 0.855 \\
\hline$* * *<001, * *<01, *<05$ & & & &
\end{tabular}

\section{Sensitivity of Relative Costs of Flat vs. Per-minute Fees on Managers' Choices:}

We investigate a boundary condition that moderates managers' choice of flat fees in the longer time-limit condition. In an additional pair of conditions $(n=83)$, we tested a flat fee of $\$ 3.00$ (i.e. doubling the cost of hiring flat fee workers) in the longer time-limit condition (with and without the additional $\$ 0.60$ recruiting fee), and found that only $29 \%$ of managers chose the flat fee, significantly less than the $89 \%$ reported above when the flat fee was lower $\left(\chi^{2}(1)=64.77, p<.001\right)$. In fact, comparing the choice of these costly flat fees in the longer time-limit condition with the choice of the regular-priced flat fees in the shorter time-limit condition (i.e., \$1 with and without the additional recruitment fee), we find that managers chose the costly flat fees significantly less in the longer time-limit condition ( $29 \%$ in longer time limit vs. $51 \%$ in shorter time limit, $\chi^{2}(1)=8.07, p=.004$ ) therefore essentially reversing the reported bias. This suggests that managers' choices were not based on a generalized preference for flat fee, but were instead based on approximately maximizing payoffs, conditional on their biased time estimates. 
Once the cost-disparity was high enough that the flat fee was less profitable even under their biased time estimates, managers showed a preference for per-minute compensation schemes. 


\section{Study 1b}

Mediation of the choice of flat fees by managers' estimated completion time for per-minute workers:

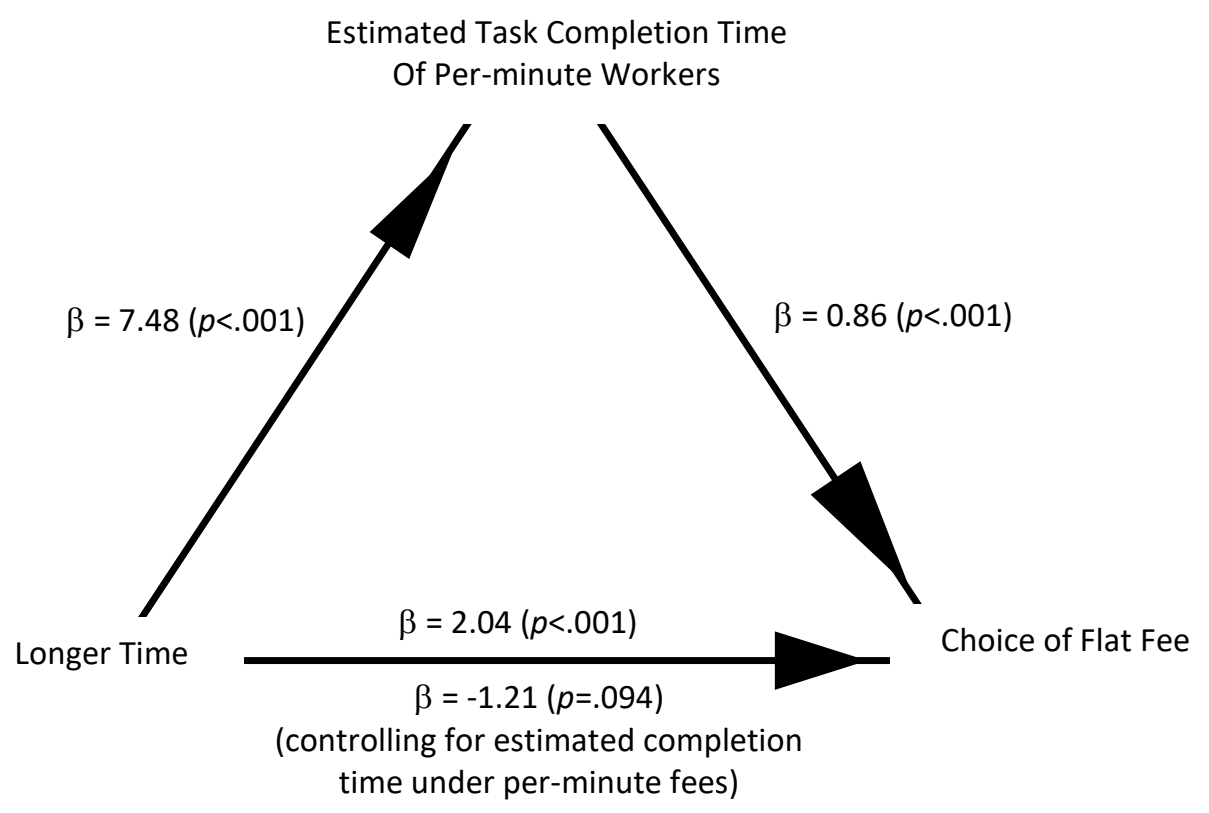

Potential moderators (Managers' choices):

Table 7: Moderation of Flat Fee Choices by Time Spent Reading Instructions

\begin{tabular}{lccccl}
\hline & $\beta$ & SE & $z$ & $p$ & \\
\hline (Intercept) & 0.514 & 0.336 & 1.531 & 0.126 & \\
Time Taken to Read Instructions & 0.003 & 0.003 & 0.999 & 0.318 & \\
Time Limit = 15 mins & 2.347 & 0.607 & 3.869 & $<.001$ & $* * *$ \\
Time Limit* Time Taken & -0.003 & 0.003 & -1.005 & 0.315 & \\
\hline
\end{tabular}

$* * *<.001, * *<.01, *<.05$

Table 8: Moderation of Flat Fee Choices by Time Spent Making Choices

\begin{tabular}{lccccl}
\hline & $\beta$ & SE & $z$ & $p$ & \\
\hline (Intercept) & 0.319 & 0.476 & 0.669 & 0.503 & \\
Time Taken to Make Choices & 0.005 & 0.005 & 1.050 & 0.294 & \\
Time Limit $=15$ mins & 4.278 & 1.083 & 3.950 & $<.001$ & $* * *$ \\
Time Limit $*$ Time Taken & -0.019 & 0.008 & -2.513 & 0.012 & $*$ \\
\hline$* * *<.001, * *<.01, *<.05$ & & & & &
\end{tabular}

The interaction from the regression in Table 14 is shown below. As the time taken to make choices increased, the choice of flat fees decreased when time limits were longer, but not when time limits were 
shorter. While significant in this study, we did not consistently replicate this pattern of results in the other studies that captured time taken.

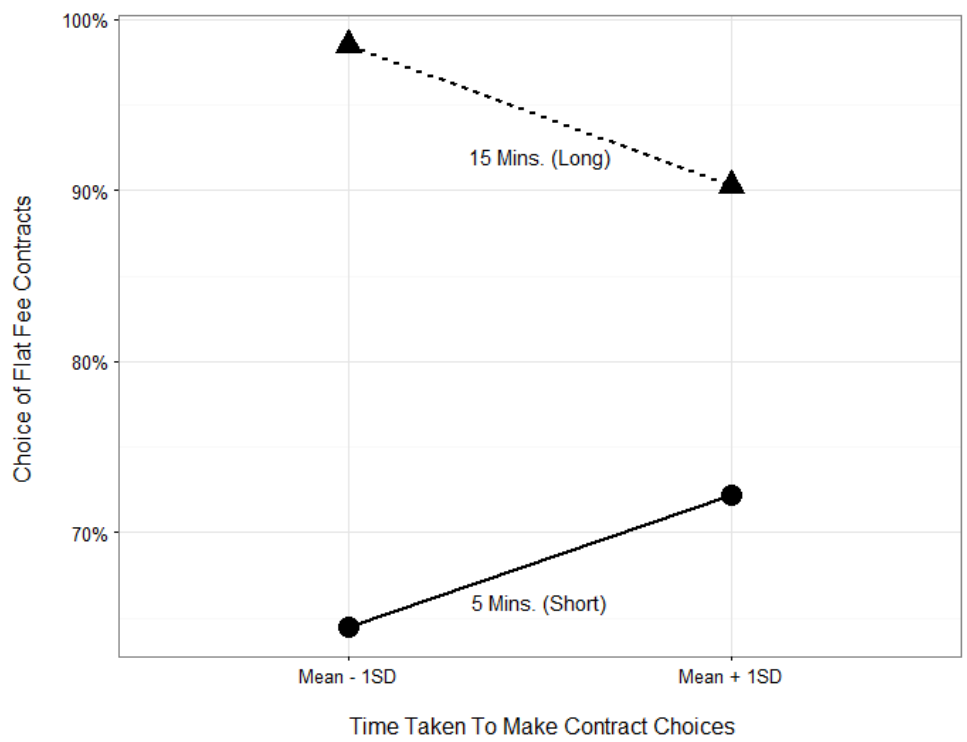

Table 9: Moderation of Flat Fee Choices by Time Spent Making Equivalent Gamble Choices

\begin{tabular}{lccccc}
\hline & $\beta$ & SE & $z$ & $p$ & \\
\hline (Intercept) & 0.205 & 0.419 & 0.489 & 0.625 & \\
Time Taken to Choose Gambles & 0.025 & 0.017 & 1.514 & 0.130 & \\
Time Limit = 15 mins & 2.514 & 0.734 & 3.423 & 0.001 & $* * *$ \\
Time Limit * Time Taken & -0.022 & 0.022 & -1.022 & 0.307 & \\
\hline
\end{tabular}

$* * *<.001, * *<.01, *<.05$

Table 10: Moderation of Flat Fee Choices by Depth of Processing (measured using CRT)

\begin{tabular}{lccccl}
\hline & $\beta$ & SE & $z$ & $p$ & \\
\hline (Intercept) & 0.511 & 0.387 & 1.321 & 0.186 & \\
CRT Score & 0.166 & 0.198 & 0.839 & 0.402 & \\
Time Limit = 15 mins & 2.095 & 0.875 & 2.394 & 0.017 & $*$ \\
Time Limit * CRT Score & -0.038 & 0.442 & -0.087 & 0.931 & \\
\hline
\end{tabular}

$* * *<.001, * *<.01, *<.05$

Table 11: Moderation of Flat Fee Choices by Knowledge of Jigsaw Puzzles

\begin{tabular}{lcccc}
\hline & $\beta$ & $\mathrm{SE}$ & $\mathrm{z}$ & $\mathrm{p}$ \\
\hline (Intercept) & 0.180 & 0.788 & 0.229 & 0.819
\end{tabular}




\begin{tabular}{lccccc} 
Knowledge of Jigsaw Puzzles & 0.196 & 0.250 & 0.786 & 0.432 & \\
Time Limit $=15$ mins & 4.284 & 1.908 & 2.245 & 0.025 & $*$ \\
Time Limit * Knowledge & -0.715 & 0.556 & -1.285 & 0.199 & \\
\hline
\end{tabular}

Table 12: Moderation of Flat Fee Choices by Frequency of Playing Jigsaw Puzzles (proxy for Experience)

\begin{tabular}{lcccc}
\hline & $\beta$ & $\mathrm{SE}$ & $\mathrm{z}$ & $\mathrm{p}$ \\
\hline (Intercept) & 1.063 & 0.774 & 1.374 & 0.170 \\
Frequency of playing Jigsaw & -0.121 & 0.312 & -0.387 & 0.699 \\
Time Limit = 15 mins & 1.247 & 1.717 & 0.726 & 0.468 \\
Time Limit * Frequency & 0.347 & 0.732 & 0.475 & 0.635 \\
\hline
\end{tabular}

$* * *<.001, * *<.01, *<.05$

\section{Results with Only Managers Who Passed the Comprehension Check (Robustness Check):}

In Study 1b, managers were informed about the two time limits and told that workers were randomly assigned to one of the conditions. This was done to eliminate any information inferred from a particular time limit condition. To ensure that this aspect of the experimental design worked as expected, we confirmed that managers understood that workers were randomly assigned to one of two possible time limits. In this analysis, we examine the robustness of our finding by limiting the analysis to only managers who passed the comprehension check conducted after the key dependent measures were recorded.

Eighty-four percent of the participants $(\mathrm{N}=150)$ in the study, acting as managers, understood that workers were randomly assigned to one of two time-limit conditions. In the analysis below, we use only use these managers who passed the manipulation check to examine robustness of the reported results.

Managers were more likely to choose flat fee in the longer time-limit condition than in the shorter time-limit condition $\left(93 \%\right.$ vs. $\left.72 \%, \chi^{2}(1)=11.40, p<.001\right)$. These choices were costly and resulted in directionally higher losses, and more so in the longer time-limit condition ( $\square$ Longer time limit $=\$ 0.35$, $\square$ Shorter time limit $=\$ 0.08 ; t(24)=1.55, p=.134)$. Managers who choose a flat fee estimated a longer completion time 
for per-minute workers for shorter time limits $\left(\mathrm{M}_{\text {Chose Flat Fee }}=4.76\right.$ vs. $\mathrm{M}_{\text {Chose Per-minute Fee }}=2.71$;

$t(74)=13.96, p<.001)$ and even more so for longer time limits $\left(\mathrm{M}_{\text {Chose Flat Fee }}=12.16\right.$ vs. $\mathrm{M}_{\text {Chose Per-minute Fee }}$ $=7.60 ; t(72)=2.93, p=.004$; difference $F(1,146)=3.93, p=.049)$. Most managers' choices were consistent with their estimated times (97\% of in the shorter time-limit condition; $90 \%$ in the longer time-limit condition), and the estimated time for per-minute workers mediated the effect of deadlines on compensation scheme choices (indirect effect bootstrapped 95\% CI= $[0.36,0.79]$ ).

Contrary to a risk aversion explanation, managers were more likely to choose the flat fee than the certain outcome in the equivalent gamble, in both the longer time limit (93\% vs. $57 \%$, McNemar's $\chi^{2}(1)=$ $23.52, p<.001)$ and shorter time-limit conditions ( $72 \%$ vs. 46\%, McNemar's $\left.\chi^{2}(1)=12.50, p<.001\right)$. Likewise, CRT and knowledge of or experience with jigsaw puzzles did not moderate the results.

Therefore, we successfully replicated all the results reported in the paper using only those managers who passed the comprehension check. This further suggests that the observed preference for flat fees in the longer (vs. the shorter) time-limit condition was not on account of any information conveyed through the externally imposed time limits. 


\section{Study 2 (Phase 1):}

\section{Distribution of actual time taken by workers}

Easy Proofreading Task (means indicated with red dots)
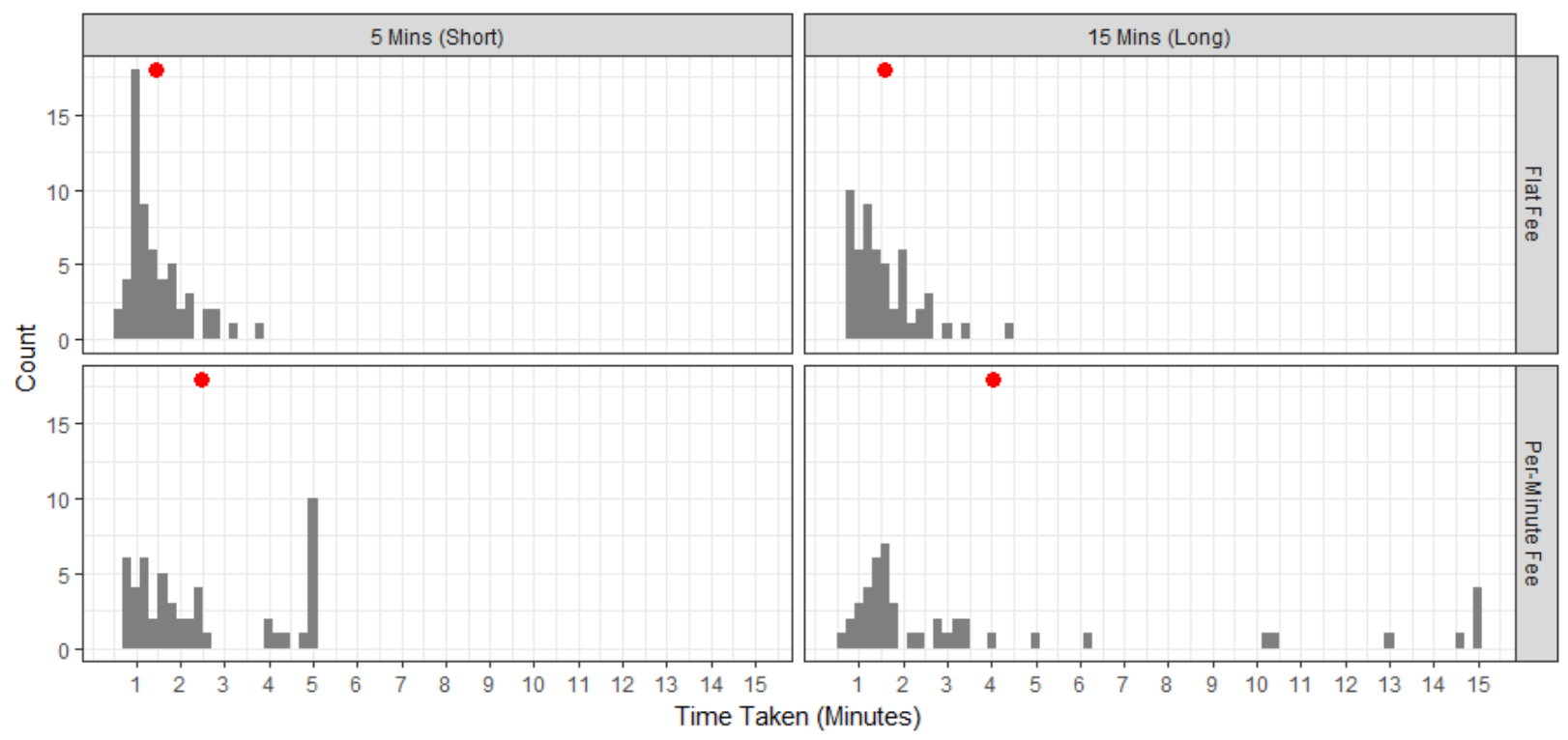

Hard Proofreading Task (means indicated with red dots)
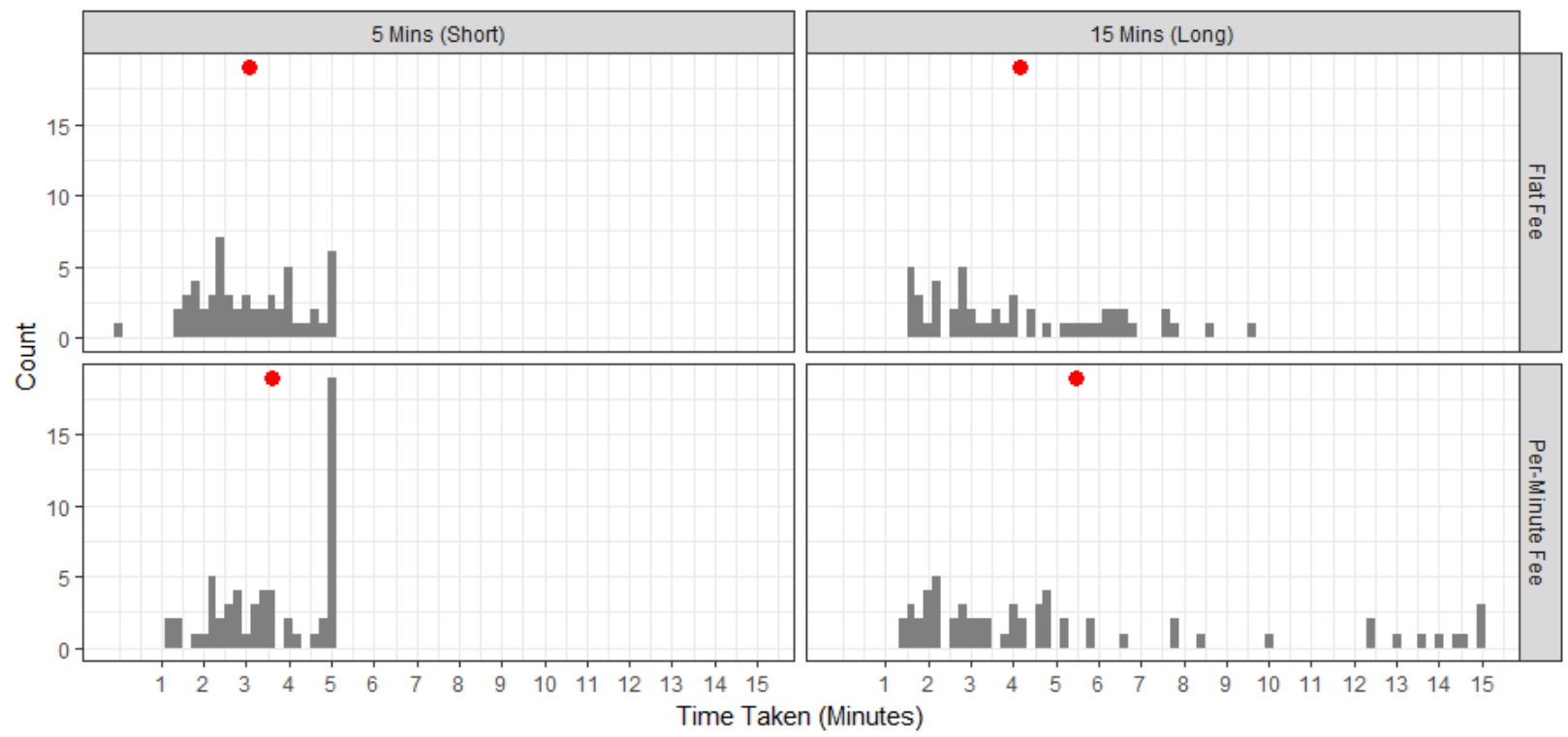
Study 2 (Phase 2):

Mediation of the choice of flat fees by managers' estimated completion time for per-minute workers:

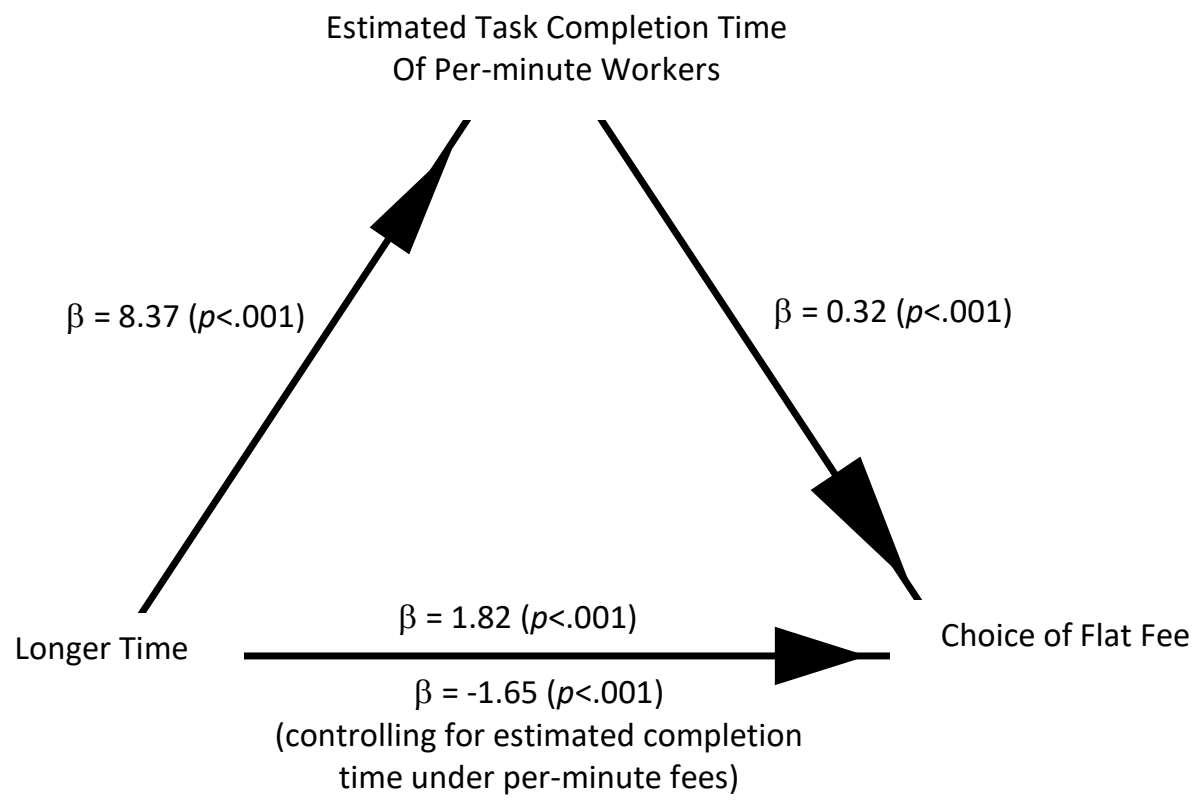

Potential moderators ((Managers' choices):

Table 13: Moderation of Flat Fee Choices by Time Spent Reading Instructions

\begin{tabular}{lccccl}
\hline & $\beta$ & SE & $z$ & $p$ & \\
\hline (Intercept) & -0.417 & 0.176 & -2.370 & 0.018 & \\
Time Limit = 15 mins & 1.548 & 0.385 & 4.020 & $<.001$ & $* * *$ \\
Time Taken to Read Instructions & 0.003 & 0.002 & 1.330 & 0.182 & \\
Time Limit * Time Taken & 0.007 & 0.007 & 1.000 & 0.319 & \\
\hline
\end{tabular}

$* * *<.001, * *<.01, *<.05$

Table 14: Moderation of Flat Fee Choices by Time Spent Making Choices

\begin{tabular}{lccccl}
\hline & $\beta$ & $\mathrm{SE}$ & $\mathrm{z}$ & $\mathrm{p}$ & \\
\hline (Intercept) & -0.054 & 0.242 & -0.220 & 0.823 & \\
Time Limit = 15 mins & 1.619 & 0.434 & 3.730 & $<.001$ & $* * *$ \\
Time Taken to Make Choices & -0.002 & 0.002 & -0.950 & 0.340 & \\
Time Limit * Time Taken & 0.002 & 0.004 & 0.570 & 0.567 & \\
\hline
\end{tabular}

$* * *<.001, * *<.01, *<.05$ 
Table 15: Moderation of Flat Fee Choices by Time Spent Making Equivalent Gamble Choices

\begin{tabular}{lccccc}
\hline & $\beta$ & SE & $z$ & $p$ & \\
\hline (Intercept) & -0.264 & 0.210 & -1.250 & 0.210 & \\
Time Limit = 15 mins & 1.239 & 0.394 & 3.140 & 0.002 & $* *$ \\
Time Taken to Choose Gambles & 0.00003 & 0.004 & 0.080 & 0.938 & \\
Time Limit * Time Taken & 0.017 & 0.009 & 1.770 & 0.076 & \\
\hline
\end{tabular}

$* * *<.001, * *<.01, *<.05$

Table 16: Moderation of Flat Fee Choices by Knowledge about English Spelling

\begin{tabular}{lcccc}
\hline & $\beta$ & SE & $z$ & $p$ \\
\hline (Intercept) & 0.445 & 0.601 & 0.740 & 0.459 \\
Time Limit = 15 mins & 1.795 & 1.036 & 1.730 & 0.083 \\
Knowledge of Jigsaw Puzzles & -0.185 & 0.156 & -1.190 & 0.235 \\
Time Limit * Knowledge & 0.014 & 0.259 & 0.050 & 0.958
\end{tabular}

$* * *<.001, * *<.01, *<.05$

Table 17: Moderation of Flat Fee Choices by Frequency of Doing Proofreading Tasks (proxy for Experience)

\begin{tabular}{lccccc}
\hline & $\beta$ & SE & $z$ & $p$ & \\
\hline (Intercept) & -0.962 & 0.496 & -1.940 & 0.052 & \\
Time Limit = 15 mins & 2.481 & 0.851 & 2.910 & 0.004 & $* *$ \\
Frequency of playing Jigsaw & 0.254 & 0.170 & 1.500 & 0.135 & \\
Time Limit * Frequency & -0.238 & 0.290 & -0.820 & 0.413 & \\
\hline
\end{tabular}

$* * *<.001, * *<.01, *<.05$ 


\section{Study 3:}

Mid-point tests of follow-up measures

\begin{tabular}{|l|c|l|}
\hline Measures & Mean* & Results $(\mathbf{v s} . \mathbf{m}=\mathbf{0})$ \\
\hline Task assigned to 15-mins more difficult & -0.314 & $t(139)=2.35, p=0.019$ \\
\hline Task assigned to 15-mins more interesting and enjoyable & 0.100 & $t(139)=0.807, p=0.421$ \\
\hline Task assigned to 15-mins more motivating to achieve & 0.085 & $t(139)=0.607, p=0.544$ \\
\hline
\end{tabular}

* positive values indicate that the task assigned to 15 minutes was perceived to have more of the corresponding measure

The mid-point test results show that judges perceived the task assigned to a 5-minutes (vs. 15minutes) time limit as more difficult. Perceptions of task difficult could be a valid input into beliefs about task scope in which case we should have expected to see a higher value of this measure for the task assigned to 15 minutes. Indeed, as reported in the manuscript, when task scope was directly elicited (e.g., "how much work is there in Task 1") using a slider (1= a little work; 100= a lot of work), managers reported a significantly higher perceived scope of work for the task that was assigned a random time limit of 15 minutes $\left(\mathrm{M}_{5}=60.32\right.$ vs. $\mathrm{M}_{15}=65.54$; paired $\left.t(139)=3.01, p=.003\right)$, which was consistent with inferring the scope of work from the deadline.

The above inconsistency might have arisen because the shorter time limit could have drawn participants' attention to ways in which completing a Math task under a demanding deadline would be challenging, beyond the scope. In particular, participants might have thought that working under a shorter deadline would entail working harder and require more effort to meet the deadline, even for a task with less scope (e.g., the perceived amount of work in the task).

Table 18: Effect of the order of Time Limits in W/S choice of compensation schemes

\begin{tabular}{lccccl}
\hline & $\beta$ & SE & $z$ & $p$ & \\
\hline (Intercept) & 0.871 & 0.277 & 3.148 & 0.002 & \\
Time Limit = 15 mins & 0.707 & 0.406 & 1.740 & 0.082 & \\
First Time Limit = 15 mins & -0.902 & 0.376 & -2.399 & 0.016 & $*$ \\
Time Limit * First Time Limit & 0.894 & 0.579 & 1.544 & 0.123 & \\
\hline
\end{tabular}

$* * *<.001, * *<.01, *<.05$

Table 19: Effect of the order of which Task (Task 1 or Task 2) was assigned to Shorter vs. Longer time limit

\begin{tabular}{lccccl}
\hline & $\beta$ & SE & $z$ & $p$ & \\
\hline (Intercept) & 0.572 & 0.255 & 2.248 & 0.025 & \\
Time Limit = 15 mins & 1.016 & 0.400 & 2.539 & 0.011 & $*$ \\
Task with 5 mins = Task 2 & -0.320 & 0.358 & -0.895 & 0.371 & \\
Time Limit * Task with 5 mins & 0.278 & 0.569 & 0.490 & 0.624 & \\
\hline
\end{tabular}

$* * *<.001, * *<.01, *<.05$ 
Table 20: Moderation of Flat Fee Choices by beliefs about whether Task with 15-mins took longer to complete

\begin{tabular}{lccccc}
\hline & $\beta$ & SE & $z$ & $p$ & \\
\hline (Intercept) & 0.375 & 0.197 & 1.904 & 0.057 & \\
Time Limit = 15 mins & 1.166 & 0.319 & 3.653 & $<.001$ & $* * *$ \\
Took more time in 15-mins & 0.066 & 0.117 & 0.563 & 0.573 & \\
Time Limit * Took more time & -0.024 & 0.185 & -0.132 & 0.895 & \\
\hline
\end{tabular}

$* * *<.001, * *<.01, *<.05$

Table 21: Moderation of Flat Fee Choices by beliefs about whether workers worked slower on the Task with 15-mins

\begin{tabular}{lccccc}
\hline & $\beta$ & SE & $z$ & $p$ & \\
\hline (Intercept) & 0.321 & 0.202 & 1.584 & 0.113 & \\
Time Limit = 15 mins & 1.049 & 0.318 & 3.300 & 0.001 & $* *$ \\
Workers slow in 15-min-Task & 0.096 & 0.101 & 0.945 & 0.345 & \\
Time Limit * Workers slow & 0.139 & 0.161 & 0.860 & 0.390 & \\
\hline
\end{tabular}

$* * *<.001, * *<.01, *<.05$

Table 22: Moderation of Flat Fee Choices by beliefs about whether workers found Task with 15-mins more difficult

\begin{tabular}{lccccc}
\hline & $\beta$ & SE & $z$ & $p$ & \\
\hline (Intercept) & 0.467 & 0.190 & 2.452 & 0.014 & \\
Time Limit = 15 mins & 1.089 & 0.300 & 3.626 & $<.001$ & $* * *$ \\
Task difficult in 15 mins & 0.131 & 0.116 & 1.132 & 0.258 & \\
Time Limit * Task difficult & -0.210 & 0.183 & -1.145 & 0.252 & \\
\hline
\end{tabular}

$* * *<.001, * *<.01, *<.05$

Table 23: Moderation of Flat Fee Choices by beliefs about whether workers found Task with 15-mins more interesting and enjoyable

\begin{tabular}{lccccl}
\hline & $\beta$ & SE & $\mathrm{z}$ & $\mathrm{p}$ & \\
\hline (Intercept) & 0.409 & 0.183 & 2.228 & 0.026 & \\
Time Limit = 15 mins & 1.167 & 0.299 & 3.904 & $<.001$ & $* * *$ \\
Task interesting in 15 mins & 0.154 & 0.124 & 1.237 & 0.216 & \\
Time Limit* Task interesting & -0.189 & 0.195 & -0.967 & 0.334 & \\
\hline
\end{tabular}

$* * *<.001, * *<.01, *<.05$ 
Table 24: Moderation of Flat Fee Choices by beliefs about whether workers found Task with 15-mins more motivating to achieve

\begin{tabular}{lccccc}
\hline & $\beta$ & SE & $z$ & $p$ & \\
\hline (Intercept) & 0.413 & 0.184 & 2.243 & 0.025 & \\
Time Limit = 15 mins & 1.164 & 0.299 & 3.896 & $<.001$ & $* * *$ \\
Task motivating in 15 mins & 0.156 & 0.110 & 1.413 & 0.158 & \\
Time Limit * Task motivating & -0.189 & 0.173 & -1.094 & 0.274 & \\
\hline
\end{tabular}

$* * *<.001, * *<.01, *<.05$

Table 25: Moderation of Flat Fee Choices by beliefs about Task scope $(1=$ a little work; $100=$ a lot of work).

\begin{tabular}{lcccc}
\hline & $\beta$ & SE & $z$ & $p$ \\
\hline (Intercept) & 0.008 & 0.537 & 0.014 & 0.988 \\
Time Limit = 15 mins & 0.882 & 0.880 & 1.002 & 0.316 \\
Task scope & 0.007 & 0.008 & 0.802 & 0.422 \\
Time Limit * Task scope & 0.004 & 0.014 & 0.264 & 0.792 \\
\hline
\end{tabular}

$* * *<.001, * *<.01, *<.05$

Table 26: Moderation of Flat Fee Choices by beliefs about whether workers would slack (No, Yes)

\begin{tabular}{lcccc}
\hline & $\beta$ & SE & $z$ & $p$ \\
\hline (Intercept) & 0.172 & 0.240 & 0.716 & 0.474 \\
Time Limit = 15 mins & 0.927 & 0.474 & 1.957 & 0.050 \\
Worried about slacking=Yes & 0.375 & 0.360 & 1.042 & 0.298 \\
Time Limit * Worried & 0.354 & 0.616 & 0.574 & 0.566 \\
\hline
\end{tabular}

$* * *<.001, * *<.01, *<.05$

Table 27: Moderation of Flat Fee Choices by individual differences in managers' Perspective Taking scores (Davis, 1983)

\begin{tabular}{lcccc}
\hline & $\beta$ & SE & $z$ & $p$ \\
\hline (Intercept) & 0.690 & 0.605 & 1.141 & 0.254 \\
Time Limit = 15 mins & 0.776 & 0.947 & 0.820 & 0.412 \\
Perspective Taking & -0.104 & 0.220 & -0.472 & 0.637 \\
Time Limit * Perspective Taking & 0.144 & 0.349 & 0.414 & 0.679 \\
\hline
\end{tabular}

$* * *<.001, * *<.01, *<.05$ 


\section{Examining mediation using bootstrapping:}

Approach: The bootstrapping code runs the following models for 500 times and computes $\left(b-b^{\prime}\right)$ in each iteration. This difference in coefs. are saved and sorted to compute the $95 \%$ CI. Hierarchical regressions are used in all cases, and $X$ donotes the covariate whose mediating effect is being studied

Base model: compensation scheme choice $=a_{0}+b *$ Time Limit

Mediation model: compensation scheme choice $=a_{1}+b^{\prime} *$ Time Limit $+c * X$

The table shows the $95 \%$ CI for each of the mediating covariates.

\begin{tabular}{|l|c|}
\hline Mediating Covariate & Indirect Effect (bootstrapped 95\% CI) \\
\hline $\begin{array}{l}\text { beliefs about whether Task with 15-mins took } \\
\text { longer to complete }\end{array}$ & {$[-0.264,0.168]$} \\
\hline $\begin{array}{l}\text { beliefs about whether workers intentionally } \\
\text { worked slower on the Task with 15-mins }\end{array}$ & {$[-0.202,0.323]$} \\
\hline $\begin{array}{l}\text { beliefs about whether workers found Task } \\
\text { with 15-mins more difficult }\end{array}$ & {$[-0.020,0.151]$} \\
\hline $\begin{array}{l}\text { beliefs about whether workers found Task } \\
\text { with 15-mins more interesting and enjoyable }\end{array}$ & {$[-0.107,0.011]$} \\
\hline $\begin{array}{l}\text { beliefs about whether workers found Task } \\
\text { with 15-mins more motivating to achieve }\end{array}$ & {$[-0.121,0.015]$} \\
\hline $\begin{array}{l}\text { beliefs about Task scope } \\
\text { beliefs about whether workers would slack }\end{array}$ & {$[-0.024,0.115]$} \\
\hline
\end{tabular}




\section{Study 4 (Phase 1):}

Distribution of actual time taken by workers (the mean is indicated with a red dot)

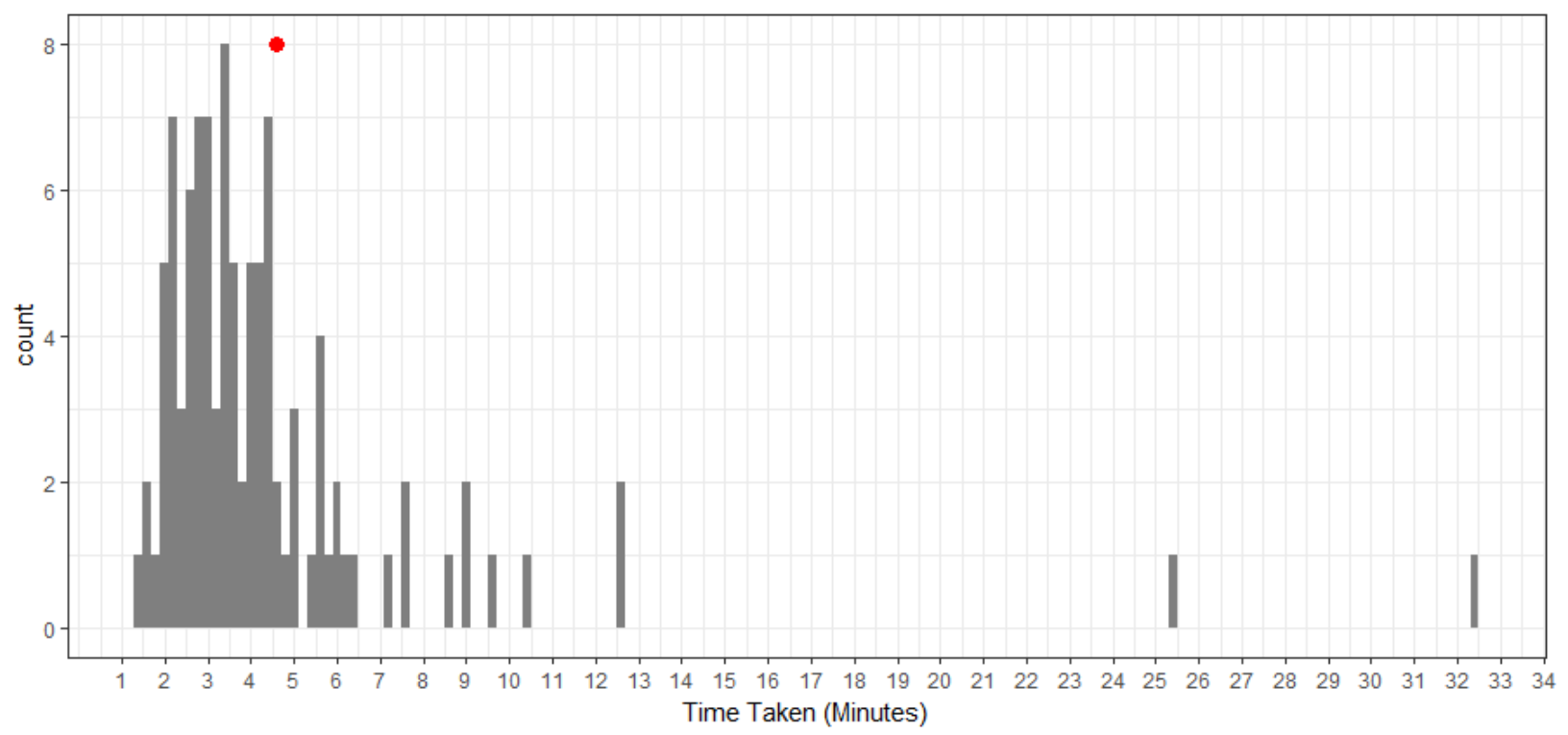

Study 4 (Phase 2)

Mediation of the choice of flat fees by managers' estimated completion time for per-minute workers:

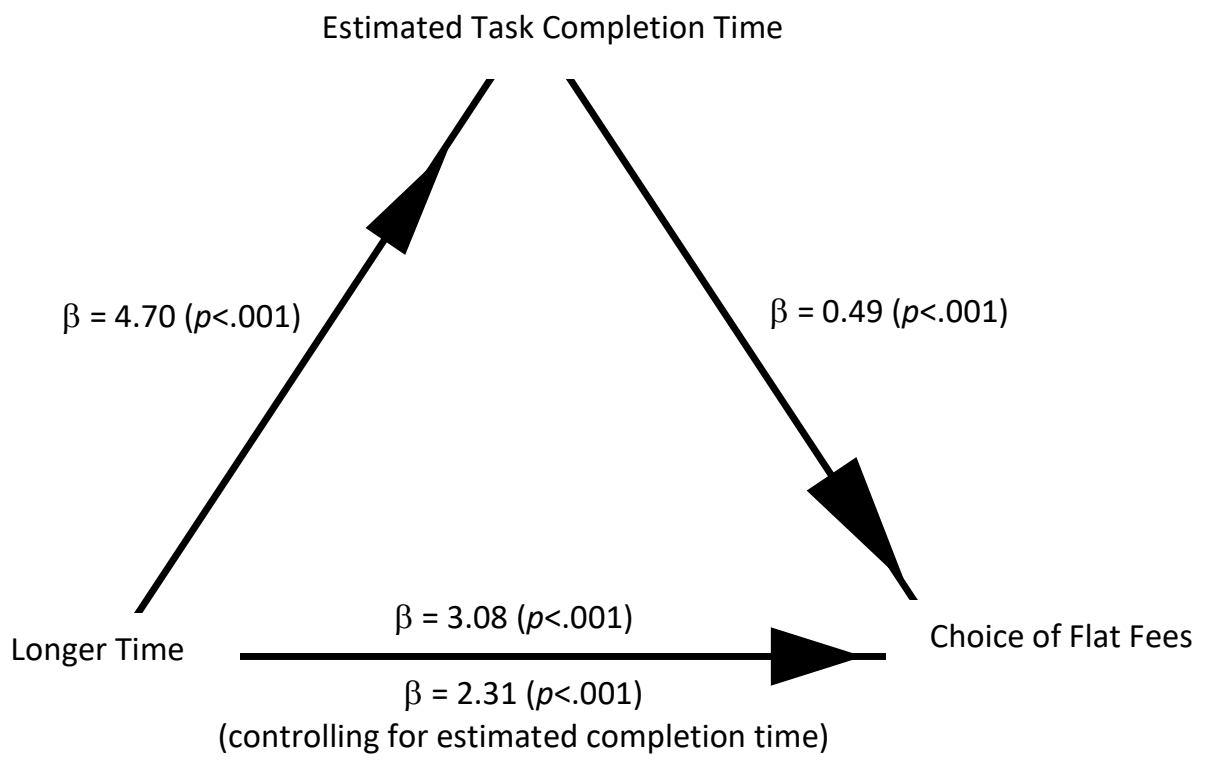


Same mediation model as above, but only using managers who made completion time estimates before choosing compensation schemes:

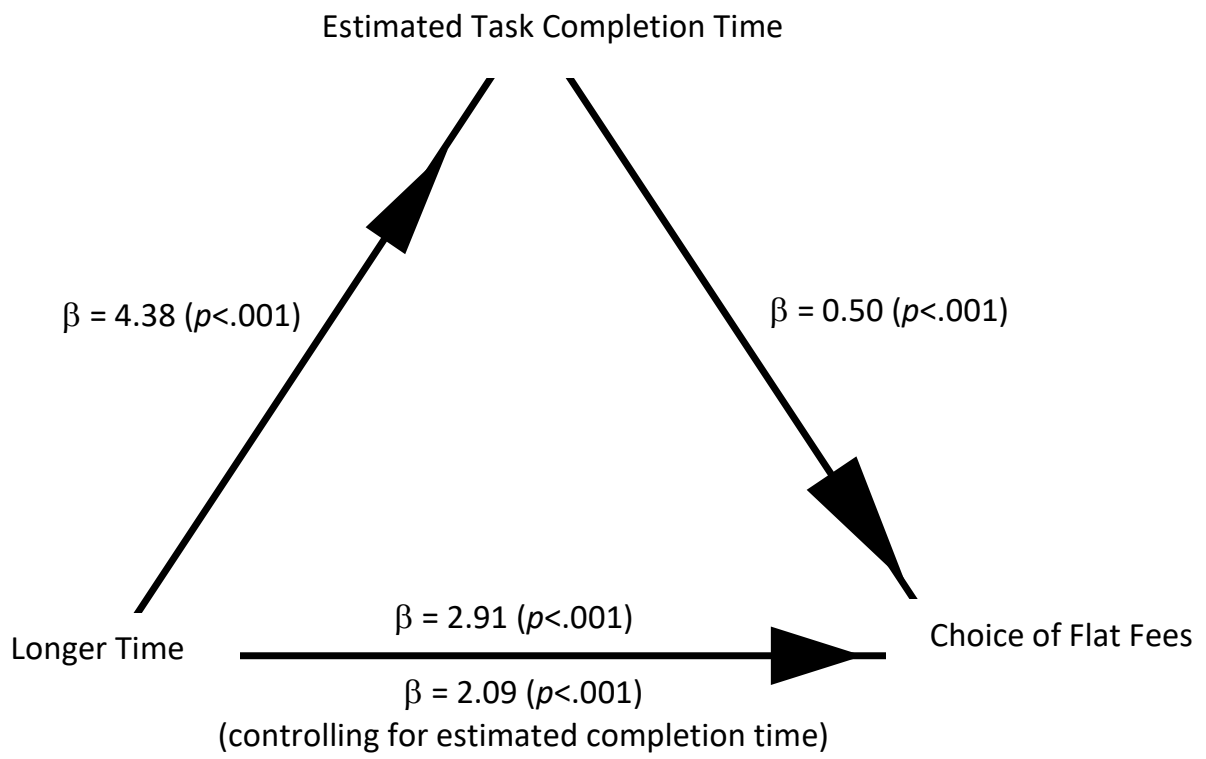

Examining the potential moderating role of order of elicitation of completion time estimates (i.e., before vs. after choice of compensation schemes) on choice of flat fee (DV: workers' completion time estimates)

Table 28: Effect of the order of elicitation in 5-mins, version 1 condition

\begin{tabular}{lcccc}
\hline & $\beta$ & $\mathrm{SE}$ & $\mathrm{z}$ & $\mathrm{p}$ \\
\hline (Intercept) & 3.233 & 0.316 & 10.231 & $<.001$ \\
Choice of Flat fee & 0.910 & 0.727 & 1.252 & 0.215 \\
Choice LATER & 0.338 & 0.493 & 0.686 & 0.495 \\
Choice of Flat fee * Choice LATER & 1.119 & 0.985 & 1.136 & 0.260 \\
\hline
\end{tabular}

$* * *<.001, * *<.01, *<.05$

Table 29: Effect of the order of elicitation in 5-mins, version 2 condition

\begin{tabular}{lcccc}
\hline & $\beta$ & $\mathrm{SE}$ & $\mathrm{z}$ & $\mathrm{p}$ \\
\hline (Intercept) & 4.409 & 0.587 & 7.514 & $<.001$ \\
Choice of Flat fee & 0.091 & 0.904 & 0.101 & 0.920 \\
Choice LATER & -1.201 & 0.812 & -1.478 & 0.144 \\
Choice of Flat fee * Choice LATER & 2.117 & 1.328 & 1.594 & 0.115 \\
\hline
\end{tabular}

$* * *<.001, * *<.01, *<.05$ 
Table 30: Effect of the order of elicitation in 5-mins condition (combined)

\begin{tabular}{lcccc}
\hline & $\beta$ & SE & $z$ & $p$ \\
\hline (Intercept) & 3.731 & 0.322 & 11.604 & $<.001$ \\
Choice of Flat fee & 0.661 & 0.581 & 1.138 & 0.257 \\
Choice LATER & -0.353 & 0.472 & -0.748 & 0.456 \\
Choice of Flat fee * Choice LATER & 1.462 & 0.837 & 1.746 & 0.083 \\
\hline
\end{tabular}

$* * *<.001, * *<.01, *<.05$

Table 31: Effect of the order of elicitation in 15-mins condition

\begin{tabular}{lcccc}
\hline & $\beta$ & SE & $z$ & $p$ \\
\hline (Intercept) & 5.400 & 2.033 & 2.656 & 0.009 \\
Choice of Flat fee & 3.900 & 2.116 & 1.843 & 0.067 \\
Choice LATER & 1.600 & 2.592 & 0.617 & 0.538 \\
Choice of Flat fee * Choice LATER & -2.275 & 2.711 & -0.839 & 0.403 \\
\hline
\end{tabular}

$* * *<.001, * *<.01, *<.05$

Other Potential moderators (on Managers' choices):

Table 32: Moderation of Flat Fee Choices by Time Spent Reading Instructions

\begin{tabular}{lccccl}
\hline & $\beta$ & $\mathrm{SE}$ & $\mathrm{z}$ & $\mathrm{p}$ & \\
\hline (Intercept) & -0.846 & 0.211 & -4.020 & $<.001$ & \\
Time Limit = 15 mins & 2.832 & 0.503 & 5.633 & $<.001$ & $* * *$ \\
Time Taken to Read Instructions & 0.0003 & 0.000 & 0.730 & 0.466 & \\
Time Limit * Time Taken & 0.001 & 0.002 & 0.648 & 0.517 & \\
\hline
\end{tabular}

$* * *<.001, * *<.01, *<.05$

Table 33: Moderation of Flat Fee Choices by Time Spent Making Choices

\begin{tabular}{lccccl}
\hline & $\beta$ & SE & $z$ & $p$ & \\
\hline (Intercept) & -0.866 & 0.245 & -3.535 & $<.001$ & \\
Time Limit = 15 mins & 2.857 & 0.488 & 5.849 & $<.001$ & $* * *$ \\
Time Taken to Make Choices & 0.003 & 0.005 & 0.598 & 0.550 & \\
Time Limit * Time Taken & 0.010 & 0.016 & 0.657 & 0.511 & \\
\hline
\end{tabular}

$* * *<.001, * *<.01, *<.05$ 
Table 34: Moderation of Flat Fee Choices by Time Spent Making Equivalent Employment Gamble Choices

\begin{tabular}{lccccl}
\hline & $\beta$ & SE & $z$ & $p$ & \\
\hline (Intercept) & -0.273 & 0.337 & -0.811 & 0.417 & \\
Time Limit = 15 mins & 2.338 & 0.586 & 3.992 & $<.001$ & $* * *$ \\
Time Taken to Choose Gambles & -0.019 & 0.012 & -1.616 & 0.106 & \\
Time Limit * Time Taken & 0.025 & 0.016 & 1.601 & 0.109 & \\
\hline
\end{tabular}

Table 35: Moderation of Flat Fee Choices by Gender

\begin{tabular}{lccccc}
\hline & $\beta$ & SE & $z$ & $p$ & \\
\hline (Intercept) & -0.719 & 0.280 & -2.570 & 0.010 & \\
Time Limit = 15 mins & 2.871 & 0.549 & 5.228 & $<.001$ & $* * *$ \\
Gender=Male & -0.048 & 0.367 & -0.131 & 0.896 & \\
Time Limit* Gender=Male & 0.306 & 0.703 & 0.435 & 0.664 & \\
\hline
\end{tabular}

$* * *<.001, * *<.01, *<.05$

\section{Results with Only Managers Who Passed the Recall Check that all Workers were paid a Flat Fee (Robustness Check):}

In Study 4, managers were accurately informed that all workers earned a flat fee from the agency. This was done to eliminate any concerns about some workers' delaying task completion to earn more. After managers indicated their compensation scheme choice and estimated the time they believed workers took to finish the math task (counter-balanced), we asked managers a recall question to confirm their understanding (e.g., how did the agency pay the workers: all were paid a fixed amount, some were paid fixed others a variable amount, don't know/can't say). Of the managers who indicated they knew the answer to this question, 63\% (N=166) correctly recalled that all workers were paid a fixed amount. In the analysis below, we use only use the managers who passed this manipulation check to examine robustness of the reported results.

Preference for flat fees differed across the three experimental conditions $\left(\chi^{2}(2)=64.29, p<.001\right)$. In the two shorter time-limit conditions, fewer participants chose the flat fee than the per-minute fee, at similar rates $\left(24 \%\right.$ and $\left.36 \% ; \chi^{2}(1)=1.61, p=.205\right)$. In contrast, when the time limit was longer, an 
overwhelming majority (90\%) of managers chose the sub-optimal flat-fee option, and this rate of choosing flat fees was significantly higher than in the two shorter time-limit conditions $\left(\chi^{2}(1)=62.88\right.$, $p<.001)$. Taken together, the pattern of choices rules out an aversion to complexity account. In particular, if the preference for flat fees was driven by a motivation to avoid the cognitive cost of processing the metered-fee option when the sure bonus amount was high, the proportion of flat fee choices should have been similar in the version of the shorter time limit and the longer time limit that had the same high expected sure bonus amount (i.e., \$4.25). However, these proportions were significantly different $\left(\chi^{2}(1)=39.88, p<.001\right)$.

Given that there was an expected payoff advantage of choosing the per-minute fee particularly in the longer time-limit condition, when managers were matched to a random worker, the difference in realized less profits were comparable to the results reported in the manuscript in all the conditions (Longer time limit: $\mathrm{M}_{\text {Per-minute Fee }}=\$ 4.70, \mathrm{M}_{\text {Flat Fee }}=\$ 4.25 ; \Delta=-\$ 0.45 ;$ Shorter time-limit condition, version 1: $\mathrm{M}_{\text {Per-minute Fee }}=\$ 0.825, \mathrm{M}_{\text {Flat Fee }}=\$ 0.75 ; \Delta=-\$ 0.075$; Shorter time-limit condition, version 1: $\left.\mathrm{M}_{\text {Per-minute Fee }}=\$ 4.40, \mathrm{M}_{\text {Flat Fee }}=\$ 4.25 ; \Delta=-\$ 0.15\right)$. However, because of small sample sizes (e.g., very few choosing flat fee in longer time-limit condition in absolute terms) the statistical tests were lowpowered and yielded directional results ( $p$ s $.245, .296$, and .062 respectively).

The suboptimal choices are largely explained by the managers' estimates of task completion time. Managers who chose a flat fee estimated a longer task completion time in all the conditions (Shorter time limit, version 1: $\mathrm{M}_{\text {Chose Flat Fee }}=5.20$ vs. $\mathrm{M}_{\text {Chose Per-minute Fee }}=3.15 ; t(40)=4.54, p<.001$; Shorter time limit, version 2: $\mathrm{M}_{\text {Chose Flat Fee }}=5.33$ vs. $\mathrm{M}_{\text {Chose Per-minute Fee }}=3.31 ; t(39)=2.23, p=.031$; Longer time limit: $\mathrm{M}_{\text {Chose Flat }}$ Fee $=9.00$ vs. $\left.M_{\text {Chose Per-minute Fee }}=6.12 ; t(81)=1.76, p=.081\right)$. This was not significantly affected by order of elicitation (before vs. after choice of compensation scheme) for any of the conditions (interaction $p s>$ $.104)$, suggesting that workers' time completion estimates were not due to ex-post rationalization by managers of their preceding choices.

Indeed, managers' choices were largely rationalized by their estimates of workers' completion times. Most participants chose the option that would have provided a higher profit had their time 
estimates been correct ( $80 \%$ in the shorter time-limit conditions; $78 \%$ in the longer time-limit condition).

Furthermore, the estimated time for per-minute workers mediated the effect of deadlines on managers' choices (indirect effect bootstrapped 95\% $\mathrm{CI}=[0.09,0.41])$.

In the shorter time-limit conditions, there was no difference in the likelihood of choosing the perminute fee or risk-equivalent uncertain employment cost $\left(70 \%\right.$ vs. $64 \%$; McNemar's $\chi^{2}(1)=1.31$, $p=.251$ ). However, in the longer time-limit condition, managers were much less likely to choose the perminute fee than the equivalent uncertain employment cost $\left(10 \%\right.$ vs. $41 \%$; McNemar's $\chi^{2}(1)=24.14$, $p<.001)$. This strongly suggests that the observed compensation scheme preferences cannot be explained by managers' risk aversion when facing a choice between certain and variable employment cost outcomes, and is instead explained by mis-estimation of those outcomes.

Therefore, overall, we successfully replicated all the results reported in the paper using only those managers who passed this recall check.

\section{Results with Only Managers Who Passed the Recall Check that the Maximum Time Limit was Random (Robustness Check 2):}

In Study 4, managers were informed that time cap was randomly selected between one of two time limits: 5 minutes and 15 minutes. This was done to eliminate any information that the limits might signal. After managers indicated their compensation scheme choice and estimated the time they believed workers took to finish the math task (counter-balanced), we asked managers a recall question to confirm their understanding (e.g., for the hiring option that earned you a variable bonus, how was the time cap set: randomly, based on workers' actual completion times, don't know/can't say). Of the managers who indicated they knew the answer to this question, $70 \%(\mathrm{~N}=183)$ correctly recalled that the time limit was random. In the analysis below, we use only the managers who passed this manipulation check to examine robustness of the reported results.

Preference for flat fees differed across the three experimental conditions $\left(\chi^{2}(2)=100.44, p<.001\right)$. In the two shorter time-limit conditions, fewer participants chose the flat fee than the per-minute fee, at 
similar rates $\left(20 \%\right.$ and $\left.26 \% ; \chi^{2}(1)=0.53, p=.465\right)$. In contrast, when the time limit was longer, an overwhelming majority (96\%) of managers chose the sub-optimal flat-fee option, and this rate of choosing flat fees was significantly higher than in the two shorter time-limit conditions $\left(\chi^{2}(1)=100.05\right.$, $p<.001)$. Taken together, the pattern of choices rules out an aversion to complexity account. In particular, if the preference for flat fees was driven by a motivation to avoid the cognitive cost of processing the metered-fee option when the sure bonus amount was high, the proportion of flat fee choices should have been similar in the version of the shorter time limit and the longer time limit that had the same high expected sure bonus amount (i.e., \$4.25). However, these proportions were significantly different $\left(\chi^{2}(1)=76.53, p<.001\right)$.

Given that there was an expected payoff advantage of choosing the per-minute fee particularly in the longer time-limit condition, when managers were matched to a random worker, the difference in realized less profits were comparable to the results reported in the manuscript in all the conditions (Longer time limit: $\mathrm{M}_{\text {Per-minute Fee }}=\$ 4.60, \mathrm{M}_{\mathrm{Flat} \mathrm{Fee}}=\$ 4.25 ; \Delta=-\$ 0.35 ;$ Shorter time-limit condition, version 1: $\mathrm{M}_{\text {Per-minute Fee }}=\$ 0.95, \mathrm{M}_{\mathrm{Flat} F e}=\$ 0.75 ; \Delta=-\$ 0.20 ;$ Shorter time-limit condition, version 1: $\mathrm{M}_{\text {Per- }}$ minute Fee $=\$ 4.38, \mathrm{M}_{\mathrm{Flat} F e}=\$ 4.25 ; \Delta=-\$ 0.13$ ). However, because of small sample sizes (e.g., very few choosing flat fee in longer time limit condition in absolute terms) the statistical tests were low-powered and yielded directional results at times ( $p$ s $.327, .009$, and .078 respectively).

The suboptimal choices are largely explained by the managers' estimates of task completion time. Managers who chose a flat fee estimated a longer task completion time in all the conditions (Shorter time limit, version 1: $\mathrm{M}_{\text {Chose Flat Fee }}=5.75$ vs. $\mathrm{M}_{\text {Chose Per-minute Fee }}=3.15 ; t(39)=4.79, p<.001$; Shorter time limit, version 2: $\mathrm{M}_{\text {Chose Flat Fee }}=6.38$ vs. $\mathrm{M}_{\text {Chose Per-minute Fee }}=3.89 ; t(48)=2.48, p=.017$; Longer time limit: $\mathrm{M}_{\text {Chose Flat }}$ Fee $=8.68$ vs. $\left.\mathrm{M}_{\text {Chose Per-minute Fee }}=4.75 ; t(90)=1.92, p=.058\right)$. The time estimates were not on account of $e x$ post rationalization (i.e., managers' estimates of completion times being based on their preceding compensation scheme choices). In the longer time limit condition there was no effect of order of elicitation (interaction $p=.543$ ), while for the two shorter time-limit conditions, managers who chose flat 
fees estimated higher completion times when estimates were made before (vs. after) these choices were indicated (interaction ps .021 and .022 for version 1 and version 2 respectively).

Managers' choices were largely rationalized by their estimates of workers' completion times. Most participants chose the option that would have provided a higher profit had their time estimates been correct (88\% in the shorter time-limit conditions; $76 \%$ in the longer time-limit condition). Furthermore, the estimated time for per-minute workers mediated the effect of deadlines on managers' choices (indirect effect bootstrapped $95 \% \mathrm{CI}=[0.01,0.38])$.

In the shorter time-limit conditions, there was a smaller difference in the likelihood of choosing the per-minute fee or risk-equivalent uncertain employment cost (77\% vs. $68 \%$; McNemar's $\chi^{2}(1)=3.56$, $p=.059)$. However, in the longer time-limit condition, managers were much less likely to choose the perminute fee than the equivalent uncertain employment cost ( $4 \%$ vs. $42 \%$; McNemar's $\chi^{2}(1)=35.00$, $p<.001)$. This strongly suggests that the obsertved compensation scheme preferences cannot be explained by managers' risk aversion when facing a choice between certain and variable employment cost outcomes, and is instead explained by mis-estimation of those outcomes.

Therefore, overall, we successfully replicated all the results reported in the paper using only those managers who passed this recall check. 


\section{Study 5 (Phase 1):}

Distribution of actual time taken by workers (the mean is indicated with a red dot)

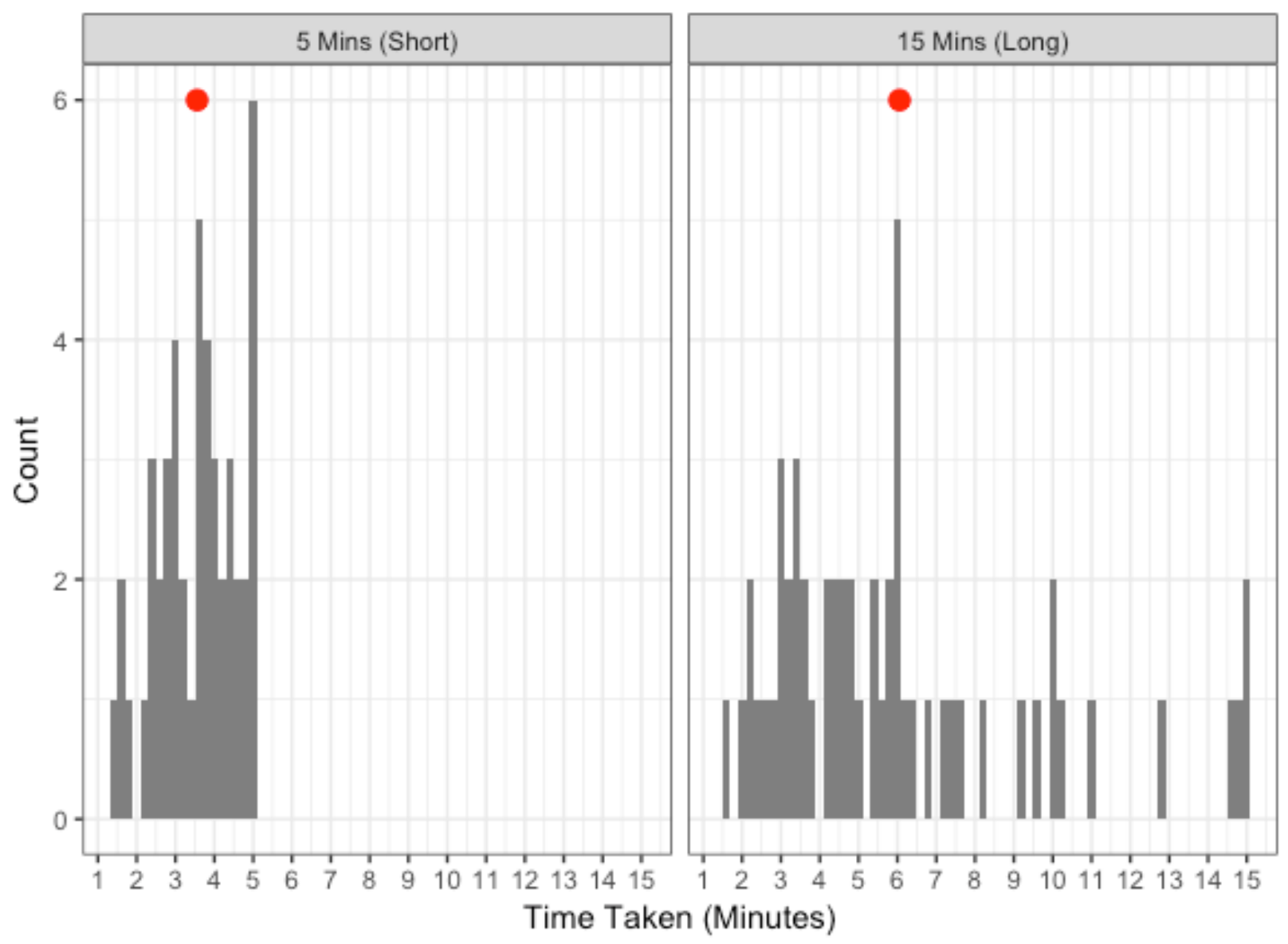

\section{Study 5 (Phase 2): Additional Analysis}

How did completion-time information affect managers' completion time estimations?

Irrespective of compensation scheme choices, when no completion-time information was available, managers estimated a longer completion time for per-minute workers when the time limit was longer than when it was shorter $\left(\mathrm{M}_{\text {Long }}=10.57\right.$ vs. $\left.\mathrm{M}_{\text {Shorter }}=4.21, \Delta=+6.36 ; t(262)=17.69, p<.001\right)$. When completion-time information was provided, the difference in completion time estimates of per-minute workers reduced, but was not eliminated $\left(\mathrm{M}_{\mathrm{Long}}=9.03 \mathrm{vs.} \mathrm{M}_{\text {Shorter }}=4.03, \Delta=+5.00 ; t(280)=12.31, p<.001\right.$; interaction: $\beta=1.36, t=2.49, p=.013)$. Therefore, beliefs about completion times, particularly when timebased compensation is used, reduced but persisted when information defining the scope of work was 
provided. This is consistent with a multiple-accounts explanation underlying the observed misestimations.

To confirm that managers' estimates represented a systematic bias it is important to compare them with time taken by actual workers. Managers, irrespective of the choices made, overestimated the expected time per-minute workers would take, compared to the actual time taken (shorter time limit: 4.21 vs. $3.56, t(180)=3.72, p<.001$; longer time limit: 10.57 vs. $6.05, t(182)=7.21, p<.001$; difference: $\beta=0.38$, $t=5.79, p<.001)$. Likewise, when information was provided, the misestimation persisted and reduced only directionally (shorter time limit: 4.03 vs. $3.56, t(184)=2.64, p=.008$; longer time limit: 9.03 vs. 6.05 , $t(196)=4.28, p<.001$; difference: $\beta=2.50, t=3.34, p<.001)$. Accordingly, the three-way interaction of role (worker, manager), time limit, and scope-information on time taken was not significant ( $p=.177$ ).

Did these misestimations of per-minute workers' completion time drive the biased compensation scheme choices, even when completion-time information was available? Replicating earlier findings, when no completion-time information was provided, managers who chose a flat fee estimated a longer completion time for per-minute workers both in the shorter $\left(\mathrm{M}_{\text {Chose Flat Fee }}=4.50\right.$ vs. $\mathrm{M}_{\text {Chose Per-minute Fee }}$ $=3.77 ; t(133)=4.15, p<.001)$ and longer time-limit conditions $\left(\mathrm{M}_{\text {Chose Flat Fee }}=11.28\right.$ vs. $\mathrm{M}_{\text {Chose Per-minute Fee }}$ $=8.10 ; t(127)=3.94, p<.001)$, but more so when the external time limits were longer $(F(1,260)=10.49$, $p=.001)$. However, even when completion-time information was available, the results persisted (Shorter time limit: $\mathrm{M}_{\text {Chose Flat Fee }}=4.35$ vs. $\mathrm{M}_{\text {Chose Per-minute Fee }}=3.63 ; t(137)=4.14, p<.001$; Longer time limit: $\mathrm{M}_{\text {Chose }}$ Flat Fee $=10.61$ vs. $\mathrm{M}_{\text {Chose Per-minute Fee }}=5.69 ; t(141)=6.73, p<.001$; interaction: $\left.F(1,278)=32.18, p=.001\right)$. Indeed, the three way interaction of completion-time information, time limit, and flat fee choice on estimates of per-minute workers' completion times was not statistically significant ( $p=.103)$. Managers who chose flat fees, also overestimated the expected time per-minute workers would take compared to the actual time taken by workers.

Like in previous studies, managers' choices were largely rationalized by their estimates of workers' completion times. When no completion-time information was provided, most participants chose the option that would have provided a higher profit had their time estimates been correct ( $82 \%$ in the 
shorter time condition; $79 \%$ in the longer time condition). These proportions remained similar when completion-time information was provided ( $83 \%$ in the shorter time condition; $77 \%$ in the longer time condition). Furthermore, the estimated time for per-minute workers completely mediated the effect of deadlines on managers' compensation scheme choices, when no completion-time information was provided (indirect effect bootstrapped $95 \% \mathrm{CI}=[0.17,0.47]$ ), and partially so in the completion-time information condition (indirect effect bootstrapped 95\% $\mathrm{CI}=[0.22,0.41]$ ). This provides further confirmation that managers' choice under different time limits was driven by their biased beliefs about task completion times, and the information intervention did little to attenuate this effect.

\section{Results with Only Managers Who Passed All the Chart-Comprehension Questions (Robustness Check 1):}

Participants in the scope-information condition answered five comprehension questions related to the information displayed on the chart. The questions were asked on the same page as the chart. The first three questions asked them to select what percentage of workers finished the task in 3-minutes or less, 5minutes or less, and 15-minutes or less (three options presented). The last two questions asked how much time limit the group of workers shown had (5-minutes, 15-minutes, No time limit), and how these workers were paid (paid a flat lump sum, paid at a certain rate per minute worked, don't know/can't say). In this section, we examine the key results of Study 5 only among participants who passed all these chartcomprehension questions. Therefore, in effect, the sample in this analysis includes everyone in the noscope-information condition, and a subset of those in scope-information condition who passed these checks.

In total, $72 \%$ of the participants $(\mathrm{N}=391)$ correctly answered all the three recall questions. When no scope information was provided, the results were the same as reported in the manuscript (i.e., $77 \%$ vs $\left.60 \% ; \chi^{2}(1)=8.59, p=.003\right)$. This is because the group of participants assigned to no-information condition did not attenuate on account of the filter used in this robustness check. 
In the scope information conditions, the preference towards flat fees in the longer time-limit condition was marginally higher than that in the shorter time-limit condition $(64 \%$ in longer vs. $51 \%$ in shorter, $\chi^{2}(1)=1.77, p=.182$ ) but this was not significantly different from the no-scope information conditions (interaction $\beta=0.286, z=0.629, p=.529$ ). As a result of the higher-expected value advantage of metered fees, managers choosing flat fees earned directionally less in the longer time-limit condition $\left(\mathrm{M}_{\text {Per-minute Fee }}=\$ 2.23, \mathrm{M}_{\text {Flat Fee }}=\$ 2.00 ; \Delta=-\$ 0.23, t(31)=1.17, p=.253\right)$, but this loss was statistically similar to the loss in earnings in the shorter time-limit condition $(t(52)=1.06, p=.291)$. In fact, the twoway interaction of time limits and completion-time information on bonuses earned was not significant $(\beta=0.137, t=0.73, p=.464)$, suggesting, overall, the additional information regarding the scope of work did not attenuate the effect of longer time limit on flat fee choices. Therefore, we substantively replicated the main findings with participants who passed all the chart-comprehension questions.

\section{Results with Only Managers Who Passed All the Recall Checks at the end of survey}

\section{(Robustness Check 2):}

All participants answered three questions at the end of the survey. The first two asked about the maximum time limit that the worker had in his/her case (5-minutes, 15-minutes, no time limit), and how this maximum time limit was selected for the worker (randomly, such that lesser skilled workers had more time). Finally, they were asked to indicate which one of the two statements was true: only workers who completed the task in the assigned time limit were available for hire or all workers were available for hire. In this section, we examine the key results of Study 5 only among participants who correctly answered all the three recall questions.

In total, $73 \%$ of the participants $(\mathrm{N}=399)$ correctly answered all the three recall questions. When no scope information was provided, managers were significantly more likely to choose the flat fee under the longer time limit $(81 \%)$ than the shorter time-limit $\left(66 \% ; \chi^{2}(1)=4.83, p=.028\right)$. Accordingly, managers who chose to pay a flat fee left more money on the table (based on realized profits after being matched to a random per-minute worker) which was directionally significant in the longer time limit 
condition $\left(\mathrm{M}_{\text {Per-minute Fee }}=\$ 2.24, \mathrm{M}_{\text {Flat Fee }}=\$ 2.00 ; \Delta=-\$ 0.24, t(18)=1.33, p=.271\right.$; difference vs. shorter time limit: $t(54)=1.25, p=.215)$.

In the scope information conditions, the biased preference towards flat fees in the longer timelimit condition attenuated $\left(66 \%\right.$ in longer vs. $63 \%$ in shorter, $\left.\chi^{2}(1)<1\right)$, however, this was not significantly different from the no-scope information conditions (interaction $\beta=0.652, z=1.46, p=.143$ ). Indeed, even when scope information was provided, managers choosing flat fees earned significantly less in the longer time-limit condition $\left(\mathrm{M}_{\text {Per-minute Fee }}=\$ 2.43, \mathrm{M}_{\text {Flat Fee }}=\$ 2.00 ; \Delta=-\$ 0.43, t(31)=3.57, p=.001\right)$, although there were no difference in the shorter time-limit condition $(p=.443)$. Therefore, providing information about scope did not arrest the loss in managers' earnings when time limits were longer compared to when lime limits were shorter $(t(65)=3.16, p=.002)$. In fact, the two-way interaction of time limits and completion-time information on bonuses earned was not significant $(\beta=0.190, t=0.95, p=.346)$. This suggests that overall the additional information regarding the scope of work did not attenuate the effect of longer time limit on flat fee choices. Therefore, the main results were substantively similar when we only included participants who passed all the end-of-survey recall questions. 


\section{Online Appendix D: Additional Studies}

\section{Study A1: The Effect of Deadlines on Multiple-worker Compensation Scheme Choices}

Instructions used in Study A1 (15 minutes condition is shown)

\section{Method}

\section{THE EMPLOYER GAME}

In this survey, you will play a game, from which you can get REAL monetary rewards, based on your decisions. In the game, you are an employer making choices about how to compensate workers.

In the game, your "company" would be paid $\$ 4.00$ for each completed jigsaw puzzle. The company will hire $\mathbf{5 0}$ workers and each worker will separately work to solve the same puzzle.

From that $\$ 4.00$, however, you need to deduct the cost of having the worker complete the puzzle for you. The remaining money, after paying for the workers, will be company's profit. TWO percent ( $2 \%$ ) of this profit will be yours to keep as a performance bonus, and you will receive that money for real via Mechanical Turk, after the study is over.

Online adult survey participants $(\mathrm{N}=146)$ recruited from Amazon Mechanical Turk participated as managers in a consequential economic game, using the same 2 (time limit: shorter $=5$ minutes vs. longer $=15$ minutes) x 2 (recruiting fee for flat-rate workers: present, absent) full-factorial design and phase 1 worker data as in Study 1a. However, unlike Study 1a, managers were told that they were hiring 50 workers, all under the same terms, and that the manager would receive $2 \%$ of the profit that remained after paying the workers.

\section{Results}

The results when choosing compensation schemes for hiring 50 workers replicated the Study 1a findings for hiring a single worker. Overall, the majority of managers (67\%) chose the lower expectedprofit flat fee. Managers were particularly likely to choose the flat fee in the longer time-limit condition, compared to those in the shorter time-limit condition ( $86 \%$ vs. $\left.49 \%, \chi^{2}(1)=22.12, p<.001\right)$, even though the expected profit advantage of the per-minute fee, taking into account the workers' actual performance, was significantly higher in the longer time-limit condition $\left(\Delta_{\text {Longer time limit }}=\$ 0.90, \Delta_{\text {Shorter time limit }}=\$ 0.35\right.$; 
interaction bootstrapped $p<.001$ ). Consequently, managers left significantly more money on the table in their actual earnings (based on randomly matching 50 workers' actual times to finish the task) when time limits were longer $\left(\Delta_{\text {Longer time limit }}=-\$ 1.15, \Delta_{\text {Shorter time limit }}=-\$ 0.35 ; t(46)=22.76, p<.001\right)$.

As in Study 1a, managers who chose a flat fee estimated a longer completion time for per-minute workers for shorter time limits $\left(\mathrm{M}_{\text {Chose Flat Fee }}=4.54\right.$ vs. $\left.\mathrm{M}_{\text {Chose Per-minute Fee }}=3.36 ; t(72)=5.73, p<.001\right)$ and even more so for longer time limits $\left(\mathrm{M}_{\mathrm{Chose}}\right.$ Flat Fee $=12.13$ vs. $\mathrm{M}_{\text {Chose Per-minute Fee }}=6.40 ; t(69)=5.34, p<.001$; difference $F(1,141)=23.28, p<.001)$. Most participants chose the option that would have been more profitable based on their time estimate ( $84 \%$ in the shorter time condition; $87 \%$ in the longer time condition), and the estimated time for per-minute workers mediated the effect of deadlines on compensation scheme choice (indirect effect bootstrapped 95\% $\mathrm{CI}=[0.45,0.67]$ ). We also find, as in the prior study, that measured general risk aversion does not explain the results.

The results of this study generalizes the results of Study 1a to compensation scheme choices for hiring multiple workers and thus provides further evidence that the biased preference for flat fees is driven by a deadline-induced time misestimation process rather than by risk preferences. 


\section{Study A2: Compensation Scheme Choices for a Fixed-Quality Task by Experienced Managers}

\section{Method}

We conducted a brief survey with MBA students $(\mathrm{N}=92)$ at a large mid-western university, who all had at least some managerial experience (4.76 average years of work experience, $63 \%$ with hiring experience).

As in Study 1a, managers played a consequential hiring game based on the Study 1a workers, choosing between a flat fee and a per-minute fee to hire multiple workers (all under the same scheme) under either the 5 minute or 15 minute time limit (between-subjects). The costs were the same as in the no-recruiting-fee condition of Study 1a: $\$ 1.50$ (longer time-limit condition) or $\$ 1$ (shorter time-limit condition) for flat fees; 25 cents per minute for a per-minute fee.

In this study, managers could earn a lump sum ( $\$ 2$ in the shorter time-limit condition, and $\$ 4$ in the longer time-limit condition) for each completed jigsaw puzzle. Managers had a chance to receive the total profit earned after paying all the workers (50 workers in the shorter time-limit condition; 20 workers in the longer time-limit condition) in the form of an Amazon gift card (given to 5 students based on a lottery). Different numbers of workers were used in the different time-limit conditions to make sure that the profit earned using the flat fee $(\$ 50)$ was the same in the two experimental conditions ${ }^{1}$.

\section{Results}

Based on the Study 1a workers' times, the flat fee had lower expected profit, both in the shorter time-limit $\left(\mathrm{M}_{\text {Per-minute Fee }}=\$ 64.84, \mathrm{M}_{\text {Flat Fee }}=\$ 50.00 ; \Delta=-\$ 14.84\right.$; bootstrapped $\left.p<.001^{2}\right)$, and in the longer time-limit condition $\left(\mathrm{M}_{\text {Per-minute Fee }}=\$ 62.07, \mathrm{M}_{\mathrm{Flat} \text { Fee }}=\$ 50.00 ; \Delta=-\$ 12.07 ;\right.$ bootstrapped $p<$ .001). There was no significant difference in the expected-profit advantage of the per-minute fee, between the longer and shorter time-limit conditions (interaction bootstrapped $p>.250$ ).

15 minutes: $50 *(\$ 2-\$ 1)=\$ 50 ; 15$ minutes: $20 *(\$ 4-\$ 1.50)=\$ 50$.

${ }^{2}$ See Online Appendix C (Additional Analysis for Study 1b) for details about the bootstrapping process 
Nevertheless, we replicated the preference for flat fees under longer time limits with experienced managers. Like in previous studies, managers showed a higher preference for the lower expected-profit flat fee (overall, $64 \%)$, more so when time limits were longer $\left(77 \%\right.$ vs. $\left.52 \% ; \chi^{2}(1)=5.44, p=.019\right)$.

Like lay participants playing the role of managers, participants with managerial experience who chose a flat fee also estimated a longer completion time under per-minute fee (Shorter Time Limit: $\mathrm{M}_{\text {Chose }}$ Flat Fee $=4.39$ vs. $\mathrm{M}_{\text {Chose Per-minute Fee }}=3.32 ; t(41)=4.75, p<.001 ;$ Longer Time Limit: $\mathrm{M}_{\text {Chose Flat Fee }}=11.67$ vs. $\mathrm{M}_{\text {Chose Per-minute Fee }}=6.61 ; t(37)=3.69, p<.001$; difference $\left.F(1,78)=10.42, p=.002\right)$. Most managers chose the option that maximized the expected payoffs based on their own time estimates (91\% in the shorter timelimit condition, $89 \%$ in the longer time-limit condition). As in the previous studies, the estimated time for per-minute workers mediated the effect of deadlines on compensation scheme choices (indirect effect bootstrapped $95 \% \mathrm{CI}=[0.30,0.64])$.

The experienced managers' choices were not explained by risk aversion, as managers were less likely to choose the certain amount in the risky choice than to select the equivalent flat fee in the longer timelimit (43\% vs. 77\%; McNemar's $\left.\chi^{2}(1)=9.80, p=.002\right)$ condition. Likewise, fewer experienced managers in the shorter time-limit condition chose the fixed amount, compared to the equivalent flat fee (28\% vs. $52 \%$ vs.; McNemar's $\left.\chi^{2}(1)=7.14, p=.008\right)$. Years of job experience, first-hand experience with hiring or compensation decisions, measured risk aversion, and gender did not moderate these results. 
Study A3: Compensation Scheme Choices for a Variable-Quality Task by Experienced Managers

\section{Method}

We recruited MBA students of a large mid-western university (N=62), who all had prior managerial experience. About half $(52 \%)$ had prior experience specifically in making hiring or compensation decisions. The methods were similar to the "difficult proofreading task" managers' choice conditions (varying shorter vs. longer time limits) in Study 2, except that the incentives were probabilistic. Participants had a chance to receive twenty times the money remaining after paying the worker, in the form of an Amazon gift card (given to three participants, who were chosen by lottery).

The managers' budget and costs were structured based on the performance of the workers in phase 1, such that, like in Study 2, there was an expected advantage of around 30 cents from choosing per-minute (vs. flat fee) compensation schemes in the longer time-limit condition (see Online Appendix B). Managers' potential revenue and costs are shown in the table below:

\begin{tabular}{|c|c|c|c|c|}
\hline \multirow[b]{2}{*}{ Time Limit } & \multirow[b]{2}{*}{$\begin{array}{l}\text { Task } \\
\text { Difficulty }\end{array}$} & \multirow[b]{2}{*}{ Budget } & \multicolumn{2}{|c|}{ Cost of hiring worker } \\
\hline & & & Flat Fee Selected & $\begin{array}{l}\text { Per-min. Fee } \\
\text { Selected }\end{array}$ \\
\hline $\begin{array}{l}15 \text { mins. } \\
\text { (longer time } \\
\text { limit) }\end{array}$ & Difficult & $\begin{array}{l}\text { Lump sum: } \$ 3.00 \\
\text { Variable: } 10 \notin \text { for } \\
\text { every correct spelling } \\
\text { ( } 24 \text { words in total) }\end{array}$ & $\begin{array}{l}\$ 1.50 \text { plus } 30 \varnothing \\
\text { recruitment fee }\end{array}$ & $\begin{array}{c}25 \varnothing \text { per minute } \\
\text { worked }\end{array}$ \\
\hline $\begin{array}{l}5 \text { mins. } \\
\text { (shorter time } \\
\text { limit) }\end{array}$ & Difficult & $\begin{array}{l}\text { Lump sum: } \$ 0.50 \\
\text { Variable: } 10 \varnothing \text { for } \\
\text { every correct spelling } \\
\text { ( } 24 \text { words in total) }\end{array}$ & $\begin{array}{l}\$ 1.00 \text { plus } 10 \varnothing \\
\text { recruitment fee }\end{array}$ & \\
\hline
\end{tabular}

\section{Results}

Based on workers' performance, the expected profits were directionally higher for the per-minute fee (vs. flat fee $)$ option in the shorter time-limit condition $\left(\mathrm{M}_{\text {Per-minute Fee }}=\$ 1.41 \mathrm{vs} . \mathrm{M}_{\text {Flat Fee }}=\$ 1.23\right.$, $t(20)=0.89, p=.383$ ), but were significantly higher for the per-minute fee (vs. flat fee) option in the longer 
time-limit condition $\left(\mathrm{M}_{\text {Per-minute Fee }}=\$ 3.72\right.$ vs. $\left.\mathrm{M}_{\text {Flat Fee }}=\$ 2.76, t(19)=2.95, p=.008\right)$. As in Study 2 , the expected profit advantage of the flat fee was higher under the longer time limit (interaction $F(1,39)=4.19$, $p=.047)$.

However, many experienced managers chose the flat fee, particularly when time limits were longer $\left(85 \%\right.$ vs. $\left.51 \% ; \chi^{2}(1)=7.75, p=.005\right)$, consistent with the findings in Study 2. Experienced managers' preference for flat fees was driven by their beliefs about the time workers would take. Managers who chose a flat fee estimated a longer completion time for workers under the per-minute fee both for shorter $\left(\mathrm{M}_{\text {Chose Flat Fee }}=4.71\right.$ vs. $\left.\mathrm{M}_{\text {Chose Per-minute Fee }}=3.80 ; t(33)=3.09, p=.004\right)$ and longer $\left(\mathrm{M}_{\text {Chose Flat }}\right.$ Fee $=12.89$ vs. MChose Per-minute Fee $\left._{\text {C. }} 7.00 ; t(24)=2.68, p=.013\right)$ time-limit conditions, but significantly more so when the time limits were longer $(F(1,57)=8.34, p=.005)$. Most managers chose the option that maximized their payoffs based on their own time estimates (83\% in the shorter time-limit condition, $85 \%$ in the longer time-limit condition). Indeed, as in the previous studies, managers' estimated time for perminute workers mediated the effect of deadlines on their choices (indirect effect bootstrapped $95 \% \mathrm{CI}=$ $[0.13,0.64])$.

As in the prior studies, the preference for flat fees under longer time limits was not explained by risk aversion. Experienced managers were less likely to select the less risky option in the gamble choice than the equivalent flat fee in the longer time limit $\left(15 \%\right.$ vs. $85 \%$; McNemar's $\left.\chi^{2}(1)=19.00, p<.001\right)$ as well as in the shorter time-limit conditions ( $6 \%$ vs. $51 \%$; McNemar's $\left.\chi^{2}(1)=16.00, p<.001\right)$. The results did not differ based on whether managers had prior experience in making specifically hiring and compensation decisions or not.

We generalized the effect of time limits on choices to situations in which experienced managers have an incentive to maintain quality, not just cut costs. Managers remained biased towards flat fees, particularly under longer time limits, due to their overestimation of the time workers would take. This bias resulted in suboptimal choices by the experienced managers, as in the previous studies. 


\section{Study A4: Online Managers Hiring Workers for Spelling Task}

\section{Method}

We ran a replication of Study 2 with online managers $(\mathrm{N}=185)$ randomly assigned to hiring workers for either easy or difficult proofreading tasks. The study used results from the same workers as in Study 2 and the information provided to managers was similar. However, the payoff structure and costs were different from Study 2, and are shown below:

\begin{tabular}{|c|c|c|c|c|}
\hline \multirow[b]{2}{*}{ Time Limit } & \multirow[b]{2}{*}{$\begin{array}{l}\text { Task } \\
\text { Difficulty }\end{array}$} & \multirow[b]{2}{*}{ Budget } & \multicolumn{2}{|c|}{ Cost of hiring worker } \\
\hline & & & Flat Fee Selected & $\begin{array}{c}\text { Per-min. Fee } \\
\text { Selected }\end{array}$ \\
\hline $\begin{array}{l}15 \text { mins. } \\
\text { (longer time } \\
\text { limit) }\end{array}$ & Easy & \multirow{2}{*}{$\begin{array}{l}\text { Lump sum: } \$ 3.00 \\
\text { Variable: } 10 \mathrm{c} \text { for } \\
\text { every correct spelling } \\
\text { ( } 24 \text { words in total) }\end{array}$} & $\begin{array}{l}\$ 1.50 \text { plus } 50 \mathrm{c} \\
\text { recruitment fee }\end{array}$ & \multirow{4}{*}{$\begin{array}{l}25 \mathrm{c} \text { per minute } \\
\text { worked }\end{array}$} \\
\hline $\begin{array}{l}15 \text { mins. } \\
\text { (longer time } \\
\text { limit) }\end{array}$ & Difficult & & $\begin{array}{l}\$ 1.50 \text { plus } 30 \mathrm{c} \\
\text { recruitment fee }\end{array}$ & \\
\hline $\begin{array}{l}5 \text { mins. } \\
\text { (shorter time } \\
\text { limit) }\end{array}$ & Easy & \multirow{2}{*}{$\begin{array}{l}\text { Lump sum: } \$ 0.50 \\
\text { Variable: } 10 \mathrm{c} \text { for } \\
\text { every correct spelling } \\
\text { ( } 24 \text { words in total) }\end{array}$} & \multirow{2}{*}{$\begin{array}{l}\$ 1.00 \text { plus } 10 \mathrm{c} \\
\text { recruitment fee }\end{array}$} & \\
\hline $\begin{array}{l}5 \text { mins. } \\
\text { (shorter time) }\end{array}$ & Difficult & & & \\
\hline
\end{tabular}

There was an expected profit advantage of choosing per-minute fees in the longer time-limit condition over those in the shorter time limit for difficult tasks (Shorter: $M_{\text {Per-minute Fee }}=\$ 1.41$ vs. $\$ 1.23$ flat fee, $t(20)=0.89, p=.383$; Longer: $\mathrm{M}_{\text {Per-minute Fee }}=\$ 3.72$ vs. $\$ 2.76$ flat fee, $t(19)=2.95, p=.008$; difference $F(1,39)=4.19, p=.047)$. Likewise, for easy tasks, there was an expected profit advantage of choosing perminute workers in both shorter $\left(\mathrm{M}_{\text {Per-minute Fee }}=\$ 2.32\right.$ vs. $\$ 1.77$ flat fee, $\left.t(19)=6.07, p<.001\right)$ and longer time limits $\left(\mathrm{M}_{\text {Per-minute Fee }}=\$ 4.19\right.$ vs. $\$ 3.26$ flat fee, $t(27)=3.06, p=.005$; difference $\left.F(1,46)=1.00, p=.322\right)$.

\section{Results}

Managers were more likely to choose the flat fee in the longer time-limit condition than in the shorter time-limit condition $\left(79 \%\right.$ vs. $\left.55 \%, \chi^{2}(1)=12.57, p<.001\right)$. The preference for flat fees in the longer time-limit condition held when the task was easy ( $76 \%$ vs. $\left.48 \%, \chi^{2}(1)=7.39, p=.007\right)$, as well as 
when the task was difficult ( $83 \%$ vs. $\left.62 \% ; \chi^{2}(1)=5.32, p=.021\right)$. There was no significant difference in the preference for flat fees under longer time limits based on task difficulty $(\beta=0.108, p=.872)$.

For easy tasks, like in previous studies, managers who chose flat fees earned significantly lower profits, both in the shorter time-limit condition $\left(\mathrm{M}_{\text {Per-minute Fee }}=\$ 2.29, \mathrm{M}_{\text {Flat Fee }}=\$ 1.76 ; \Delta=\$ 0.53\right.$; $t(44)=7.27, p<.001)$, and even more so in the longer time-limit condition $\left(\mathrm{M}_{\text {Per-minute Fee }}=\$ 4.29, \mathrm{M}_{\text {Flat Fee }}=\right.$ $\$ 3.30 ; \Delta=\$ 0.99, t(43)=5.90, p=.444$; difference $F(1,87)=7.05, p=.009)$. With difficult tasks, the profits earned by the managers on account of choosing flat fees was directionally smaller in the shorter time-limit condition $\left(\mathrm{M}_{\text {Per-minute Fee }}=\$ 1.49 \mathrm{M}_{\mathrm{Flat} \mathrm{Fee}}=\$ 1.40 ; \Delta=\$ 0.09 ; t(45)<1, p=.443\right)$, but significantly so in the longer time-limit condition $\left(\mathrm{M}_{\text {Per-minute Fee }}=\$ 3.51, \mathrm{M}_{\text {Flat Fee }}=\$ 2.85 ; \Delta=\$ 0.66, t(45)=2.95, p=.005\right.$; $F(1,90)=5.59, p=.020)$.

Consistent with the previous studies, across task types, after the managers indicated their choice of compensation scheme for the given time limit, those who choose a flat fee estimated a longer completion time for workers under per-minute fee for shorter limits $\left(\mathrm{M}_{\text {Chose Flat Fee }}=4.76\right.$ vs. $\mathrm{M}_{\text {Chose Per-minute }}$ Fee $=4.03 ; t(91)=4.85, p<.001)$ and even more so for longer time limits $\left(\mathrm{M}_{\text {Chose Flat Fee }}=13.97\right.$ vs. $\mathrm{M}_{\text {Chose Per- }}$ minute Fee $=7.53 ; t(90)=11.49, p<.001 ;$ difference $F(1,181)=113.72, p<.001)$. Most managers' choices were consistent with selecting the option that provided the higher payoff based on their own time estimates (73\% in the shorter time-limit condition, $93 \%$ in the longer time-limit condition). Finally, as in the previous studies, the estimated time for per-minute workers mediated the effect of deadlines on choices (indirect effect bootstrapped 95\% CI $=[.55, .70]$ ).

Across task types, there were no significant differences in the estimated accuracy of per-minute workers between those managers who chose per-minute fees versus flat fees for both shorter $\left(\mathrm{M}_{\mathrm{Chose}}\right.$ Perminute Fee $=19.50$ vs. $\left.\mathrm{M}_{\text {Chose Flat Fee }}=18.47 ; t(91)=1.11, p=.268\right)$ and longer time limits $\left(\mathrm{M}_{\text {Chose Per-minute Fee }}\right.$ $=20.79$ vs. M Chose Flat Fee $=19.73 ; t(90)=1.01, p=.314$; difference $F(1,181)<1, p=.981)$. The results are similar if we look at easy and difficult proofreading tasks separately. 
Managers' choices were also not explained by risk aversion, as managers were more likely to choose the certain option equivalent to the flat fee over the gamble equivalent to the per-minute fee, in the longer time-limit condition ( $79 \%$ vs. $36 \%$, McNemar's $\left.\chi^{2}(1)=30.76, p<.001\right)$. There was similar difference in the shorter time-limit condition as well (55\% vs. $16 \%$, McNemar's $\left.\chi^{2}(1)=27.00, p<.001\right)$. The results were similar for both easy and difficult proofreading tasks. Time spent to read instructions ( $p=.827)$, to make choices $(p=.957)$, knowledge of proofreading $(p=.245)$ and experience with proofreading tasks $(p=.498)$ did not moderate the results.

We replicated the managers' findings of Study 2. This suggests that our results are robust to using various payment and cost structures for hiring temporary workers. 


\section{Study A5: Online Managers Hiring Workers for Spelling Task without Workers' Accuracy Information}

\section{Method}

Mturk participants ( $\mathrm{N}=189)$, acting as managers, hired either a per-minute worker or a flat fee worker to get a proofreading task (easy vs difficult, varied between subjects) done under a certain time limit (shorter vs. longer, varied between subjects). Managers' payoffs and costs were the same as that used in Study A3. The only difference between this study and Study A3 was that the managers were not provided with workers' accuracy information for the proofreading words, as shown below:

Easy Proofreading Words

\begin{tabular}{|l|l|l|}
\hline 1) didn't & 9) somtimes & 17) asked \\
2) arround & 10) prety & 18) because \\
3) allways & 11) animals & 19) wile \\
4) tride & 12) recieved & 20) intresting \\
5) finaly & 13) boght & 21) again \\
6) meny & 14) mony & 22) once \\
7) people & 15) when & 23) untill \\
8) children & 16) said & 24) thought \\
\hline
\end{tabular}

Difficult Proofreading Words

\begin{tabular}{|l|l|l|}
\hline $\begin{array}{l}\text { 1) embarrass } \\
\text { 2) bellweather }\end{array}$ & 9) innoculate & 17) resteraunt \\
3) discipline & 11) imediate & 18) existance \\
4) twelfth & 12) quage \\
$\begin{array}{l}\text { 5) miniture } \\
\text { 6) memento }\end{array}$ & 13) noticeable & 20) playwright \\
7) medeval & 14) concensus & 22) personell \\
8) firey & 15) reference & 23) conscience \\
\hline
\end{tabular}

\section{Results}

Overall, managers were little more likely to choose the flat fee in the longer time-limit condition than in the shorter time-limit condition $\left(79 \%\right.$ vs. $\left.60 \%, \chi^{2}(1)=7.79, p=.005\right)$. The results were similar for easy tasks $\left(81 \%\right.$ vs. $\left.64 \%, \chi^{2}(1)=3.45, p=.063\right)$, as well as when the proofreading task was difficult $(76 \%$ vs. $\left.56 \% ; \chi^{2}(1)=4.55, p=.033\right)$. In fact, there were no difference in the choices of compensation schemes for different time limits between easy and difficult tasks (logistic regression interaction $\beta=-0.019$, $p=.976)$.

For easy tasks, like in the other previous studies, managers who chose flat fees earned significantly lower profits, both in the shorter time-limit condition $\left(\mathrm{M}_{\text {Per-minute Fee }}=\$ 2.35, \mathrm{M}_{\text {Flat Fee }}=\$ 1.76\right.$; $\Delta=\$ 0.59 ; t(45)=10.24, p<.001)$, and even more so in the longer time-limit condition $\left(\mathrm{M}_{\text {Per-minute Fee }}=\right.$ $\$ 4.63, \mathrm{M}_{\text {Flat Fee }}=\$ 3.30 ; \Delta=\$ 1.33, t(41)=16.19, p=.444$; difference $\left.F(1,86)=56.20, p<.001\right)$. With difficult 
tasks, the profits earned by the managers on account of choosing flat fees was not different in the shorter time-limit condition $\left(\mathrm{M}_{\text {Per-minute Fee }}=\$ 1.23 \mathrm{M}_{\text {Flat Fee }}=\$ 1.25 ; \Delta=-\$ 0.02 ; t(46)<1, p=.867\right)$, but earned significantly lower profits on account of choosing flat fees in the longer time-limit condition $\left(\mathrm{M}_{\text {Per-minute Fee }}\right.$ $\left.=\$ 3.86, \mathrm{M}_{\text {Flat Fee }}=\$ 2.81 ; \Delta=\$ 1.05, t(49)=5.44, p<.001 ; F(1,95)=20.80, p<.001\right)$.

Consistent with the previous studies, across task types, after the managers indicated their choice of compensation scheme for the given time limit, those who choose a flat fee estimated a longer completion time for workers under per-minute fee for shorter limits $\left(\mathrm{M}_{\text {Chose Flat Fee }}=4.86 \mathrm{vs}\right.$. $\mathrm{M}_{\text {Chose Per-minute }}$ Fee $=3.89 ; t(93)=6.66, p<.001)$ and even more so for longer time limits $\left(\mathrm{M}_{\text {Chose Flat Fee }}=13.91\right.$ vs. $\mathrm{M}_{\text {Chose Per- }}$ minute Fee $=8.55 ; t(92)=8.15, p<.001$; difference $F(1,185)=49.39, p<.001)$. Most managers' choices were consistent with the maximizing expected payoffs condition on their own time estimates (84\% in the shorter time-limit condition, $87 \%$ in the longer time-limit condition). Finally, as in the previous studies, the estimated time for per-minute workers mediated the effect of deadlines on choices (indirect effect bootstrapped $95 \% \mathrm{CI}=[0.46,0.66])$.

After the managers indicated their hiring preference, they also indicated their beliefs about workers' accuracy - both for the type they selected as well as for the one they did not select. Across task types, there were no significant differences in the estimated accuracy of per-minute workers between those managers who chose per-minute fees versus flat fees for both shorter $\left(\mathrm{M}_{\text {Chose Per-minute Fee }}=20.29\right.$ vs. $\left.\mathrm{M}_{\text {Chose Flat Fee }}=19.49 ; t(93)=1.03, p=.303\right)$ and longer time limits $\left(\mathrm{M}_{\text {Chose Per-minute Fee }}=20.20\right.$ vs. M $_{\text {Chose Flat Fee }}$ $=20.74 ; t(92)<1, p=.599$; difference $F(1,185)=1.07, p=.294)$. The results are similar if we look at easy and difficult proofreading tasks separately.

The experienced managers' choices were not explained by risk aversion, as managers were more likely to choose the flat fee than the certain outcome in the equivalent gamble in the longer time limit (79\% vs. $29 \%$, McNemar's $\left.\chi^{2}(1)=40.16, p<.001\right)$. There was similar difference in the shorter time-limit condition as well $\left(60 \%\right.$ vs. $21 \%$, McNemar's $\left.\chi^{2}(1)=27.94, p<.001\right)$. The results were similar for both 
easy and difficult proofreading tasks. Time spent to read instructions ( $p=.666)$ or make choices $(p=.829)$, knowledge of ( $p=.196)$ or experience with $(p=.315)$ proofreading tasks did not moderate the results.

Therefore, the results replicated prior findings even when managers did not have information about workers' success rate for the proofreading task. This suggests that providing workers' accuracy information did not change the nature of the qualitative task for the managers. Managers continued to show a preference for flat fees when their profits were dependent on the quality of the final output, even when that quality was more difficult to judge, as in this study. 


\section{Study A6: Hypothetical Choice of Compensation Schemes for both Time Limits}

\section{Method}

The design was very similar to Study 3. Online participants $(\mathrm{N}=179)$ played the role of managers. Managers were shown hiring game scenarios and decided which compensation to use for hiring a worker to complete a simple math task. Managers made two hiring decisions for two different tasks, one for each worker time limit (5 vs. 15 minutes; manipulated within-subjects, counterbalanced). The same two math tasks (assignment to time limits counter-balanced) as in Study 3 were used, and the terms of the hiring were also the same. Managers were informed that the game would only be played once and they would not need to build a long-term relationship with the hired worker. Finally, managers were also told that workers only knew about their own hiring terms (i.e., time limit and flat fee or perminute fee) before starting their work.

After making compensation choices for both time limits, managers answered a series of follow-up questions on 7-point bipolar scales indicating for which of the two tasks the workers took more time to complete, worked harder, did a more thorough job, invested more effort to get the right answer, worked slow intentionally, delayed completion to make more money, found more interesting and enjoyable, and inspired a higher achievement motivation. After the managers answered these questions, they were asked to choose a statement that reflected what influenced their compensation scheme choice the most. The question was asked separately for each of the two tasks (assigned to different time limits). The options were: the possibility that the worker would intentionally delay completion to earn more, the possibility that the worker would work slowly to do a thorough job, the possibility that the worker would find it difficult and need to take their time to get it right, the possibility that the worker would rush to complete it, and none of these. Details of both the tasks (e.g., time limits, revenue, cost of flat fee and per-minute fee) were displayed on the same screen as the follow-up questions. Finally, managers also answered a 7item empathy scale that captured individual differences in perspective taking (Davis, 1983).

\section{Results}


Estimates from a hierarchical regression strongly replicated the effect of external time limits on compensation decisions. More participants (84\%) preferred the flat fee in the longer time-limit condition than in the shorter time-limit condition $(61 \% ; \beta=1.17, z=4.37, p<.001)$. The results were not moderated by the order of time limits or by the order of the two math tasks used in the study. Mid-point tests revealed that managers perceived the two tasks differently. Managers strongly believed that workers would require more time to complete the 15 -minute deadline task than the 5-minute deadline task $(M=+1.25, t(178)=10.73, p<.001)$, a belief consistent with the time mis-estimation results in the prior studies. Thus, we replicate the prior findings in a within-subjects study, even when managers evaluated both time limits in the same study and did not make numerical estimates of the time taken before making choices. This again suggests that biased compensation scheme choices on facing longer deadlines is unlikely to be because of implicit anchoring on time limits.

Managers were more concerned about workers slacking in the 15-minute condition. They thought that in the 15-minute task workers would be more likely to intentionally work slower and take longer than necessary $(M=+1.05, t(178)=8.26, p<.001)$, and delay completion to make more money $(M=+0.78, t(178)=5.82, p<.001)$. Indeed, when asked to indicate which factor was most important to make compensation choice decisions, a significantly larger portion of managers indicated a concern for workers' intentionally delaying completion to earn more in the longer compared to the shorter time-limit condition (44\% vs. $27 \%$, McNemar's $\left.\chi^{2}(1)=16.49, p<.001\right)$.

Managers thought workers worked harder $(M=-0.36, t(178)=2.63, p=.009)$ and invested more effort $(M=-0.26, t(178)=2.12, p=.035)$ when the time limits were shorter, but did a more thorough job when time limits were longer $(M=+0.61, t(178)=4.91, p<.001)$. Consistent with this, a significantly higher proportion of judges in the shorter time-limit condition indicated that the possibility that workers would feel rushed to complete the task affected their decision (21\% vs $10 \%$ in longer time limit; McNemar's $\left.\chi^{2}(1)=8.80, p<.001\right)$. Therefore, as such, workers self-reports indicated mixed feelings about task scope as a function of external time limits. 
There was no difference in managers' judgments of workers' intrinsic motivation $(M=+0.08$, $t(178)<1)$ as a function of time limits. Managers also felt that workers would be directionally more motivated to achieve in the shorter time limit condition $(M=-0.21, t(178)=1.62, p=.106)$. Finally, individual differences in perspective taking did not moderate the effect of time limits on compensation scheme choices in a hierarchical regression model $(p=0.426)$. 


\section{Study A7: Choice for both Time Limits with Extra Questions to Probe Task-Scope Beliefs}

\section{Method}

The design was very similar to Study 3 and A5, but we used a larger sample size $(\mathrm{N}=398)$ to make sure we have enough power to detect differences in self-reports. After making compensation choices for both time limits, managers answered the same follow-up questions as Study A5, including a 7-item empathy scale that captured individual differences in perspective taking.

In addition to the above questions, managers were prompted to think about a new scenario involving the same tasks they saw earlier, but where workers did not have any time limits. Using a similar 7-point bipolar scale, managers were asked to indicate which of the two tasks (i.e., the task they saw associated with a shorter or with a longer time limit) the workers would take longer to complete, would find more difficult, and would invest more effort to complete. These three questions were included to investigate how external time limit affect beliefs about task scope. All judges were required to confirm (using customized validation) that the new scenario involved no time limits before answering these three questions.

\section{Results}

Estimates from a hierarchical regression strongly replicated the effect of external time limits on compensation decisions. More participants (86\%) preferred the flat fee in the longer time-limit condition than in the shorter time-limit condition $(68 \% ; \beta=1.08, z=5.79, p<.001)$. In this study there was a marginally significant moderation by the order of time limits $(p=.066)$. In particular, when managers saw the shorter time limit first, $72 \%$ choose the flat fee which increased to $84 \%$ when they made a subsequent choice for the task with the longer time limit. A similar proportion chose the flat fee (87\%) when the longer time limit was presented first, but revised their choices to a greater extent when they made a subsequent choice for the task with the shorter time limit (65\%). Unlike other studies, the order of the two math tasks used also had a marginally significant moderating effect $(p=.072)$. 
Like the previous studies, managers strongly believed that workers would require more time to complete the 15-minute deadline task than the 5-minute deadline task $(M=+0.91, t(397)=10.76, p<.001)$, a belief consistent with the time mis-estimation results in the prior studies. Thus, we replicate the prior findings in a within-subjects study, even when managers evaluated both time limits in the same study and did not make numerical estimates of the time taken before making choices. This again suggests that biased compensation scheme choices on facing longer deadlines is unlikely to be because of implicit anchoring on time limits.

Managers were more concerned about workers slacking in the 15-minute condition. They thought that in the 15-minute task workers would be more likely to intentionally work slower and take longer than necessary $(M=+1.15, t(397)=12.71, p<.001)$, and delay completion to make more money $(M=+0.94, t(397)=10.62, p<.001)$.

However, there was also evidence consistent with a scope perception belief. Longer time limit made managers believe that workers did a more thorough job even when the quality of the task was fixed $(M=+0.59, t(397)=6.97, p<.001)$. More importantly, when answering questions about their beliefs in the new untimed setting, judges responses to the three questions (completion time, task difficulty, effort required) lent support to scope perception beliefs. The three measures were internally consistent (Cronbach's $\alpha=0.71$ ) and were combined into a task-scope variable. Mid-point test revealed that the task associated with a longer time limit was perceived to have a great scope $(M=+0.16, t(397)=3.02$, $p=.003)$.

Like the previous studies, managers did not perceive a difference in intrinsic motivation $(M=-$ $0.08, t(397)=1.14, p=.253)$ or achievement motivation $(M=-0.13, t(397)=1.14, p=.128)$ as a function of time limits. Finally, individual differences in perspective taking did not moderate the effect of time limits on choices in a hierarchical regression model $(p=0.466)$.

Therefore, all the various versions of Study 3, taken together, suggest that longer time limits influenced managers' beliefs both about the extent of slacking and about the perceived "scope" of work. 


\section{Study A8: Managers' Compensation Scheme Choices for the Math task with Scope Information}

\section{Method}

A sample of online participants $(\mathrm{N}=632)$ played the role of managers in a pre-registered study (http://aspredicted.org/blind.php? $\mathrm{x}=\mathrm{kv6an6}$ ). The design of the study was similar to that of Study 5, except for a few small changes. Specifically, the comprehension on all the chart-information questions were enforced and respondents could not proceed without answering them correctly. Likewise, managers were required to correctly recall the maximum time limit workers had before proceeding to make their choices.

\section{Results}

Based on the actual completion times of workers operating under a per-minute fee in phase 1 , there was an expected-value advantage of choosing to pay per-minute in the longer time limit $\left(\mathrm{M}_{\text {Per-minute }}\right.$ Fee $=\$ 2.35$ vs. $\$ 2.00$ flat fee; $\Delta=\$ 0.35, t(54)=3.01, p=.004)$, a significant difference by time limit in the incentive to choose the per-minute fee $(t(100)=2.65, p=.009)$.

When no scope information was provided, managers choose flat fee directionally more under the longer time limit ( $74 \%$ vs. $\left.69 \% ; \chi^{2}(1)=1.80, p=.179\right)$. Based on these pattern of choices and the expected-value differences, managers who chose to pay a flat fee left more money on the table both when the time limit was longer $\left(\mathrm{M}_{\text {Per-minute Fee }}=\$ 2.73, \mathrm{M}_{\text {Flat Fee }}=\$ 2.00 ; \Delta=-\$ 0.73, t(34)=8.24, p<.001\right)$ as well as when the time limit was shorter $\left(\mathrm{M}_{\text {Per-minute Fee }}=\$ 3.08, \mathrm{M}_{\text {Flat Fee }}=\$ 3.00 ; \Delta=-\$ 0.08, t(59)=2.04\right.$, $p=.045)$, with the incurred loss being higher when the time limit was longer $(t(93)=8.13, p<.001)$. Therefore, we strongly replicated the results of the prior studies when managers made compensation scheme choices without any additional task-scope information.

When scope information was provided, the difference was attenuated $\left(68 \%\right.$ vs. $\left.64 \% ; \chi^{2}(1)<1\right)$, but this change was not significant compared to the no-scope-information condition (interaction $\beta=0.562$, $z=1.61, p=.107)$. Managers who chose to pay a flat fee left significantly more money on the table when 
the time limit was longer $\left(\mathrm{M}_{\text {Per-minute Fee }}=\$ 2.28, \mathrm{M}_{\mathrm{Flat} \mathrm{Fee}}=\$ 2.00 ; \Delta=-\$ 0.28, t(63)=2.65, p=010\right)$, but there was no difference in earning when the time limit was shorter. Taken together, managers lost significantly more money on account of their sub-optimal preference for flat fee in the longer time limit $(t 105)=2.11$, $p=.037)$. A two-way interaction of time limits and completion-time information on bonuses earned suggested that scope-information significantly reduced (although did not eliminate) this loss in earning from a preference for flat fees $(\beta=0.379, t=2.32, p=.021)$.

Irrespective of compensation scheme choices, when no completion-time information was available, managers estimated a longer completion time for per-minute workers when the time limit was longer than when it was shorter $\left(\mathrm{M}_{\text {Long }}=10.75\right.$ vs. $\left.\mathrm{M}_{\text {Shorter }}=4.32, \Delta=+6.43 ; t(316)=18.73, p<.001\right)$. When completion-time information was provided, the difference in completion time estimates of per-minute workers reduced, but was not eliminated $\left(\mathrm{M}_{\mathrm{Long}}=9.14\right.$ vs. $\mathrm{M}_{\text {Shorter }}=4.15, \Delta=+4.99 ; t(312)=12.14, p<.001$; interaction: $\beta=1.44, t=2.69, p=.007)$. Therefore, beliefs about completion times, particularly when timebased compensation is used, reduced but persisted when information defining the scope of work was provided. This is consistent with a multiple-accounts explanation underlying the observed misestimations.

Did these misestimations of per-minute workers' completion time drive the biased compensation scheme choices, even when completion-time information was available? Replicating earlier findings, when no completion-time information was provided, managers who chose a flat fee estimated a longer completion time for per-minute workers both in the shorter $\left(\mathrm{M}_{\text {Chose Flat Fee }}=4.59\right.$ vs. $\mathrm{M}_{\text {Chose Per-minute Fee }}$ $=3.78 ; t(179)=6.39, p<.001)$ and in the longer time-limit conditions $\left(\mathrm{M}_{\text {Chose Flat Fee }}=11.64 \mathrm{vs}\right.$. $\mathrm{M}_{\text {Chose Per- }}$ minute Fee $=8.17 ; t(135)=4.16, p<.001)$, but more so when the external time limits were longer $(F(1,314)=13.67, p<.001)$. Moreover, even when completion-time information was available, the results persisted (Shorter time limit: $\mathrm{M}_{\text {Chose Flat Fee }}=4.33$ vs. $\mathrm{M}_{\text {Chose Per-minute Fee }}=3.77 ; t(134)=2.98, p=.003$; Longer time limit: $\mathrm{M}_{\text {Chose Flat Fee }}=10.83$ vs. $\mathrm{M}_{\text {Chose Per-minute Fee }}=6.13 ; t(176)=7.28, p<.001$; interaction: $F(1,310)=28.81, p<.001)$. Indeed, the three way interaction of completion-time information, time limit, and flat fee choice on estimates of per-minute workers' completion times was not statistically significant 
$(p=.162)$. Managers who chose flat fees, also overestimated the expected time per-minute workers would take compared to the actual time taken by workers.

Like in previous studies, managers' choices were largely rationalized by their estimates of workers' completion times. When no completion-time information was provided, most participants chose the option that would have provided a higher profit had their time estimates been correct $(86 \%$ in the shorter time condition; $76 \%$ in the longer time condition). These proportions remained similar when completion-time information was provided ( $82 \%$ in the shorter time condition; $76 \%$ in the longer time condition). The striking similarity of results in the control and in the scope-information condition suggets that the information intervention did little to attenuate our observed effect. Indeed, if our observed effects are determined by beliefs about slacking when time limits are longer and the compensation scheme is time based, providing information about flat-fee workers under untimed condition should do little to attenuate the observed behavior. This is indeed what we find in this study. 


\section{Online Appendix E: Pre-registrations}

\section{Study 4:}

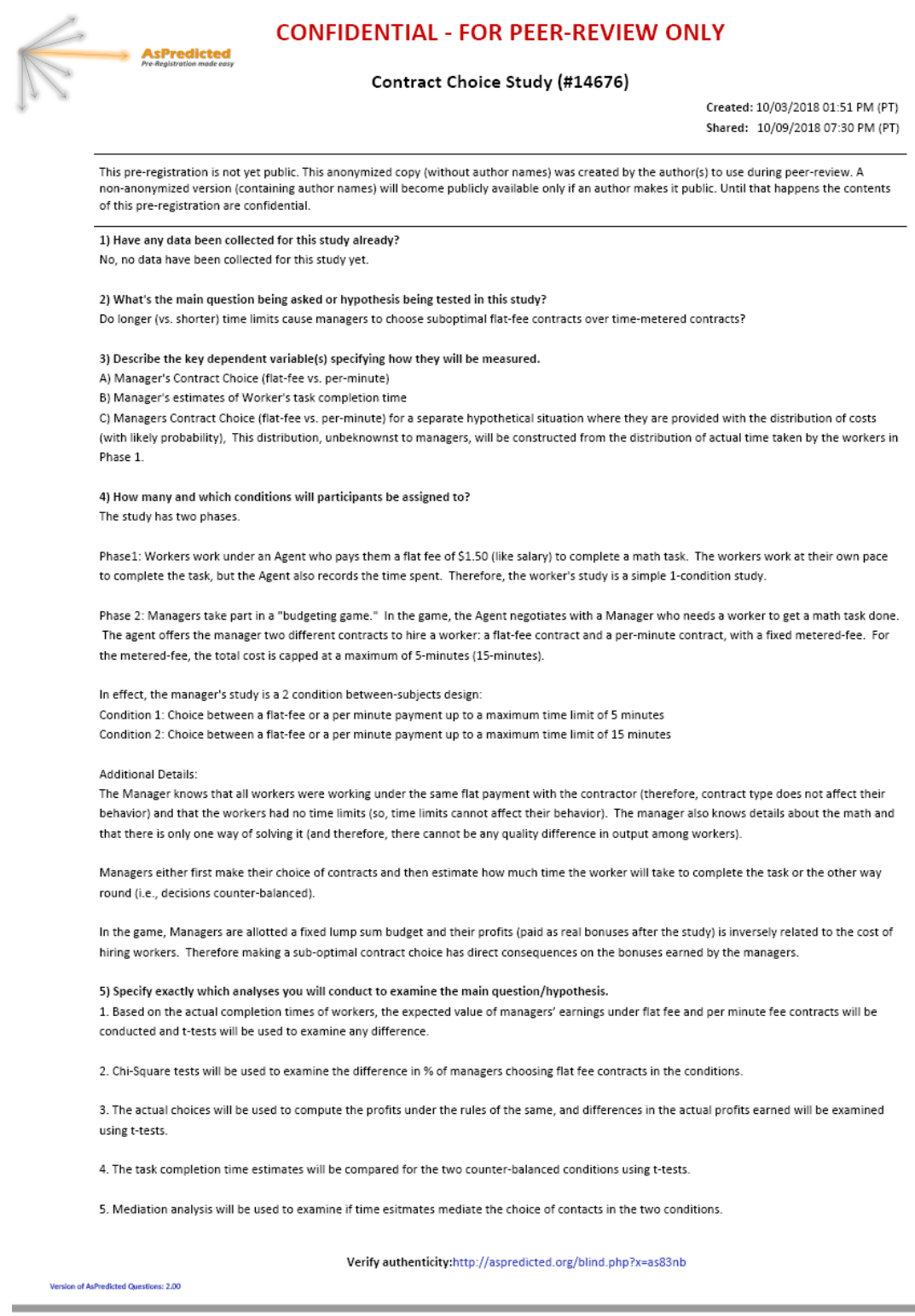

\section{Aspredicted}

6. Finally, using McNemar's Chi-Square test we will examine the within-manager difference in choice of contract types between the consequential contract choice and the hypothetical choice where distribution of costs were provided.

6) Describe exactly how outliers will be defined and handled, and your precise rule(s) for excluding observations. In both phases, responses from duplicate IPs will be excluded prior to analyzing the data.

In Phase 2 , an attention check question will be administered at the end of the survey. Those failing this test will be excluded prior to analyzing the data.

7) How many observations will be collected or what will determine sample size? No need to justify decision, but be precise about exactly how the number will be determined.

Phase 1: We will target a sample of 100 Workers on the Mturk platform. Phase 2: We will target a sample of 300 Managers on the Mturk platform.

8) Anything else you would like to pre-register? (e.g., secondary analyses, variables collected for exploratory purposes, unusual analyses planned?)

None. 
CONFIDENTIAL - FOR PEER-REVIEW ONLY

Created: 10/25/2018 06:30 AM (PT) Shared: $10 / 25 / 201806: 57$ AM (PT)

This pre-registration is not yet public. This anonymized copy (without author names) was created by the author(s) to use during peer-review. A This pre-registration is not yet pubic. This anonymized copy (without author names) was created by the author(s) to use during peer-review. A non-anonymized version (containing auth
of this pre-registration are confidential.

1) Have any data been collected for this study already?

No, no data have been collected for this study yet.

2) What's the main question being asked or hypothesis being tested in this study?

Do longer (vs. shorter) time limits cause managers to choose suboptimal flat-fee contracts over time-metered contracts?

3) Describe the key dependent variable(s) specifying how they will be measured.

A) Manager's Contract Choice (flat-fee vs. per-minute)

B) Manager's estimate of Worker's task completion time

C) Manager's Contract Choice (flat-fee vs. per-minute) for a separate hypothetical situation where they are provided with the distribution of costs (with likely probability), This distribution, unbeknownst to managers, will be constructed from the distribution of actual time taken by the workers in a separate study (see Phase 1 of pre-registered study \# Contract Choice Study \#14676 at aspredicted.org)

4) How many and which conditions will participants be assigned to?

This pre-registration is an addendum to the Phase 2 of Study \#14676 at aspredicted.org and contain details of the hiring game that the Managers will play in Phase 2. Also, in the revised Phase 2 design, there are three conditions, as follows:

Condition 1a details: Managers are given a budget of $\$ 2.50$. They can hire a worker under a flat-fee contract (cost \$1.75) or metered rate of 40 cents/min with the total cost is capped at a maximum of 5 -minute. This means the bonus (budget - cost of hiring) that a manager can earn is either $\$ 0.75$ (when choosing fixed fee) or can range between $[\$ 0.50, \$ 2.10]$ (when choosing metered fee)

Condition $1 \mathrm{~b}$ details: Managers are given a budget of $\$ 6.00$. They can hire a worker under a flat-fee contract (cost $\$ 1.75$ ) or metered rate of 40 cents/min with the total cost is capped at a maximum of 5 -minute. This means the bonus (budget - cost of hiring) that a manager can earn is either $\$ 4.25$ (when choosing fixed fee) or can range between [\$4, \$5.60] (when choosing metered fee)

Condition 2 details: Managers are given a budget of $\$ 6.50$. They can hire a worker under a flat-fee contract (cost $\$ 2.25$ ) or metered rate of 40 cents/min with the total cost is capped at a maximum of 15 -minute. This means the bonus (budget - cost of hiring) that a manager can earn is either $\$ 4.25$ (when choosing fixed fee) or can range between $[\$ 0.50, \$ 6.10]$ (when choosing metered fee)

In conditions $1 \mathrm{a}$ and 2 , per-minute worst case scenario is the same ( 50 cents). Conditions $1 \mathrm{~b}$ and 2 are matched on the attractiveness of the flat fee contract (both can earn \$4.25) and therefore will help us examine if flat fee preference is on account of confusion with per-minute earnings.

Additional study design information provided under 'Additional Details' in Pre-registered Study \#14676 is still valid.

5) Specify exactly which analyses you will conduct to examine the main question/hypothesis.

Analysis plan is the same as Pre-registered Study \#14676. Copying here for completeness.

Selecting a pair at a time among conditions $1 \mathrm{a}, 1 \mathrm{~b}$, and 2 , we will conduct the following analysis.

1. Based on the actual completion times of workers, the expected value of managers' earnings under flat fee and per minute fee contracts will be conducted and $t$-tests will be used to examine any difference.

2. Chi-Square tests will be used to examine the difference in \% of managers choosing flat fee contracts in the conditions.

3. The actual choices will be used to compute the profits under the rules of the same, and differences in the actual profits earned will be examined using t-tests.

4. The task completion time estimates will be compared for the two counter-balanced conditions (manager choose contract time and then estimate completion time, or the other way round) using t-tests.

5. Mediation analysis will be used to examine if time esitmates mediate the choice of contacts in the two conditions.

6. Finally, using McNemar's Chi-Square test we will examine the within-manager difference in choice of contract types between the consequential

contract choice and the hypothetical choice where distribution of costs were provided.

6) Describe exactly how outliers will be defined and handled, and your precise rule(s) for excluding observations.

Verify authenticity:http://aspredicted.org/blind.php?x=wm6wx3

\section{Aspredicted}

No change from Pre-registered Study \#14676. Copying here for completeness.

a) Responses from duplicate IPs will be excluded prior to analyzing the data.

b) In the managers' study, an attention check question will be administered at the end of the survey. Those failing this test will be excluded prior to

analyzing the data.

7) How many observations will be collected or what will determine sample size? No need to justify decision, but be precise about exactly how the number will be determined.

As mentioned in pre-registered Study $\# 14676$, we will target a sample of 300 Managers on the Mturk platform. We will assign 150 people in the 15-min condition (condition 2) and split the other 150 between the two 5-min conditions (conditions $1 \mathrm{a}$ and $2 \mathrm{~b}$ ).

8) Anything else you would like to pre-register? (e.g., secondary analyses, variables collected for exploratory purposes, unusual analyses planned?)

None 


\section{Study 5:}

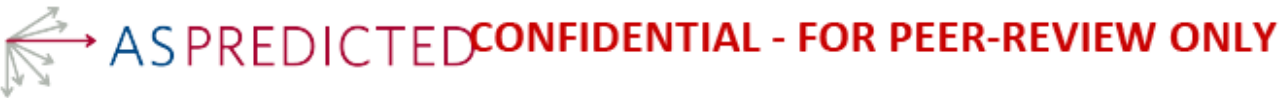

MathTask_Workers_PerMinuteFees (\#25972)

Created: 07/19/2019 03:20 PM (PT)

Shared: $08 / 20 / 2019$ 07:53 AM (PT)

This pre-registration is not yet public. This anonymized copy (without author names) was created by the author(s) to use during peer-review. A non-anonymized version (containing author names) will become publicly available only if an author makes it public. Until that happens the contents of this pre-registration are confidential.

1) Have any data been collected for this study already?

No, no data have been collected for this study yet.

2) What's the main question being asked or hypothesis being tested in this study?

Ps work on a simple math task under varying external time limits ( 5 mins or 15 mins). They are paid at a rate of 25 cents per minute for completing this task (additional bonus over a nominal base participation fee).

We want to look at the distribution of workers' actual time to complete a simple math task under the different time limits.

3) Describe the key dependent variable(s) specifying how they will be measured.

Task completion time and money earned.

4) How many and which conditions will participants be assigned to?

One condition: Time limit (5, 15 mins; b/s).

5) Specify exactly which analyses you will conduct to examine the main question/hypothesis.

We would also look at the difference in the average completion times (t-tests) in the two time limit conditions. We expect the completion times in 15 mins to be either statistically greater or not-different from that in the 5 mins condition. We would compare these actual completion times with prediction of Judges (separate study) and look at the difference in respective time limits (t-test) as well as an interaction (F-test). Based on this study and the separate Judges study, we expect to see a significant interaction driven by judges' overestimation of completion times, particularly in the 15-mins condition.

6) Describe exactly how outliers will be defined and handled, and your precise rule(s) for excluding observations.

Ps with duplicate IPs, incomplete surveys, and those who fail an end-of-survey attention check question will be excluded prior to analysis.

7) How many observations will be collected or what will determine sample size? No need to justify decision, but be precise about exactly how the number will be determined.

We are going to aim for 120 Mturk participants.

8) Anything else you would like to pre-register? (e.g., secondary analyses, variables collected for exploratory purposes, unusual analyses planned?)

None 


\section{ASPREDICTEDCONFIDENTIAL - FOR PEER-REVIEW ONLY}

Managers Math Task Distb Info (\#26133)

Created: 07/24/2019 05:24 PM (PT)

Shared: $08 / 20 / 201909 / 40 \mathrm{AM}$ (PT)

This pre-registration is not yet public. This anonymized cogy (without author names) was created by the author(s) to use during peer-review. A non-nonymized version (containing author names) will become publicly available only if an author makes it public. Until that happens the contents of this pre-reglatration are confidential.

1) Have any data been collected for this study already?

No, no data have been collected for this study yet.

2) What's the main question being asked or hypothesis being tested in this study?

We are looking at the effect of external time limits on choices between flat fee and metered contracts to hire a temporary worker to complete a given task. Our prior results show that judges show a blased preference for flat fee contracts when the time limit is longer, even when they are told that the time limits are random.

We want to continue imestigation of the same hypothesis in a situation where judges are given complete distribution of time taken by real workers to complete the task when no time limits are imposed and paid a flat fee. The idea is to replicate the basic effect and then imestigate the extent to which the choices are determined by a concern that workers delay completion under metered fees (e.g., gold-bricking) or workers' perception of the amount of work (e.8. work scope) changes according to the time limit to complete the work.

Gwen that judges have full information about the scope of the work, any difference in choices in the two time limilts would be on account of concern that workers would intentionally take more time to complete when the time limit is longer (and therefore become more expeneive under metered fees).

3) Describe the key dependent varlable(s) speclfying how they will be measured.

Choice of Flat Fee (vs. Per-Minute of Metered Fee). Judges will indicate their choice by answering a dichotomous question.

After they indicate their choice, Ps are asked to indicate their beliefs about the completion timse both under their chosen compensation scheme, and under the alternative scheme.

4) How many and which conditions will participants be assigned to?

The study will use a 2(Distribution Info: Yes, No) x 2(Time Limits: 5 Mins, 15 Mins) b/s design.

5) Specify exactly which analyses you will conduct to examine the main question/lippothesis.

When no distribution information is provided, we expect to replicate our basic finding (Chi-Sq test of proportion choosing Flat Fee in different time Iimit conditions). When dstribution information is provided, we will examine using chilsq test how the choices look like in the different time limit conditions. We will also do an interaction test to see if there is a difference in choices (longer vs shorter time limits) when additional distribution information is provided vs. withheld.

Using elicited beliefs about completion times, we will examine if such beliefs medlate the effect of time limits on contract choices (using logistic regession in the joint regression).

6) Describe exactly how outliers will be defined and handled, and your precise rule(s) for excluding observations. Incomplete surveys, surveys from Ps with duplicate IPs and those who fall a basic attention check question will be excluded from the analysis. The basic attention check question used is:

People vary in the amount they pay attention to these kinds of surveys. Some take them seriously and read each question, whereas others go wery quickly and barely read the questions at all. If you have read this question carefully, please write the word yes in the blank Other box below.

The options are:

1 (Not al all), 2, 3,4,5 (A great deall, Ocher

Robustness checks will be done by excluding Ps who fail (a) comprehension questions to interpret the data depicted in the distribution of completion time chart (b) recall questions at the end of the study.

7) How mary observations will be collected or what will determine sample size? No need to justify decision, but be precise about exactly how the number will be determined.

We plan to run the study on Amazon Mechanical Turk, and request $600 \mathrm{HIrS}$.

Verify authentikitythttp//aspredictedong/blind phpixenr 4 py6

8) Anything else you would like to pre-register? (eg. secondary analyses, varlables collected for exploratory purposes, unusual analyses planned?)

None 